Supporting Information for

\title{
Exploring Homogeneous Conditions for Mild Buchwald-Hartwig Amination in Batch and Flow
}

\author{
Saeed K. Kashani, Jacob E. Jessiman and Stephen G. Newman \\ Centre for Catalysis Research and Innovation \\ Department of Chemistry and Biomolecular Sciences \\ University of Ottawa \\ 10 Marie-Curie, Ottawa, Ontario, Canada, K1N 6N5. \\ *E-mail: stephen.newman@uottawa.ca
}

\section{Table of Contents}

1 - General experimental details....................................................S1

2- General procedures and optimizations.......................................S2

3- Characterization data for formed products in batch reactions.................S18

4- Characterization data for formed products in batch reactions..................S21

5- HPLC chromatograms...................................................S26

6- NMR spectra.................................................................S27

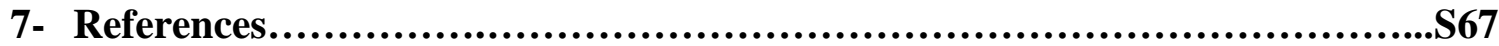

\section{General experimental details}

Unless otherwise indicated, reagents were obtained from Sigma Aldrich, Fisher Scientific or Combi-Blocks and used as received. Column chromatography was performed using Silicycle F60 40-63 $\mu \mathrm{m}$ silica gel. Analytical thin layer chromatography (TLC) was conducted using aluminumbacked EMD Millipore Silica Gel 60. Visualization of developed plates was performed under UV light $(254 \mathrm{~nm})$ and/or using $\mathrm{KMnO}_{4}$, ninhydrin or $\mathrm{I}_{2}$ stains. 


\subsection{Instrumentation and flow reactor details}

${ }^{1} \mathrm{H}$ NMR and ${ }^{13} \mathrm{C}$ NMR were recorded on a Bruker AVANCE $400 \mathrm{MHz}$ spectrometer and referenced to residual solvent signals. Data for ${ }^{1} \mathrm{H}$ NMR are reported as follows: chemical shift $(\delta$ $\mathrm{ppm}$ ), multiplicity $(\mathrm{s}=$ singlet, $\mathrm{d}=$ doublet, $\mathrm{t}=$ triplet, $\mathrm{q}=$ quartet, $\mathrm{m}=$ multiplet $)$, coupling constant $(\mathrm{Hz})$, integration. Yields for optimization and HTE studies were determined by NMR or GC analysis of the crude reaction mixture using 1,3,5-trimethoxybenzene as an internal standard. IR spectra were collected on a Thermo Scientific Nicolet 6700 FTIR equipped with a diamond ATR crystal (ThermoScientific) and are reported in terms of frequency of absorption $\left(\mathrm{cm}^{-1}\right)$. GC analysis were conducted on an Agilent Technologies 7890B GC with $30 \mathrm{~m} \times 0.25 \mathrm{~mm}$ HP-5 column. Accurate mass data were obtained from an Agilent 5977A GC/MS using MassWorks 4.0 from CERNO bioscience. Unless otherwise indicated, continuous flow experiments were performed using $1.0 \mathrm{~mm}$ inner diameter PFA tubing reactor coils heated in silicone oil baths. Either Nexsus 6000 (from Chemyx) or NE-300 syringe pumps (from New Era Pump Systems Inc.) were installed with 5 or $10 \mathrm{~mL}$ Hamilton Gastight glass syringes for reagents and $10 \mathrm{~mL}$ HSW NormJect plastic syringes for quench streams when necessary. PEEK fittings, tee mixers, and backpressure regulators were purchased from Upchurch Scientific. The determination of enantiomeric excess was performed by chiral phase HPLC analysis using an Agilent 1200 Series instrument and Diacel ChiralPak columns.

\section{General Procedures}

\subsection{General procedure for HTE analysis}

HTE was performed using five different 96 well plates equipped with $8 \times 40 \mathrm{~mm}$ glass vials. Metals, ligands, bases, and other additives were added to individual vials on the bench, provided they were air-stable solids. A magnetic stir bar was added to each vial and the plate was brought into a nitrogen-filled glovebox. Inside the glovebox, stock solutions were prepared for the amine and aryl halide coupling partners with the appropriate reaction solvent. Other additives, including air sensitive and/or liquid metals, ligands, and bases, were similarly diluted in the appropriate solvent. These stock solutions were dosed into the corresponding reaction vials and any extra solvent necessary was added to give $0.33 \mathrm{~mL}$ volume at $0.1 \mathrm{M}$ final concentration. The plate was then sealed, heated, and stirred at the desired temperature for 18 hours in an aluminum heating block. Upon cooling, the plate was opened and a solution of either 1,3,5-trimethoxybenzene or 
dodecane was added to each vial as internal standard. Then contents of each vial were passed through a multi-well filtration plate filled with silica gel, eluting with acetonitrile. The filtrates were diluted to an appropriate concentration and then analyzed by GC-MS. The effectiveness of each reaction was monitored by integration of the product peak relative to the internal standard.

\subsection{General procedure for determining the crude yield of each reaction in HTE}

To estimate the yield of each reaction, GC analysis of available molecules which were structurally similar to expected HTE products were performed. Relative response factor, in comparison to the response factor for an equal molar amount of either dodecane or 1,3,5-trimethoxybenzene, was calculated. The resultant data was used to approximate a yield, as well as starting material recovery, for each of the HTE reactions.

\subsubsection{HTE results and statistics}

A total of 480 experiments were performed, composed of each possible combination of two different solvents (S1, S2), 6 different aryl(pseudo)halide electrophiles (E1 - E6), 4 amine nucleophiles (N1 - N4), and 10 different ligands (L1 - L10) as varied parameters. $\mathrm{Pd}_{2}(\mathrm{dba})_{3}$ as Pd source, DBU as base, and $100^{\circ} \mathrm{C}$ reaction temperature were fixed across all reactions (Scheme $\mathrm{S} 1$ ). In total, 35 different reactions showed detectable amounts of the desired product by GC-MS (Figure S1). The relative success for each different aryl halide, nucleophile, ligand, and solvent were tabulated. 
Scheme S1 Exploring Buchwald-Hartwig aminations using high throughput experimentation

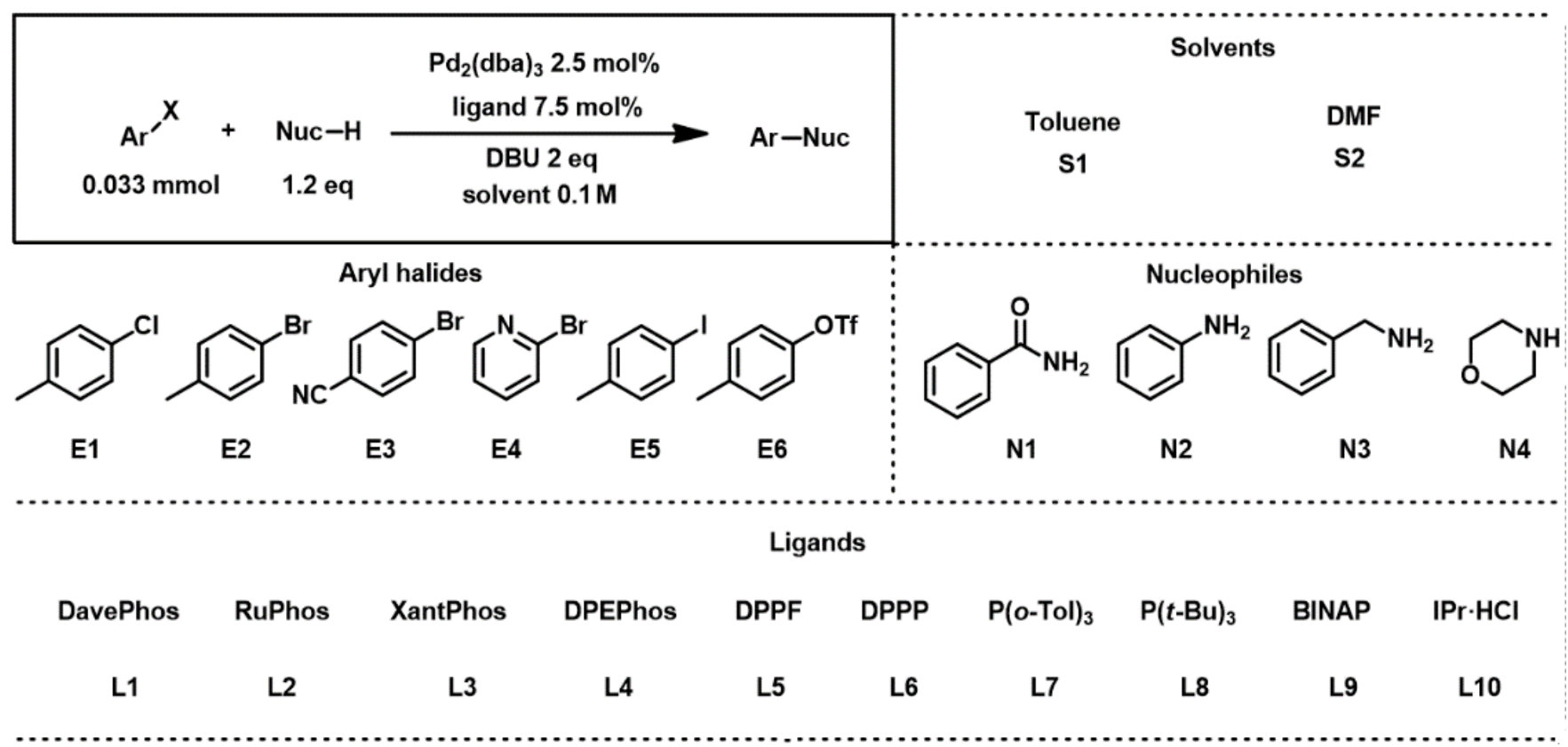

Figure S1 Heat map for the aminations in HTE

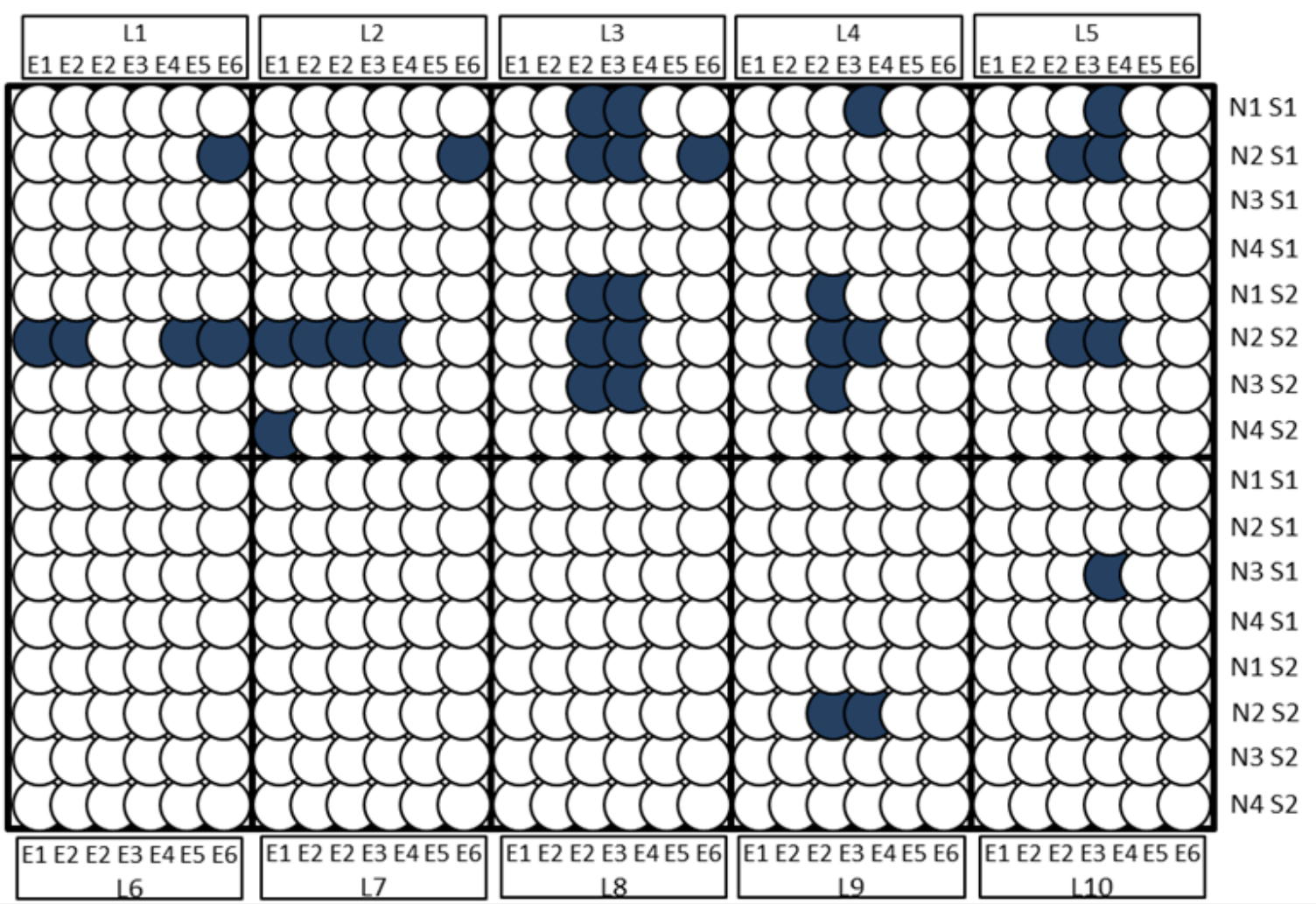




\section{Aryl (pseudo) halides:}

Among the six different aryl halides studied, the fewest hits were observed using 4-chlorotoluene (E1), and the most with 2-bromopyridine (E4) (Table S1). In general, electron-poor substrates are more effective in the presence of DBU as a weak base.

Table S1 Statistic analysis for the HTE results based on aryl (pseudo) halides

\begin{tabular}{cccc|}
\hline Aryl halide & \# successful rxns & $\begin{array}{c}\text { Avg estimated yield in } \\
\text { successful rxns }\end{array}$ & $\begin{array}{c}\text { Avg estimated yield in all } \\
\text { reactions }\end{array}$ \\
\hline E1 & 3 & $2.3 \%$ & $0.09 \%$ \\
E2 & 2 & $2.5 \%$ & $0.06 \%$ \\
$\mathbf{E 3}$ & 12 & $41 \%$ & $6.15 \%$ \\
$\mathbf{E 4}$ & 13 & $10 \%$ & $1.63 \%$ \\
$\mathbf{E 5}$ & 1 & $2 \%$ & $0.03 \%$ \\
$\mathbf{E 6}$ & 4 & $7 \%$ & $0.35 \%$ \\
\hline
\end{tabular}

\section{Nucleophiles:}

Among the four different amine sources which were used across the HTE plates, aniline and benzamide showed the best result based on number of successful reactions and average of the estimated yield respectably. However, benzylamine and morpholine gave fewer hits and average yields in estimated conversions (Table S2).

Table S2 Statistic analysis for the HTE results based on nucleophiles

\begin{tabular}{cccc|}
\hline Nucleophiles & $\begin{array}{c}\text { \# successful } \\
\text { rxns }\end{array}$ & $\begin{array}{c}\text { Avg estimated yield in } \\
\text { successful rxns }\end{array}$ & $\begin{array}{c}\text { Avg estimated yield in all } \\
\text { reactions }\end{array}$ \\
\hline $\mathbf{N 1}$ & 7 & $39 \%$ & $2.28 \%$ \\
$\mathbf{N} 2$ & 23 & $15 \%$ & $2.88 \%$ \\
$\mathbf{N 3}$ & 4 & $14 \%$ & $0.47 \%$ \\
$\mathbf{N 4}$ & 1 & $2 \%$ & $0.02 \%$ \\
\hline
\end{tabular}




\section{Solvents:}

Two different solvents were used in our studies, one polar (DMF) and one non-polar (Toluene).

DMF gave more hits across the HTE plates (Table S3).

Table S3 Statistic analysis for the HTE results based on ligands

\begin{tabular}{cccc|}
\hline Solvents & \# successful rxns & $\begin{array}{c}\text { Avg estimated yield in } \\
\text { successful rxns }\end{array}$ & $\begin{array}{c}\text { Avg estimated yield in all } \\
\text { reactions }\end{array}$ \\
\hline Toluene & 12 & $16 \%$ & $0.79 \%$ \\
DMF & 23 & $21 \%$ & $1.98 \%$ \\
\hline
\end{tabular}

\section{Ligands:}

Ten different commercially available ligands were used in our studies. Xantphos was found to perform the best of all ligands tested. DPPP, $\mathrm{P}(\mathrm{o}-\mathrm{Tol})_{3}, \mathrm{P}(\mathrm{t}-\mathrm{Bu})_{3}$ did not show any hits (Table S4).

Table S4 Statistic analysis for the HTE results based on ligands

\begin{tabular}{cccc}
\hline Ligand & \# successful rxns & $\begin{array}{c}\text { Avg estimated yield in successful } \\
\text { rxns }\end{array}$ & $\begin{array}{c}\text { Avg estimated yield in all } \\
\text { reactions }\end{array}$ \\
\hline DavePhos (L1) & 5 & $6 \%$ & $0.63 \%$ \\
RuPhos (L2) & 6 & $3 \%$ & $0.38 \%$ \\
XantPhos (L3) & 11 & $38 \%$ & $8.69 \%$ \\
DPEPhos (L4) & 5 & $23 \%$ & $2.44 \%$ \\
DPPF (L5) & 5 & $14 \%$ & $1.50 \%$ \\
DPPP (L6) & 0 & $0 \%$ & $0.00 \%$ \\
P(o-Tol) $)_{3}(\mathbf{L} 7)$ & 0 & $0 \%$ & $0.00 \%$ \\
P(t-Bu) $(\mathbf{L 8})$ & 0 & $0 \%$ & $0.00 \%$ \\
BINAP (L9) & 2 & $3.5 \%$ & $0.15 \%$ \\
IPr·HCl (L10) & 1 & $2 \%$ & $0.04 \%$ \\
\hline
\end{tabular}


The approximate yields for all 480 experiments classified by using ten different ligands:

Figure S2 Estimated yields for reactions in the presence of DavePhos as ligand.

Davephos

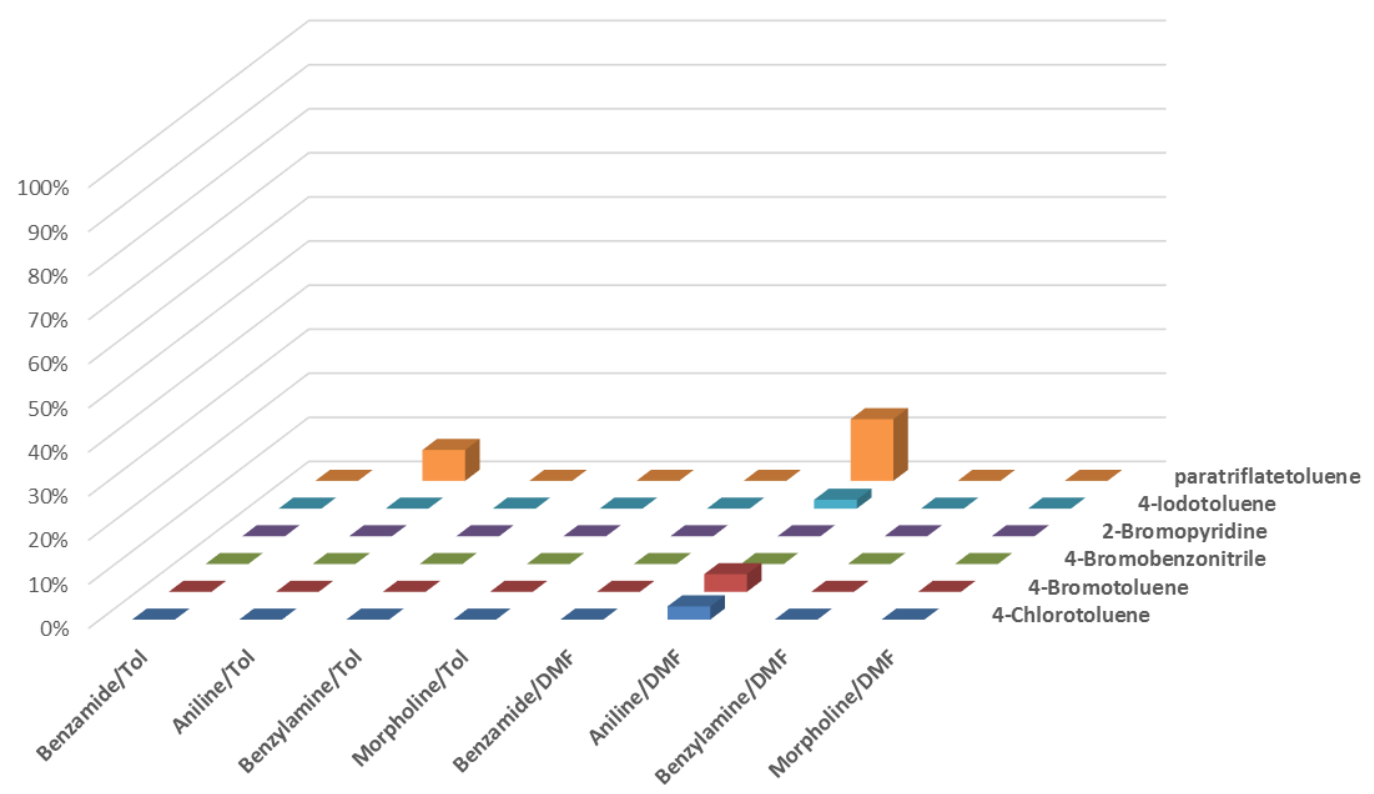

Figure S3 Estimated yields for reactions in the presence of RuPhos as ligand.

RuPhos

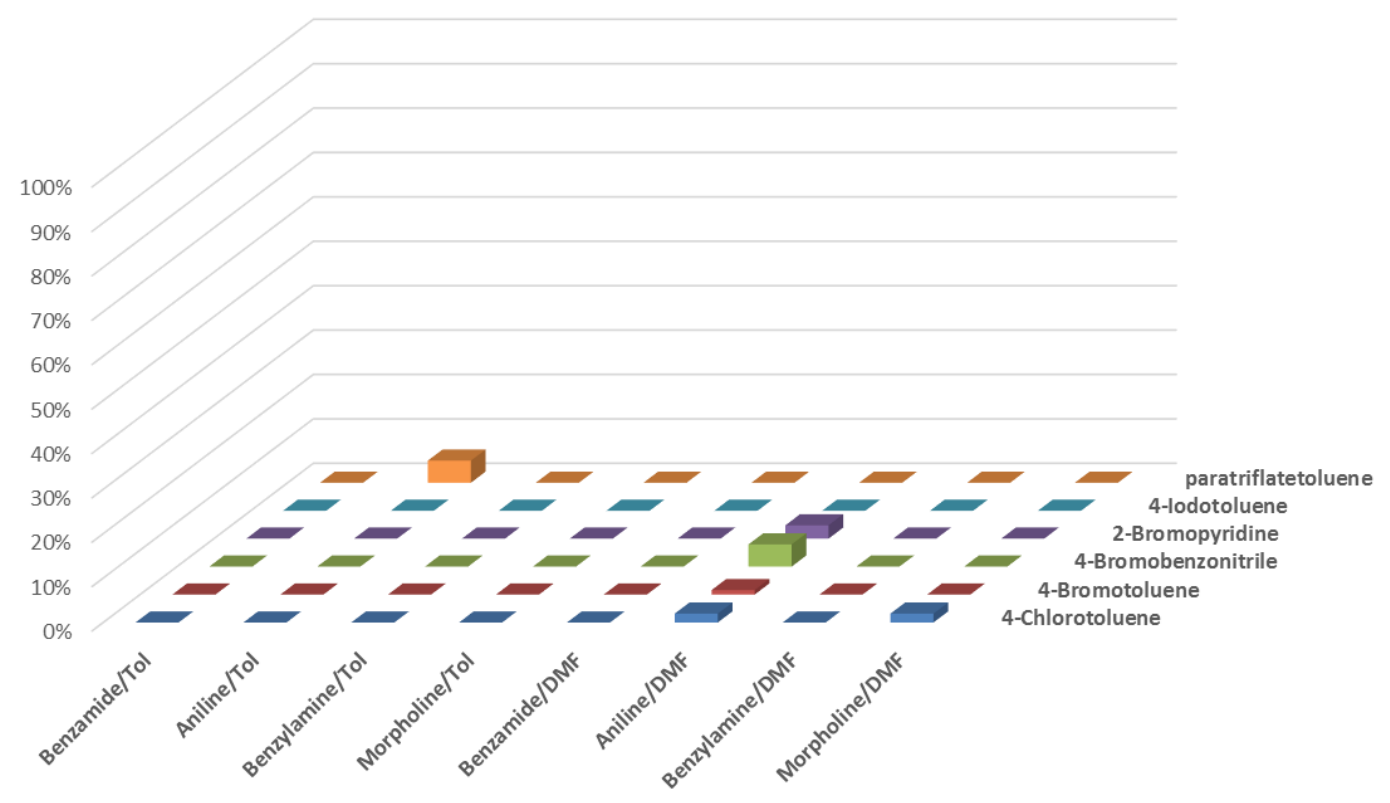


Figure S4 Estimated yields for reactions in the presence of XantPhos as ligand.

XantPhos

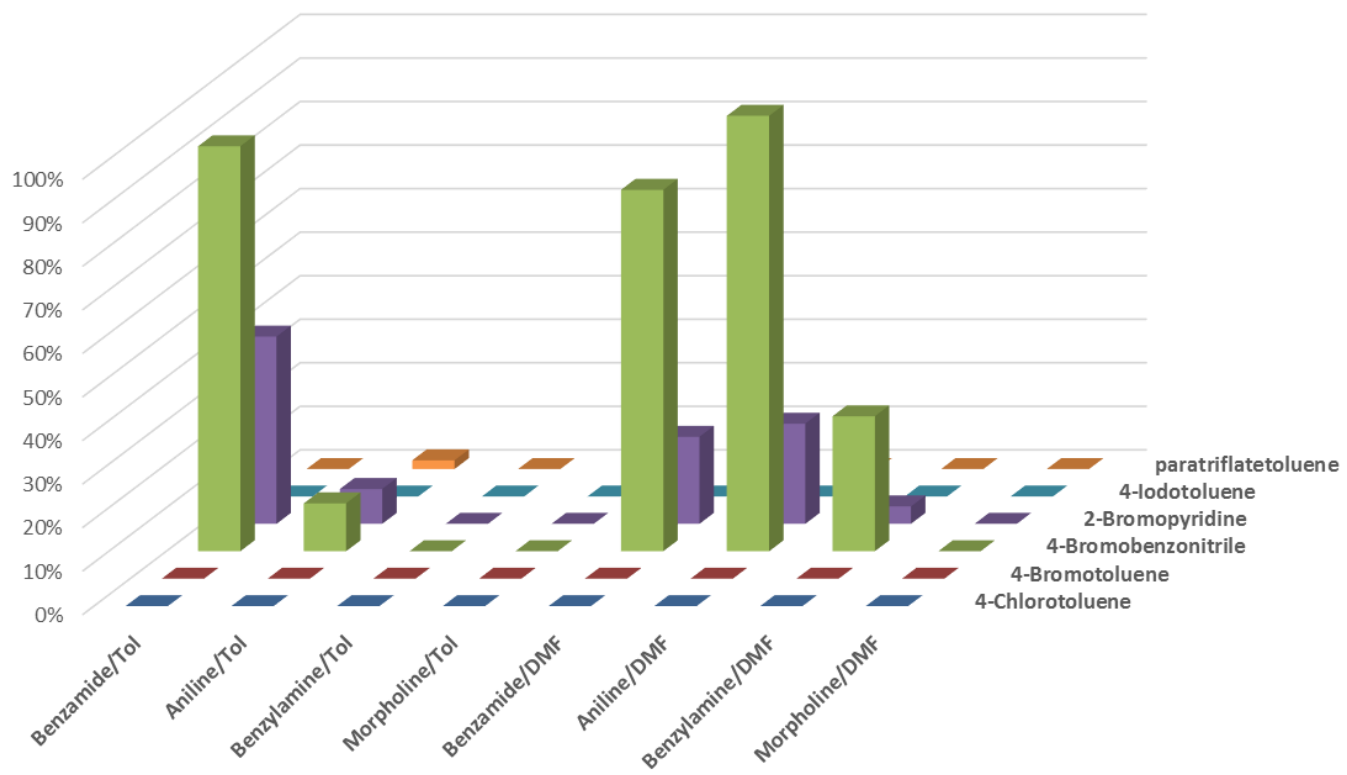

Figure S5 Estimated yields for reactions in the presence of DPEPhos as ligand.

DPEPhos

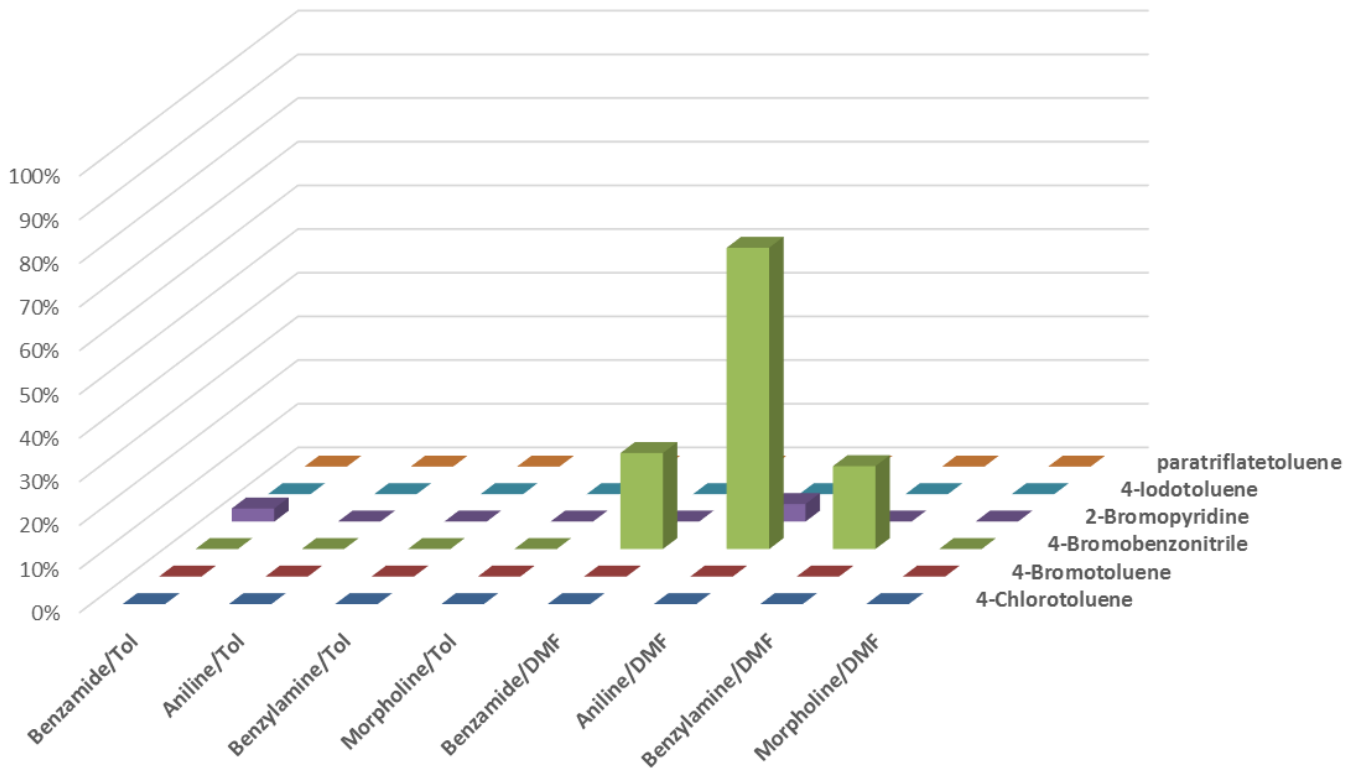


Figure S6 Estimated yields for reactions in the presence of DPPF as ligand.

DPPF

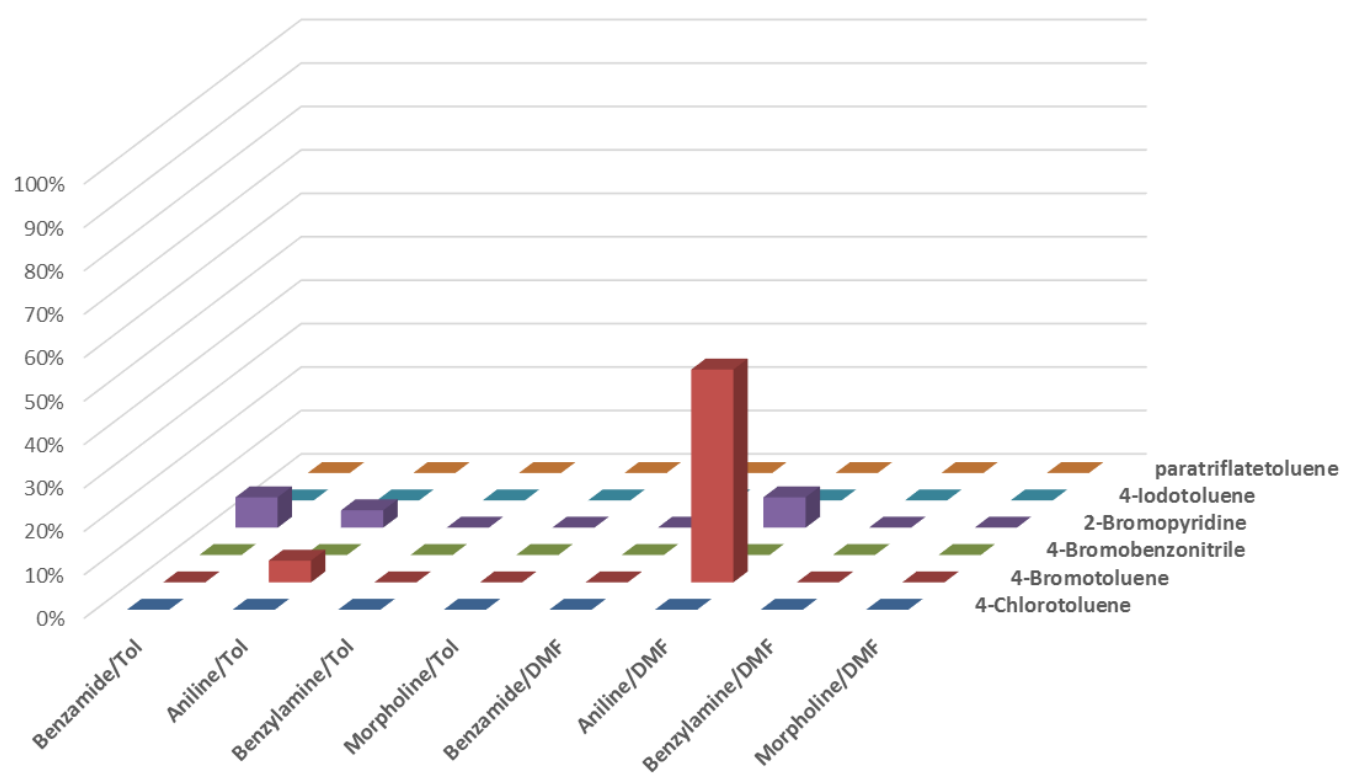

Figure S7 Estimated yields for reactions in the presence of DPPP as ligand.

DPPP

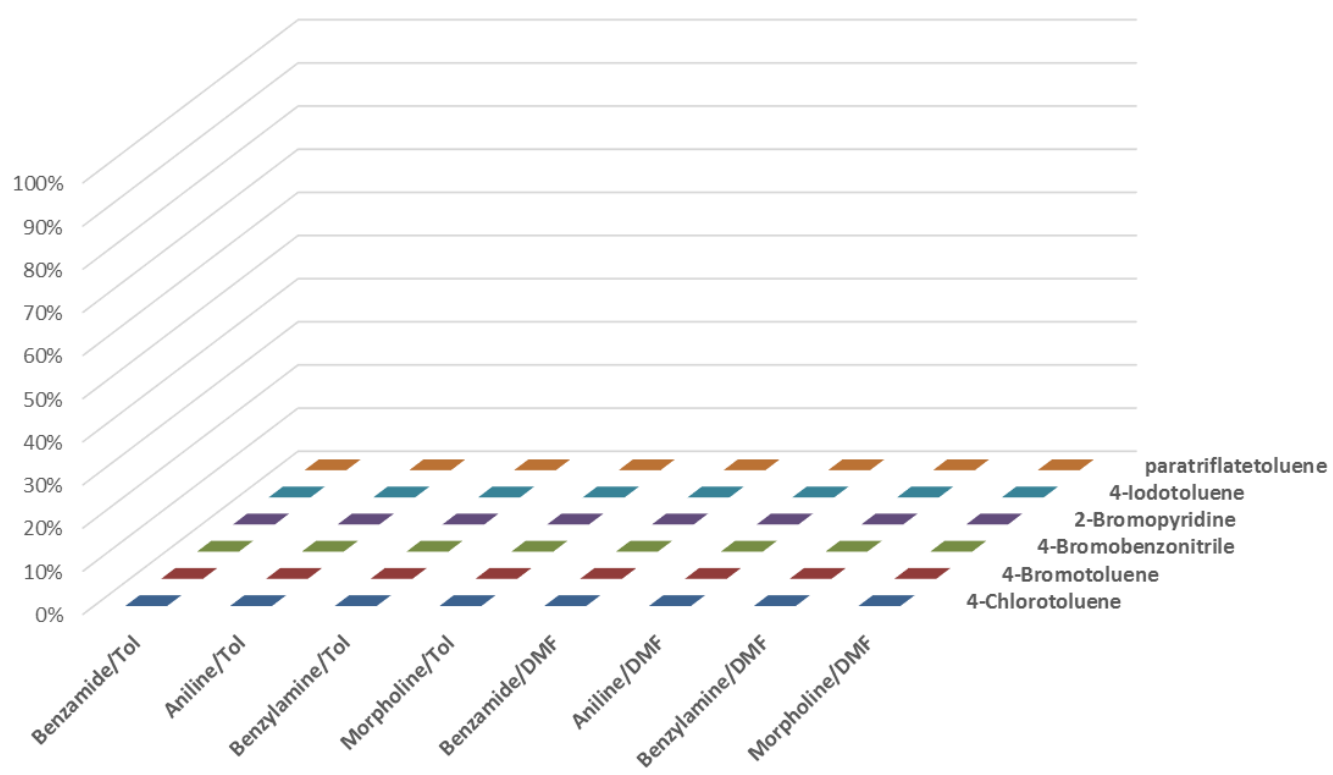


Figure S8 Estimated yields for reactions in the presence of $\mathrm{P}(\mathrm{o} \text {-tol })_{3}$ as ligand.

$\mathrm{P}(\mathrm{O}-\mathrm{Tol})_{3}$

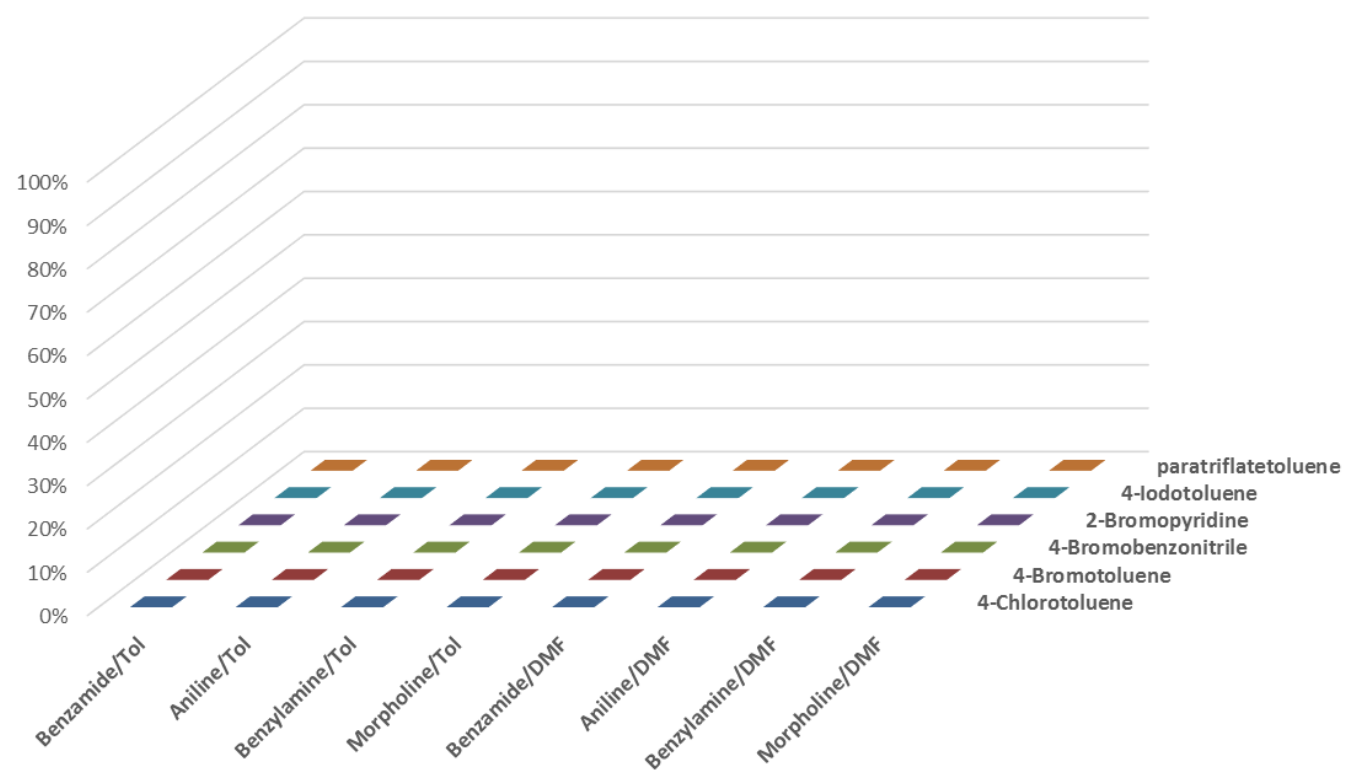

Figure S9 Estimated yields for reactions in the presence of $\mathrm{P}(\mathrm{t}-\mathrm{Bu})_{3}$ as ligand.

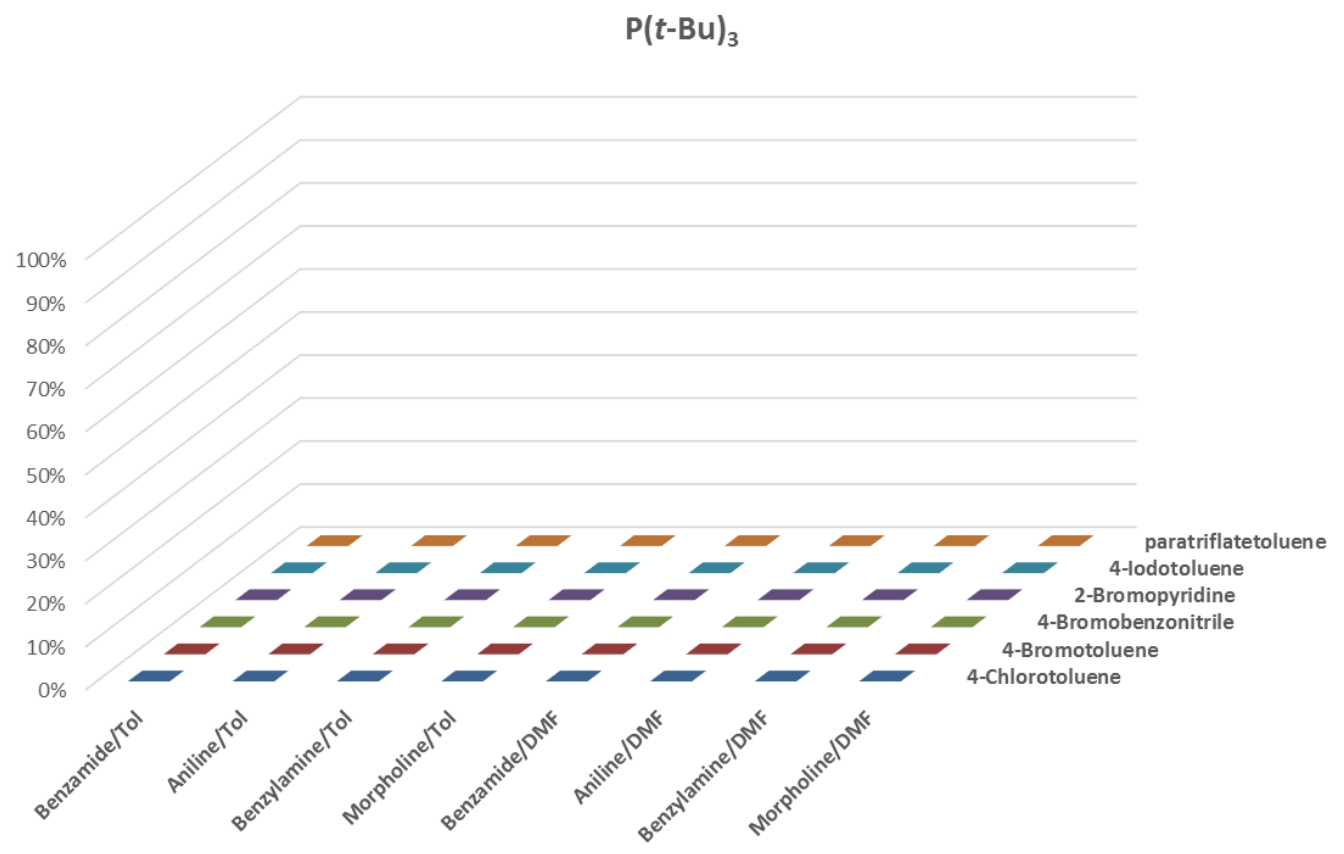


Figure S10 Estimated yields for reactions in the presence of BINAP as ligand.

BINAP

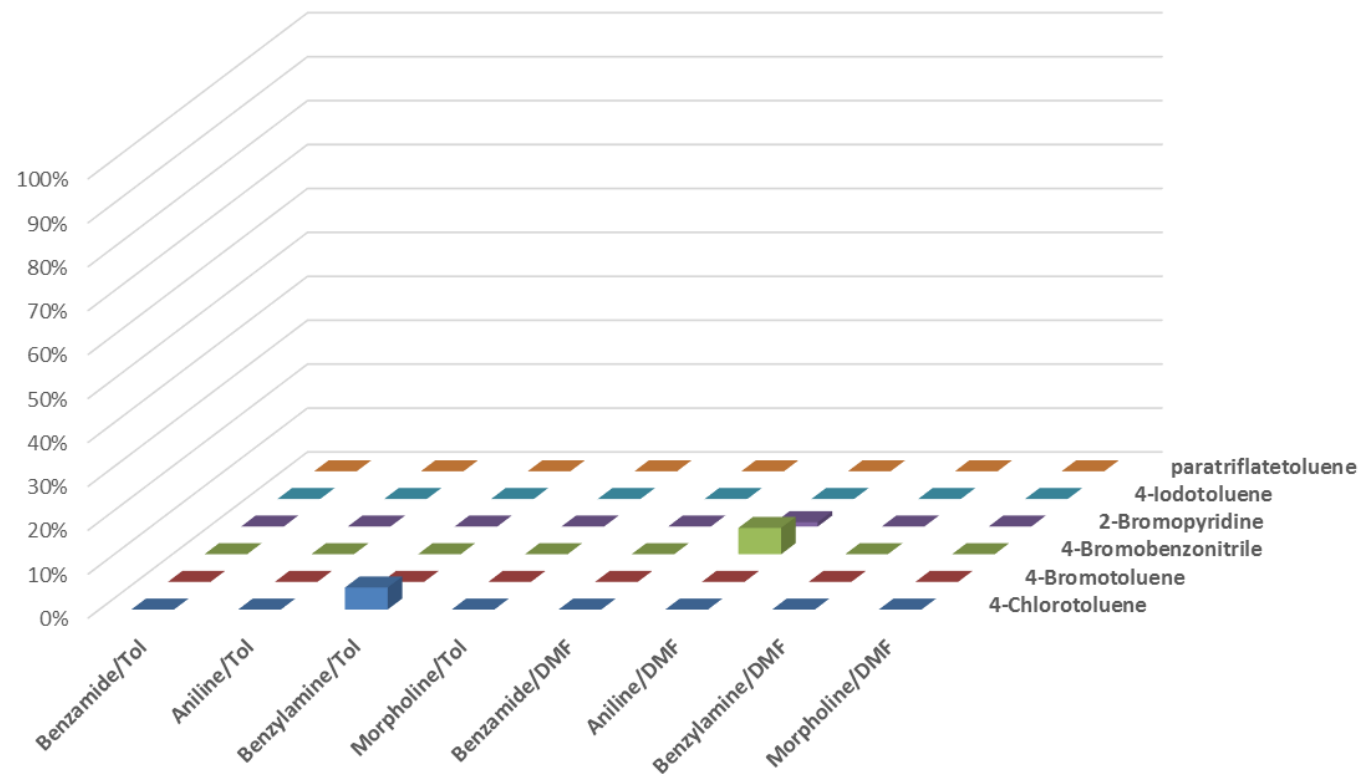

Figure S11 Estimated yields for reactions in the presence of IPr.HCl as ligand.

Ipr. $\mathrm{HCl}$

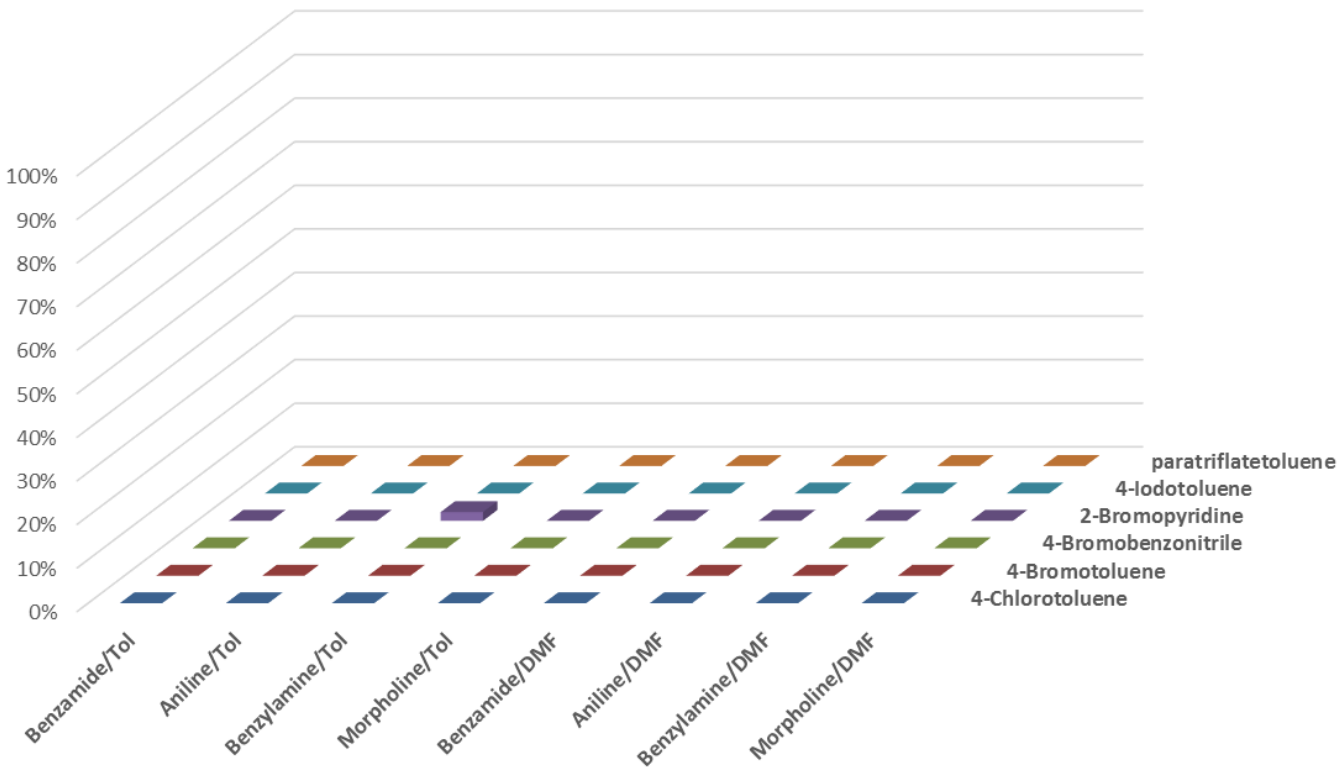




\subsection{General Procedure A for aminations with amides and electron-poor aryl halides in batch}

The procedure used for the data in Scheme 4 is as follows. To an $8 \mathrm{~mL}$ screw-capped reaction vial equipped with a magnetic stir bar, $\left[\mathrm{Pd}(\text { cinnamyl)Cl}]_{2}(1.6 \mathrm{mg}, 1.5 \mathrm{~mol} \%)\right.$, XantPhos $(7 \mathrm{mg}, 6$ mol\%), 4-Chlorobenzonitrile (27.5 mg mg, $0.2 \mathrm{mmol}$ ) and benzamide (48.4 mg, $0.4 \mathrm{mmol}$ ) were added. Then, inside the glovebox, DBU $(60 \mu \mathrm{l}, 0.4 \mathrm{mmol})$ was added, and the reaction was diluted to $\sim 2 \mathrm{~mL}(0.1 \mathrm{M})$ with Toluene (for other examples, all the liquids were added inside the glove box). The vial was capped, removed from the glove box, and placed in an oil bath pre-heated to $100{ }^{\circ} \mathrm{C}$. After stirring for 18 hours, the reaction vial was removed from the oil bath and cooled down to room temperature. 1,3,5-trimethoxybenzene was added as an internal standard prior to filtering the reaction over a short pad of silica gel, washing with $\mathrm{MeCN}$. The filtrate was diluted to an appropriate concentration and analyzed by GC-MS and ${ }^{1} \mathrm{H}-\mathrm{NMR}$ to determine the yield. The reactions for the scope table were isolated by column chromatography.

\subsection{General Procedure B for amination using benzylamine and aryl halide on batch}

To an $8 \mathrm{~mL}$ screw-capped reaction vial equipped with a magnetic stir bar, $[\mathrm{Pd}(\text { cinnamyl }) \mathrm{Cl}]_{2}(2.6$ $\mathrm{mg}, 2.5 \mathrm{~mol} \%$ ), XantPhos ( $8.6 \mathrm{mg}, 7.5 \mathrm{~mol} \%$ ), and 4-bromobenzonitrile ( $36.4 \mathrm{mg}, 0.2 \mathrm{mmol}$ ) were added. Then, inside the glovebox, benzylamine ( $44 \mu \mathrm{l}, 0.4 \mathrm{mmol})$ and DBU (60 $\mu \mathrm{l}, 0.4 \mathrm{mmol})$ were added, and the reaction was diluted to $\sim 0.6 \mathrm{~mL}(0.33 \mathrm{M})$ with DMSO. The vial was capped, removed from the glove box, and placed in an oil bath pre-heated to $100{ }^{\circ} \mathrm{C}$. After stirring for 18 hours, the reaction vial was removed from the oil bath and cooled down to room temperature. 1,3,5-trimethoxybenzene was added as an internal standard prior to filtering the reaction over a short pad of silica gel, washing with $\mathrm{MeCN}$. The filtrate was diluted to an appropriate concentration and analyzed by GC-MS and ${ }^{1} \mathrm{H}-\mathrm{NMR}$ to determine the yield. The reactions for the scope table were isolated by column chromatography. 


\subsubsection{Optimization of amination with aniline and aryl triflates}

Table S5 Optimization of Buchwald-Hartwig amination with benzylamine and aryl halide

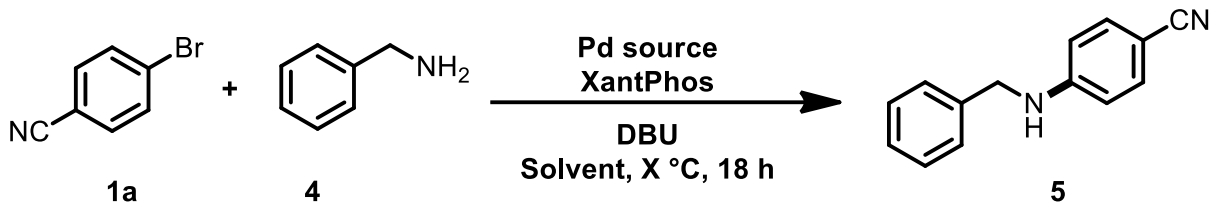

\begin{tabular}{|c|c|c|c|c|c|c|}
\hline Entry & $\begin{array}{c}4 \\
(\mathrm{eq})\end{array}$ & $\begin{array}{l}\text { DBU } \\
(\text { eq) }\end{array}$ & $\begin{array}{c}\text { Catatlys, Ligand } \\
(\mathrm{mol} \%)\end{array}$ & $\begin{array}{c}\text { Solvent } \\
\text { Conc. }(\mathrm{M})\end{array}$ & $\mathbf{T}\left({ }^{\circ} \mathbf{C}\right)$ & $\begin{array}{l}\text { Yield } \\
(\%)\end{array}$ \\
\hline 1 & 1.2 & 2 & $\mathrm{Pd}_{2}(\mathrm{dba})_{3} 2.5$, XantPhos 7.5 & $\operatorname{DMF}(0.1 \mathrm{M})$ & 100 & 20 \\
\hline 2 & 1.2 & 2 & $\mathrm{Pd}(\mathrm{OAc})_{2} 5$, XantPhos 7.5 & $\mathrm{DMF}(0.1 \mathrm{M})$ & 100 & 3 \\
\hline 3 & 1.2 & 2 & {$[\mathrm{Pd}(\text { Allyl }) \mathrm{Cl}]_{2} 2.5$, XantPhos 7.5} & $\mathrm{DMF}(0.1 \mathrm{M})$ & 100 & 24 \\
\hline 4 & 1.2 & 2 & {$[\mathrm{Pd}(\text { Cinnamyl }) \mathrm{Cl}]_{2} 2.5$, XantPhos 7.5} & $\operatorname{DMF}(0.1 \mathrm{M})$ & 100 & 30 \\
\hline 5 & 1.2 & 2 & {$[\mathrm{Pd}(\text { Cinnamyl }) \mathrm{Cl}]_{2} 2.5$, XantPhos 7.5} & $\operatorname{DMF}(0.33 \mathrm{M})$ & 100 & 18 \\
\hline 6 & 1.2 & 4 & {$[\mathrm{Pd}(\text { Cinnamyl }) \mathrm{Cl}]_{2} 2.5$, XantPhos 7.5} & DMF $(0.1 \mathrm{M})$ & 100 & 8 \\
\hline 7 & 2 & 2 & {$[\mathrm{Pd}(\text { Cinnamyl }) \mathrm{Cl}]_{2} 2.5$, XantPhos 10} & $\operatorname{DMF}(0.1 \mathrm{M})$ & 100 & 19 \\
\hline 8 & 1.2 & 2 & {$[\mathrm{Pd}(\text { Cinnamyl }) \mathrm{Cl}]_{2} 2.5$, XantPhos 7.5} & $\operatorname{DMSO}(0.1 \mathrm{M})$ & 100 & 47 \\
\hline 9 & 2 & 2 & {$[\mathrm{Pd}(\text { Cinnamyl }) \mathrm{Cl}]_{2}$ 2.5, XantPhos 7.5} & $\operatorname{DMSO}(0.33 \mathrm{M})$ & 100 & 75 \\
\hline
\end{tabular}

\subsection{General Procedure $\mathrm{C}$ for amination using aniline and aryl triflates in batch}

To an $8 \mathrm{~mL}$ screw-capped reaction vial equipped with a magnetic stir bar, $[\mathrm{Pd}(\text { allyl }) \mathrm{Cl}]_{2}(1.8 \mathrm{mg}$, $2.5 \mathrm{~mol} \%)$ and DavePhos ( $8 \mathrm{mg}, 10 \mathrm{~mol} \%)$ were added. Then, inside the glovebox, aniline (40 $\mu 1$, $0.2 \mathrm{mmol}), p$-tolyl methanesulfonate ( $36 \mu \mathrm{l}, 0.2 \mathrm{mmol})$, and DBU (60 $\mu 1,0.4 \mathrm{mmol})$ were added, and the reaction was diluted to $\sim 0.6 \mathrm{~mL}(0.33 \mathrm{M})$ with DMF. The vial was capped, removed from the glove box, and placed in an oil bath pre-heated to $120^{\circ} \mathrm{C}$. After stirring for 18 hours, the reaction vial was removed from the oil bath and cooled down to room temperature. 1,3,5trimethoxybenzene was added as an internal standard prior to filtering the reaction over a short pad of silica gel, washing with $\mathrm{MeCN}$. The filtrate was diluted to an appropriate concentration and analyzed by GC-MS and ${ }^{1} \mathrm{H}-\mathrm{NMR}$ to determine the yield. The reactions for the scope table were isolated by column chromatography. 


\subsubsection{Optimization of amination with aniline and aryl triflates}

Table S6 Optimization of Buchwald-Hartwig amination with aniline and aryl triflates

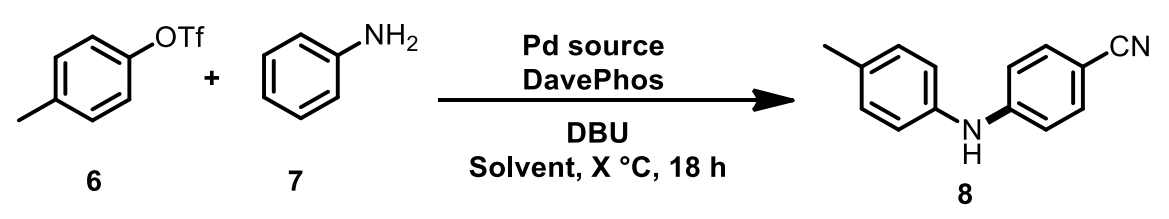

\begin{tabular}{|c|c|c|c|c|c|c|}
\hline Entry & $\begin{array}{c}7 \\
(\mathrm{eq})\end{array}$ & $\begin{array}{c}\mathrm{DBU} \\
(\mathrm{eq})\end{array}$ & $\begin{array}{c}\text { Catalyst, Ligand } \\
(\mathrm{mol} \%)\end{array}$ & $\begin{array}{c}\text { Solvent } \\
\text { Conc. }(M)\end{array}$ & $\mathbf{T}\left({ }^{\circ} \mathrm{C}\right)$ & $\begin{array}{l}\text { Yield } \\
(\%)\end{array}$ \\
\hline 1 & 1.2 & 2 & $\mathrm{Pd}_{2}(\mathrm{dba})_{3} 2.5$, DavePhos 7.5 & $\operatorname{DMF}(0.1)$ & 100 & trace \\
\hline 2 & 1.2 & 2 & $\mathrm{Pd}(\mathrm{OAc})_{2} 5$, DavePhos 7.5 & $\operatorname{DMF}(0.1)$ & 100 & trace \\
\hline 3 & 1.2 & 2 & $\begin{array}{c}{[\mathrm{Pd}(\text { Cinnamyl }) \mathrm{Cl}]_{2} 2.5} \\
\text { DavePhos } 7.5\end{array}$ & $\operatorname{DMF}(0.1)$ & 100 & trace \\
\hline 4 & 1.2 & 2 & {$[\mathrm{Pd}(\text { allyl }) \mathrm{Cl}]_{2} 2.5$, DavePhos 7.5} & $\operatorname{DMF}(0.1)$ & 100 & 10 \\
\hline 5 & 1.2 & 2 & {$[\mathrm{Pd}(\text { allyl }) \mathrm{Cl}]_{2} 2.5$, DavePhos 7.5} & $\operatorname{DMF}(0.1)$ & 120 & 45 \\
\hline 6 & 1.2 & 2 & {$[\mathrm{Pd}(\text { allyl }) \mathrm{Cl}]_{2} 2.5$, DavePhos 7.5} & $\operatorname{DMF}(0.33)$ & 100 & 38 \\
\hline 7 & 1.2 & 2 & {$[\mathrm{Pd}(\text { allyl }) \mathrm{Cl}]_{2} 2.5$, DavePhos 7.5} & $\operatorname{MeCN}(0.1)$ & 100 & 29 \\
\hline 8 & 1.2 & 2 & {$[\mathrm{Pd}(\text { allyl }) \mathrm{Cl}]_{2} 2.5$, DavePhos 7.5} & Dioxane $(0.1)$ & 100 & 22 \\
\hline 9 & 2 & 2 & {$[\mathrm{Pd}(\text { allyl }) \mathrm{Cl}]_{2} 2.5$, DavePhos 7.5} & $\operatorname{DMF}(0.1)$ & 100 & 56 \\
\hline 10 & 2 & 2 & {$[\mathrm{Pd}(\text { allyl }) \mathrm{Cl}]_{2} 2.5$, DavePhos 7.5} & $\operatorname{DMF}(0.33)$ & 120 & 61 \\
\hline 11 & 2 & 2 & {$[\mathrm{Pd}(\text { allyl }) \mathrm{Cl}]_{2} 2.5$, DavePhos 10} & DMF (0.33) & 120 & 85 \\
\hline
\end{tabular}

\subsection{General Procedure D for Buchwald-Hartwig amination in flow}

The procedure used for the data in Scheme 5 is provided below. In the glovebox, halide (1.2 mmol), amine/amide $(1.2 \mathrm{mmol})$ and DBU $(2.4 \mathrm{mmol})$ were combined in a $6 \mathrm{~mL}$ screw cap vial and made up to $3.00 \mathrm{~mL}$ with acetonitrile to give a $0.4 \mathrm{M}$ solution of halide, which was subsequently loaded into an $8 \mathrm{~mL}$ stainless steel syringe. In the glovebox, palladium pre-catalyst $(0.06 \mathrm{mmol})$ was made up to $3.00 \mathrm{~mL}$ in a $6 \mathrm{~mL}$ screw cap vial with a 1:1 mixture of acetonitrile and toluene and loaded into a second $8 \mathrm{~mL}$ stainless steel syringe. The syringes were then attached in the glovebox to the steel continuous flow reactor depicted in Figure S1, which was subsequently shipped out of the glovebox. Syringes were loaded into Nexus 6000 pumps, and the reactor coil was submerged in an oil bath pre-heated to $140{ }^{\circ} \mathrm{C}$. Both pumps were simultaneously set to deliver the syringe 
contents at $8.75 \mathrm{uL} / \mathrm{min}$ through a $1.05 \mathrm{~mL}$ stainless steel coil, with a 130 psi back pressure regulator set at the outlet. The first 3 hours ( 3 residence volumes) of effluent was discarded to reach steady state, followed by collection of effluent for the specified amount of time. Unless otherwise specified, solvent was evaporated, and the resulting material was dissolved in DCM (30 $\mathrm{mL})$. The resulting solution was mixed and separated with saturated $\mathrm{NaCl}(30 \mathrm{~mL})$, followed by 2 more washes of the aqueous layer with DCM $(2 \times 30 \mathrm{~mL})$. The combined organic extracts were dried over $\mathrm{Na}_{2} \mathrm{SO}_{4}$, and the solvent was evaporated. Product was purified via silica gel column chromatography, dried again with $\mathrm{Na}_{2} \mathrm{SO}_{4}$, solvent was evaporated, and the product was dried under high vacuum.

Figure S1 Schematic of flow reactor used for Buchwald-Hartwig reactions.

Amine, Aryl halide, Base $0.4 \mathrm{M}$ in acetonitrile $8.75 \mu \mathrm{L} / \mathrm{min}$

$\mathrm{Pd}$

$0.4 \mathrm{M}$ in $1: 1$ acetonitrile:toluene $8.75 \mu \mathrm{L} / \mathrm{min}$

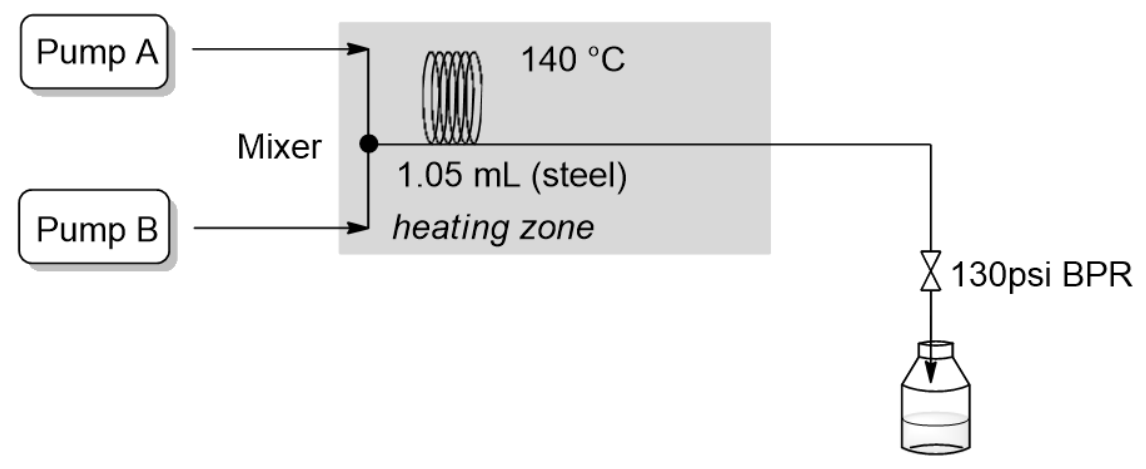

\section{Rational for $140{ }^{\circ} \mathrm{C}$ Reaction Temperature}

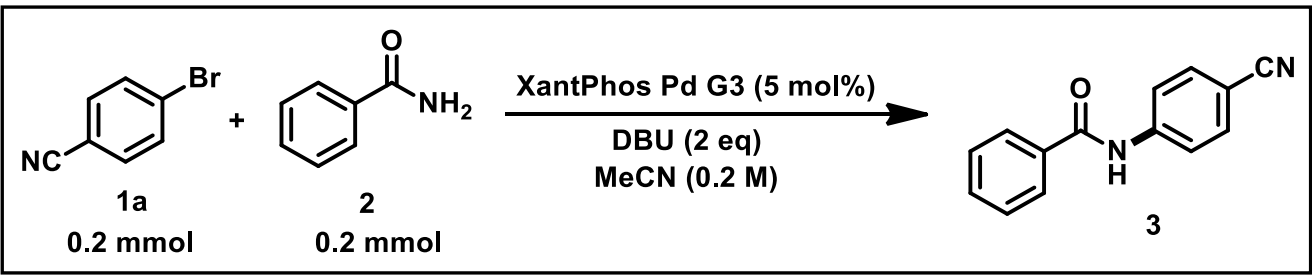

\begin{tabular}{|c|c|c|}
\hline T $\left({ }^{\circ} \mathbf{C}\right)$ & Reaction Time & NMR Yield \\
\hline $\mathbf{1 0 0}$ & $18 \mathrm{hr}$ & $95 \%$ \\
\hline $\mathbf{1 0 0}$ & $1 \mathrm{hr}$ & $22 \%$ \\
\hline $\mathbf{1 2 0}$ & $4 \mathrm{hr}$ & $96 \%$ \\
\hline $\mathbf{1 2 0}$ & $1 \mathrm{hr}$ & $34 \%$ \\
\hline $\mathbf{1 4 0}$ & $1 \mathrm{hr}$ & $88 \%$ \\
\hline
\end{tabular}




\subsection{General Procedure E for Mizoroki-Heck reaction in flow}

The procedure used for the data in Scheme 5 is provided below. In the glovebox, halide $(1.2 \mathrm{mmol})$ and tributylamine $(3.6 \mathrm{mmol})$ were combined in a $6 \mathrm{~mL}$ screw cap vial and made up to $3.00 \mathrm{~mL}$ with 1,4-dioxane to give a $0.4 \mathrm{M}$ solution of halide, which was subsequently loaded into a $5 \mathrm{~mL}$ Hamilton Gastight syringe. In the glovebox, olefin $(1.8 \mathrm{mmol})$ and palladium pre-catalyst $(0.036$ mmol) were combined in a $6 \mathrm{~mL}$ screw cap vial, made up to $3.00 \mathrm{~mL}$ with 1,4-dioxane, and loaded into a second $5 \mathrm{~mL}$ Hamilton Gastight syringe. The syringes were then attached in the glovebox to the PFA tubing continuous flow reactor depicted in Figure S2, which was subsequently shipped out of the glovebox. Syringes were loaded into Nexus 6000 pumps, and the reactor coil was submerged in an oil bath pre-heated to $90{ }^{\circ} \mathrm{C}$. Both pumps were simultaneously set to deliver the syringe contents at $8.333 \mathrm{uL} / \mathrm{min}$ through a $1 \mathrm{~mL}$ PFA coil of $0.5 \mathrm{~mm}$ i.d., with a 5 psi back pressure regulator set at the outlet. The first 3 hours ( 3 residence volumes) of effluent was discarded to reach steady state, followed by collection of effluent for the specified amount of time. Unless otherwise specified, solvent was evaporated, and the resulting material was dissolved in DCM $(30 \mathrm{~mL})$. The resultant solution was mixed and separated with $1 \mathrm{M} \mathrm{HCl}(30 \mathrm{~mL})$, followed by 2 more washes of the aqueous layer with DCM $(2 \times 30 \mathrm{~mL})$. The combined organic extracts were washed with saturated $\mathrm{NaCl}$ solution $(30 \mathrm{ml})$, dried over $\mathrm{Na}_{2} \mathrm{SO}_{4}$, and the solvent was evaporated. Product was purified via silica gel column chromatography, dried again with $\mathrm{Na}_{2} \mathrm{SO}_{4}$, solvent was evaporated, and the product was dried under high vacuum.

Figure S2 Schematic of flow reactor used for Heck reactions.

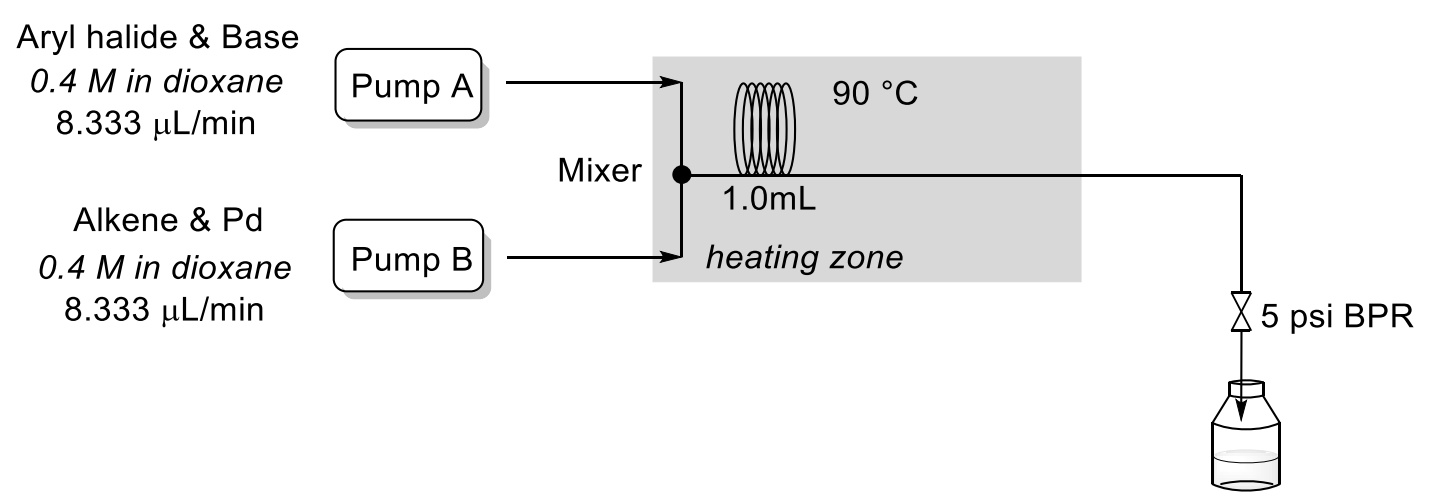

\subsection{General Procedure F for Sonogashira coupling in flow}

The procedure used for the data in Scheme 5 is provided below. In the glovebox, organohalide (1.5 $\mathrm{mmol})$ and alkyne $(2.25 \mathrm{mmol})$ and Tetrakis(triphenylphosphine)palladium(0) $(0.03 \mathrm{mmol})$ were 
combined in a $6 \mathrm{~mL}$ screw cap vial and diluted to $3.00 \mathrm{~mL}$ with THF to give a $0.5 \mathrm{M}$ solution of organohalide, which was subsequently loaded into a $10 \mathrm{~mL}$ Hamilton Gastight syringe. In a separate $6 \mathrm{~mL}$ vial, copper iodide $(0.03 \mathrm{mmol})$ and tributylamine $(4.5 \mathrm{mmol})$ were combined, diluted to $3.00 \mathrm{~mL}$ with THF, and loaded into a second $10 \mathrm{~mL}$ Hamilton Gastight syringe. The syringes were then attached in the glovebox to the PFA continuous flow reactor depicted in Figure S3, which was subsequently shipped out of the glovebox. Syringes were loaded into Nexus 6000 pumps, and the reactor coil was submerged in an oil bath pre-heated to $100{ }^{\circ} \mathrm{C}$. Both pumps were simultaneously set to deliver the syringe contents at $16.66 \mathrm{uL} / \mathrm{min}$ through a $1 \mathrm{~mL}$ PFA coil of 0.5 mm i.d., with a 40 psi back pressure regulator set at the outlet. The first 1.5 hours (3 residence volumes) of effluent was discarded to reach steady state, followed by collection of effluent for the specified amount of time. Unless otherwise specified, solvent was evaporated, and the resulting material was dissolved in DCM (30 mL). The resultant solution was mixed and separated with $1 \mathrm{M}$ $\mathrm{HCl}(30 \mathrm{~mL})$, followed by 2 more washes of the aqueous layer with DCM $(2 \times 30 \mathrm{~mL})$. The combined organic extracts were washed with saturated $\mathrm{NaCl}$ solution $(30 \mathrm{ml})$, dried over $\mathrm{Na}_{2} \mathrm{SO}_{4}$, and the solvent was evaporated. Product was purified via silica gel column chromatography, dried again with $\mathrm{Na}_{2} \mathrm{SO}_{4}$, solvent was evaporated, and the product was dried under high vacuum.

Figure S3 Schematic of flow reactor used for Sonogashira reactions.

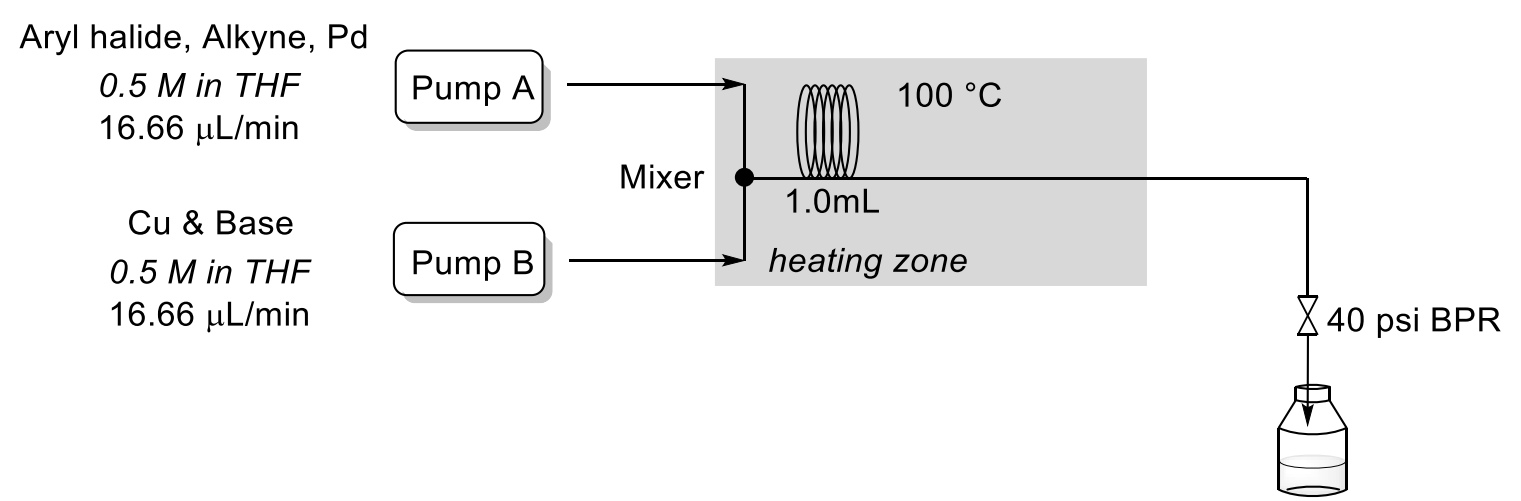




\section{Characterization data for products formed in batch reactions}

\section{N-(4-cyanophenyl)benzamide (3)}<smiles>N#Cc1ccc(NC(=O)c2ccccc2)cc1</smiles>

$\mathbf{X}=\mathbf{C l}$, General Procedure A was followed using benzamide (48.4 mg) and 4-chlorobenzonitirle (27.6 mg). Column chromatography (1:2 EtOAc in hexanes) yielded the pure product as a white crystal (38 mg, 85\% yield). Characterization data is in agreement with the literature. ${ }^{1} \mathrm{H}$ NMR $\left(400 \mathrm{MHz}, \mathrm{CDCl}_{3}\right): \delta 8.04(\mathrm{~s}, 1 \mathrm{H}), 7.90-7.85(\mathrm{~d}, \mathrm{~J}=7.2 \mathrm{~Hz}, 2 \mathrm{H}), 7.82-7.77(\mathrm{~d}, \mathrm{~J}=8.8 \mathrm{~Hz}, 2 \mathrm{H})$, 7.68-7.63 (d, J = 8.8 Hz, 2H), 7.63-7.57 (t, J = 7.4 Hz, 1H), 7.55-7.48 (t, J = 7.2 Hz, 2H). ${ }^{13} \mathrm{C}$ NMR $\left(100 \mathrm{MHz}_{\mathrm{CDCl}}\right): \delta 166.0,142.1,134.3,133.5,132.7,129.2,127.2,120.0,118.9,107.6$.

$\mathbf{X}=\mathbf{B r}$, General Procedure A was followed using benzamide (48.4 mg) and 4-bromobenzonitirle (36.4 mg). Column chromatography (1:2 EtOAc in hexanes) yielded the pure product as a white crystal (40 mg, 91\% yield). Characterization data is in agreement with the literature. ${ }^{1}{ }^{1} \mathrm{H}$ NMR $\left(400 \mathrm{MHz}, \mathrm{CDCl}_{3}\right): \delta 8.01(\mathrm{~s}, 1 \mathrm{H}), 7.91-7.84(\mathrm{~d}, \mathrm{~J}=7.2 \mathrm{~Hz}, 2 \mathrm{H}), 7.83-7.77(\mathrm{~d}, \mathrm{~J}=8.8 \mathrm{~Hz}, 2 \mathrm{H})$, 7.69-7.64 (d, J = 8.8 Hz, 2H), 7.63-7.57 (t, J = 7.4 Hz, 1H), 7.55-7.48 (t, J = 7.2 Hz, 2H). ${ }^{13} \mathrm{C}$ NMR $\left(100 \mathrm{MHz}, \mathrm{CDCl}_{3}\right): \delta 166.0,142.1,134.3,133.5,132.7,129.2,127.3,120.1,118.9,107.6$.

$\mathbf{X}=\mathbf{I}$, General Procedure A was followed using benzamide (48.4 mg) and 4-iodobenzonitirle (46 mg). Column chromatography (1:2 EtOAc in hexanes) yielded the pure product as a white crystal (31 mg, 70\% yield). Characterization data is in agreement with the literature. ${ }^{1}{ }^{1} \mathrm{H} \mathrm{NMR}(400 \mathrm{MHz}$, $\left.\mathrm{CDCl}_{3}\right): \delta 7.97(\mathrm{~s}, 1 \mathrm{H}), 7.92-7.84(\mathrm{~d}, \mathrm{~J}=6.9 \mathrm{~Hz}, 2 \mathrm{H}), 7.84-7.76(\mathrm{~d}, \mathrm{~J}=8.8 \mathrm{~Hz}, 2 \mathrm{H}), 7.70-7.64(\mathrm{~d}$, $\mathrm{J}=8.8 \mathrm{~Hz}, 2 \mathrm{H}), 7.63-7.57(\mathrm{t}, \mathrm{J}=7.4 \mathrm{~Hz}, 1 \mathrm{H}), 7.56-7.49(\mathrm{t}, \mathrm{J}=7.2 \mathrm{~Hz}, 2 \mathrm{H}) .{ }^{13} \mathrm{C} \mathrm{NMR}(100 \mathrm{MHz}$, $\left.\mathrm{CDCl}_{3}\right): \delta 166.0,142.2,134.3,133.5,132.7,129.2,127.2,120.1,119.0,107.6$.

\section{4-(benzylamino)benzonitrile (5)}

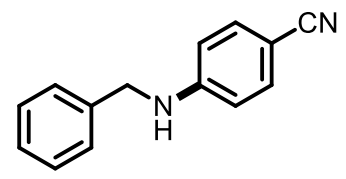

General Procedure B was followed. Column chromatography (8:1 Ether in $\mathrm{MeOH}$ ) yielded the pure product as a white solid (29 $\mathrm{mg}, 70 \%$ yield). Characterization data is in agreement with the 
literature. ${ }^{2}{ }^{1} \mathrm{H}$ NMR $\left(400 \mathrm{MHz}, \mathrm{CDCl}_{3}\right): \delta$ 7.44-7.40 (d, J = 7.9 Hz, 2H), 7.40-7.28 (m, 5H), 6.61$6.57(\mathrm{~d}, \mathrm{~J}=8.0 \mathrm{~Hz}, 2 \mathrm{H}), 4.59(\mathrm{~s}, 1 \mathrm{H}), 4.38(\mathrm{~s}, 2 \mathrm{H}) .{ }^{13} \mathrm{C} \mathrm{NMR}\left(100 \mathrm{MHz}, \mathrm{CDCl}_{3}\right): \delta 151.2,137.9$, $133.9,129.0,127.9,127.5,120.5,112.6,99.3,47.7$.

\section{4-methyl-N-phenylaniline (8)}<smiles>Cc1ccc(Nc2ccccc2)cc1</smiles>

General Procedure $\mathrm{C}$ was followed. Column chromatography (1:10 EtOAc in hexanes) yielded the pure product as a white crystal $(31.2 \mathrm{mg}, 85 \%$ yield). Characterization data is in agreement with the literature. ${ }^{3}{ }^{1} \mathrm{H}$ NMR (400 MHz, $\left.\mathrm{CDCl}_{3}\right): \delta 7.28-7.21(\mathrm{t}, \mathrm{J}=8.2 \mathrm{~Hz}, 2 \mathrm{H}), 7.12-7.07(\mathrm{~d}, \mathrm{~J}=7.8$ $\mathrm{Hz}, 2 \mathrm{H}), 7.04-6.99$ (m, 4H), 6.92-6.85 (t, J = 7.2 Hz, 1H), 5.60 (s, 1H), 2.31 (s, 1H). ${ }^{13} \mathrm{C}$ NMR (100 MHz, $\left.\mathrm{CDCl}_{3}\right): \delta 144.1,140.4,131.1,130.0,129.4,120.4,119.0,117.0,20.8$.

\section{4-methoxy-N-(pyridin-2-yl)benzamide (9)}<smiles>COc1ccc(C(=O)Nc2ccccn2)cc1</smiles>

General Procedure A was followed using 4-methoxybenzamide $(60.5 \mathrm{mg})$ and 2-bromopyridine $(19.1 \mu 1)$. Column chromatography (1:3 EtOAc in hexanes) yielded the pure product as a yellow solid (34.0 mg, 75\% yield). Characterization data is in agreement with the literature. ${ }^{4}{ }^{1} \mathrm{H}$ NMR $\left(400 \mathrm{MHz}, \mathrm{CDCl}_{3}\right): \delta 8.76(\mathrm{~s}, 1 \mathrm{H}), 8.45-8.40(\mathrm{~d}, \mathrm{~J}=8.4 \mathrm{~Hz}, 1 \mathrm{H}), 8.32-8.27(\mathrm{~m}, 1 \mathrm{H}), 7.96-7.90(\mathrm{dt}$, $\mathrm{J}=8.9 \mathrm{~Hz}, 2.8 \mathrm{~Hz}, 2 \mathrm{H}), 7.82-7.75(\mathrm{~m}, 1 \mathrm{H}), 7.12-7.05(\mathrm{~m}, 1 \mathrm{H}), 7.02-6.95(\mathrm{dt}, \mathrm{J}=8.8 \mathrm{~Hz}, 3.1 \mathrm{~Hz}$, 2H), 3.88 (s, 3H). ${ }^{13} \mathrm{C}$ NMR (100 MHz, $\left.\mathrm{CDCl}_{3}\right): \delta$ 165.3, 163.1, 151.8, 147.2, 139.1, 129.4, 126.4 , $119.8,114.5,114.2,55.7$.

\section{N-(4-nitrophenyl)isonicotinamide (10)}<smiles>O=C(Nc1ccc([N+](=O)[O-])cc1)c1ccncc1</smiles> 
General Procedure A was followed using 4-nicotinamide (48.8 mg) and 1-chloro-4-nitrobenzene (31.5 mg). Column chromatography (8:1 EtOAc in hexanes) yielded the pure product as a yellow powder (46.6 mg, 96\% yield). Characterization data is in agreement with the literature. ${ }^{5}{ }^{1} \mathrm{H}$ NMR $\left(400 \mathrm{MHz}, \mathrm{CDCl}_{3}\right): \delta 8.90-8.82(\mathrm{~d}, \mathrm{~J}=5.6 \mathrm{~Hz}, 2 \mathrm{H}), 8.33-8.26(\mathrm{~d}, \mathrm{~J}=9.3 \mathrm{~Hz}, 2 \mathrm{H}), 8.07(\mathrm{~S}, 1 \mathrm{H})$, 7.89-7.83 (d, J = 9.2 Hz, 2H), 7.75-7.70 (d, J = 6.0 Hz, 2H). ${ }^{13} \mathrm{C}$ NMR (100 MHz, DMSO-d6): $\delta$ $164.8,150.3,144.8,142.9,141.3,124.8,121.7,120.1$.

\section{2-(2-oxopyrrolidin-1-yl)benzonitrile (11)}

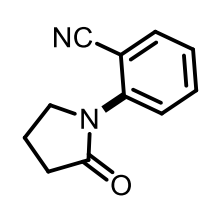

General Procedure A was followed using 2-pyrrolidinone (30 $\mu$ l) and 2-iodobenzonitrile (45.8 $\mathrm{mg})$. Column chromatography (1:1 EtOAc in DCM) yielded the pure product as a yellow solid (34.8 mg, 93\% yield). MP: $97{ }^{\circ} \mathrm{C} .{ }^{1} \mathrm{H}$ NMR $\left(400 \mathrm{MHz}, \mathrm{CDCl}_{3}\right): \delta 7.74-7.67$ (dd, J = 7.9 Hz, 1.5 $\mathrm{Hz}, 1 \mathrm{H}), 7.67-7.60$ (td, J= 7.9 Hz, 1.6 Hz, 2H), 7.47-7.40 (d, J = 8.0 Hz, 1H), 7.40-7.34 (td, J = 7.7 $\mathrm{Hz}, 1.1 \mathrm{~Hz}, 1 \mathrm{H}), 3.99-3.90$ (t, J = 6.9 Hz, 2H), 2.67-2.58 (t, J = 8.2 Hz, 2H), 2.32-2.21 (m, 2H). ${ }^{13} \mathrm{C}$ NMR $\left(100 \mathrm{MHz}, \mathrm{CDCl}_{3}\right): \delta 174.9,141.9,133.9,133.8,127.4,127.2,116.9,110.5,50.3,31.4$, 19.3. IR $v\left(\mathrm{~cm}^{-1}\right) 2985,2952,2923,2894,2852,2228,1690,1593,1491,1453,1401,1312,1273$, 1117. Accurate mass (EI): $\mathrm{m} / \mathrm{z}$ calcd for $\mathrm{C}_{11} \mathrm{H}_{10} \mathrm{~N}_{2} \mathrm{O}: 186.0788$. Found 186.0878 , Spectral accuracy $=99.7 \%$.

\section{N-(4-acetylphenyl)acetamide (12)}<smiles>CC(=O)Nc1ccc(C(C)=O)cc1</smiles>

General Procedure A was followed using acetamide $(23.6 \mathrm{mg})$ and 4-bromoacetophenone (39.8 $\mathrm{mg}$ ). Column chromatography (2:1 EtOAc in hexanes) yielded the pure product as a cream solid (28.1 mg, 79\% yield). Characterization data is in agreement with the literature. ${ }^{6}{ }^{1} \mathrm{H}$ NMR (400 $\left.\mathrm{MHz}, \mathrm{CDCl}_{3}\right): \delta$ 7.96-7.92 (dt, J = 8.7 Hz, 2.0 Hz, 2H), 7.67-7.55 (d, J= 8.9 Hz, 2H), $7.38(\mathrm{~s}, 1 \mathrm{H})$, $2.58(\mathrm{~s}, 3 \mathrm{H}), 2.22(\mathrm{~s}, 3 \mathrm{H}) .{ }^{13} \mathrm{C}$ NMR $\left(100 \mathrm{MHz}, \mathrm{CDCl}_{3}\right): \delta 197.0,168.6,142.3,133.0,129.9,118.9$, 26.5, 24.9. 
(R)-1-acetyl-N-(4-cyanophenyl) pyrrolidine-2-carboxamide (13)<smiles>CC(=O)N1CCC[C@H]1C(=O)Nc1ccc(C#N)cc1</smiles>

General Procedure A was followed using N-acetyl-L-prolinamide (62.5 mg) and 4bromobenzonitrile $(36.4 \mathrm{mg})$. The reaction was stopped after $2 \mathrm{hrs}$ instead of $18 \mathrm{hrs}$. Column chromatography (8:1 Ether in $\mathrm{MeOH})$ yielded the pure product as a white solid (47.6 mg, 92\% yield). MP: $225{ }^{\circ} \mathrm{C} .{ }^{1} \mathrm{H}$ NMR (400 MHz, $\left.\mathrm{CDCl}_{3}\right): \delta 10.23(\mathrm{~s}, 1 \mathrm{H}), 7.61-7.56(\mathrm{~d}, \mathrm{~J}=8.9 \mathrm{~Hz}, 2 \mathrm{H})$, 7.53-7.48 (d, J= 9.2 Hz, 2H), 4.80-4.75 (d, J = 7.4 Hz, 1H), 3.65-3.57 (m, 1H), 3.53-3.44 (m, 1H), 2.60-2.48 (m, 1H), $2.17(\mathrm{~m}, 3 \mathrm{H}), 2.15-1.99(\mathrm{~m}, 2 \mathrm{H}), 1.93-1.83(\mathrm{~m}, 1 \mathrm{H}) .{ }^{13} \mathrm{C} \mathrm{NMR}(100 \mathrm{MHz}$, $\left.\mathrm{CDCl}_{3}\right): \delta 172.1,169.6,142.5,133.2,119.7,119.1,106.7,60.1,48.8,26.9,25.2,22.7 . \mathrm{IR} v\left(\mathrm{~cm}^{-1}\right)$ 3254, 3181, 3094, 3040, 2881, 2222, 1709, 1623, 1599, 1535, 1508, 1452, 1359, 1306, 1252, 1176, 1001.Accurate mass (EI): $\mathrm{m} / \mathrm{z}$ calcd for $\mathrm{C}_{14} \mathrm{H}_{15} \mathrm{~N}_{2} \mathrm{O}: 257.1159$. Found 257.1167, Spectral accuracy $=99.2 \%$. HPLC: IA chiral column, $10 \% \mathrm{iPrOH}$ in hexanes, $1.0 \mathrm{~mL} / \mathrm{min}, 254 \mathrm{~nm}$, $\mathrm{tR} 1$ (minor) = $26.8 \mathrm{~min}, \mathrm{tR} 2$ (major) $=35.4 \mathrm{~min}$.

\section{Characterization data for products formed in flow reactions}

\subsection{Buchwald-Hartwig aminations in flow}

\section{N-(4-cyanophenyl)benzamide (14)}<smiles>N#Cc1ccc(NC(=O)c2ccccc2)cc1</smiles>

General Procedure D was followed for the reaction of 4-bromobenzonitrile and benzamide using $8 \mathrm{~mL}$ stainless steel syringes. Column chromatography (20\% acetone in hexanes) yielded the product as an off white solid (76.5 min collection time, $50.3 \mathrm{mg}$, 85\% yield). Characterization data is in agreement with the literature. ${ }^{7}{ }^{1} \mathrm{H} \mathrm{NMR}\left(400 \mathrm{MHz}, \mathrm{CDCl}_{3}\right): \delta 8.01(\mathrm{br}, 1 \mathrm{H}), 7.90-7.85(\mathrm{~m}$, 2H), 7.83-7.77 (m, 2H), 7.68-7.64 (m, 2H), $7.60(\mathrm{tt}, \mathrm{J}=7.4,2.1,1 \mathrm{H}), 7.54-7.49(\mathrm{~m}, 2 \mathrm{H}) .{ }^{13} \mathrm{C}$ NMR (400 MHz, $\left.\mathrm{CDCl}_{3}\right): \delta 165.8,142.0,134.1,133.4,132.5,129.0,127.1,119.9,188.8,107.5$. 


\section{1-(4-nitrophenyl)pyrrolidin-2-one (15)}<smiles>O=C1CCCN1c1ccc([N+](=O)[O-])cc1</smiles>

General Procedure D was followed for the reaction of 4-chloronitrobenzene and 2-pyrrolidone using $8 \mathrm{~mL}$ stainless steel syringes. Column chromatography (20\% acetone in hexanes) yielded the product as an orange solid (67.0 min collection time, $42.6 \mathrm{mg}, 88 \%$ yield). Characterization data is in agreement with the literature. ${ }^{8} \mathrm{H}$ NMR (400 MHz, $\left.\mathrm{CDCl}_{3}\right): \delta 8.26-8.20(\mathrm{~m}, 2 \mathrm{H}), 7.86-$ $7.81(\mathrm{~m}, 2 \mathrm{H}), 3.92(\mathrm{t}, \mathrm{J}=7.0,2 \mathrm{H}), 2.67(\mathrm{t}, \mathrm{J}=8.3,2 \mathrm{H}), 2.28-2.18(\mathrm{~m}, 2 \mathrm{H}){ }^{13} \mathrm{C} \mathrm{NMR}(400 \mathrm{MHz}$, $\left.\mathrm{CDCl}_{3}\right): \delta 174.9,144.9,143.4,124.7,118.7,48.5,32.8,17.8$.

\section{4-(phenylamino)benzonitrile (16)}<smiles>N#Cc1ccc(Nc2ccccc2)cc1</smiles>

General Procedure D was followed for the reaction of 4-bromobenzonitrile and analine using $8 \mathrm{ml}$ stainless steel syringes. Column chromatography (15\% ethyl acetate in hexanes) yielded the product as a pale orange solid (104.5 min collection time, $57.4 \mathrm{mg}, 81 \%$ yield). Characterization data is in agreement with the literature. ${ }^{9}{ }^{1} \mathrm{H} \mathrm{NMR}\left(400 \mathrm{MHz}, \mathrm{CDCl}_{3}\right): \delta 7.50-7.46(\mathrm{~m}, 2 \mathrm{H}), 7.39$ $7.33(\mathrm{~m}, 2 \mathrm{H}), 7.19-7.09(\mathrm{~m}, 2 \mathrm{H}), 7.00-7.95$ (m, 2H), 6.05 (br, 1H). ${ }^{13} \mathrm{C} \mathrm{NMR}\left(400 \mathrm{MHz}, \mathrm{CDCl}_{3}\right)$ : $\delta 148.0,140.0,133.8,129.7,124.0,121.3,119.9,114.9,101.6$.

\section{1-(4-((4-methoxyphenyl)amino)phenyl)ethanone (17)}<smiles>COc1ccc(Nc2ccc(C(C)=O)cc2)cc1</smiles>

General Procedure D was followed for the reaction of 4-bromoacetophenone and 4methoxyanaline using $8 \mathrm{~mL}$ stainless steel syringes. Column chromatography (0-35\% acetone in hexanes, $5 \%$ increase $/ 50 \mathrm{~mL}$ ) yielded the product as a pale yellow solid (92.8 min collection time, $61.0 \mathrm{mg}, 78 \%$ yield). Characterization data is in agreement with the literature. ${ }^{10}{ }^{1} \mathrm{H}$ NMR (400 $\left.\mathrm{MHz}, \mathrm{CDCl}_{3}\right): \delta$ 7.85-7.80 (m, 2H), 7.16-7.11 (m, 2H), 6.94-6.88 (m, 2H), 6.84-6.79 (m, 2H), 5.98 
(s, 1H), $3.82(\mathrm{~s}, 3 \mathrm{H}), 2.51(\mathrm{~s}, 3 \mathrm{H}) .{ }^{13} \mathrm{C}$ NMR $\left(400 \mathrm{MHz}, \mathrm{CDCl}_{3}\right): \delta 196.3,156.7,150.1,133.2$ 130.7, 128.2, 124.6, 114.8, 113.1, 55.6, 26.1.

\subsection{Mizoroki-Heck couplings in flow}

\section{1-methoxy-4-styryl-benzene (18)}

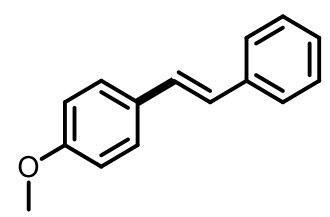

General Procedure E was followed for the reaction of 4-iodoanisole and styrene using $5 \mathrm{~mL}$ Hamilton Gastight syringes. Column chromatography (7.5\% EtOAc in hexanes) yielded the product as a white solid (105.6 min collection time, $66.4 \mathrm{mg}$, 90\% yield). Characterization data is in agreement with the literature. ${ }^{11}{ }^{1} \mathrm{H}$ NMR $\left(400 \mathrm{MHz}, \mathrm{CDCl}_{3}\right)$, E isomer: $\delta$ 7.52-7.44 (m, 4H), 7.38-7.32 (m, 2H), 7.27-7.22 (m, 1H), 7.08 (d, J = 16.3 Hz, 1H), 6.98 (d, J = 16.3 Hz, 1H), 6.94$6.89(\mathrm{~m}, 2 \mathrm{H}), 6.84(\mathrm{~s}, 3 \mathrm{H}) .{ }^{1} \mathrm{H}$ NMR (400 MHz, $\mathrm{CDCl}_{3}$ ), terminal olefin: 7.31-7.27 (m, 2H), 6.89$6.85(\mathrm{~m}, 2 \mathrm{H}), 5.41(\mathrm{~d}, \mathrm{~J}=2.1 \mathrm{~Hz}, 1 \mathrm{H}), 5.37(\mathrm{~d}, \mathrm{~J}=2.2 \mathrm{~Hz}, 1 \mathrm{H}), 3.83(\mathrm{~s}, 3 \mathrm{H})$. Other resonances are obscured by the resonances of the $\mathrm{E}$ isomer. ${ }^{13} \mathrm{C} \mathrm{NMR}\left(400 \mathrm{MHz}, \mathrm{CDCl}_{3}\right)$, $\mathrm{E}$ isomer: $\delta 159.4$, $137.8,130.3,129.5,128.8,128.5,128.4,128.3$ 127.9, 127.3, 126.8, 126.4, 114.3, 55.5.

\section{1-methyl-4-styryl-benzene (19)}

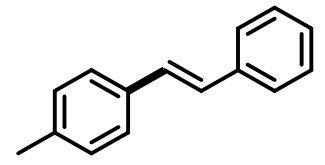

General Procedure E was followed for the reaction of 4-iodotoluene and styrene using $5 \mathrm{~mL}$ Hamilton Gastight syringes. Column chromatography (pure hexanes) yielded the product as a white solid ( $89.0 \mathrm{~min}$ collection time, $46.6 \mathrm{mg}, 81 \%$ yield). Characterization data is in agreement with the literature. ${ }^{12}{ }^{1} \mathrm{H}$ NMR (400 MHz, $\left.\mathrm{CDCl}_{3}\right)$, E isomer: $\delta$ 7.54-7.49 (m, 2H), 7.45-7.41 (m, 2H), 7.39-7.34 (m, 2H), 7.29-7.23 (m, 1H), 7.21-7.16 (m, 2H), 7.10-7.08 (m, 2H). ${ }^{1} \mathrm{H}$ NMR (400 $\left.\mathrm{MHz}, \mathrm{CDCl}_{3}\right)$, terminal olefin: $\delta 5.45(\mathrm{~d}, \mathrm{~J}=1.2,1 \mathrm{H}), 5.44(\mathrm{~d}, \mathrm{~J}=1.2,1 \mathrm{H})$. Other resonances are obscured by the resonances of the $\mathrm{E}$ isomer. ${ }^{13} \mathrm{C} \mathrm{NMR}\left(400 \mathrm{MHz}, \mathrm{CDCl}_{3}\right)$, $\mathrm{E}$ isomer: $\delta 137.7$, $134.7,129.5,128.79,128.76,127.8,127.5,126.57,126.53,21.4$. 


\section{1-cyano-4-styryl-benzene (20)}<smiles>N#Cc1ccc(/C=C/c2ccccc2)cc1</smiles>

General Procedure E was followed for the reaction of 4-iodobenzonitrile and styrene using $10 \mathrm{~mL}$ Hamilton Gastight syringes. Column chromatography (15\% EtOAc in hexanes) yielded the product as a white solid (113.9 min collection time, $74.7 \mathrm{mg}, 96 \%$ yield). Characterization data is in agreement with the literature. ${ }^{13}{ }^{1} \mathrm{H}$ NMR $\left(400 \mathrm{MHz}, \mathrm{CDCl}_{3}\right), \mathrm{E}$ isomer: $\delta$ 7.66-7.51 (m, 6H), 7.42-7.37 (m, 2H), 7.35-7.30 (m, 1H), $7.22(\mathrm{~d}, \mathrm{~J}=16.3,1 \mathrm{H}), 7.09$ (d, J = 16.3, 1H). ${ }^{1} \mathrm{H}$ NMR (400 $\left.\mathrm{MHz}, \mathrm{CDCl}_{3}\right)$, terminal olefin: $\delta 5.59(\mathrm{~d}, \mathrm{~J}=0.6 .1 \mathrm{H}), 5.54(\mathrm{~d}, \mathrm{~J}=0.6,1 \mathrm{H})$. Other resonances are obscured by the resonances of the E isomer. ${ }^{13} \mathrm{C} \mathrm{NMR}\left(400 \mathrm{MHz}, \mathrm{CDCl}_{3}\right), \mathrm{E}$ isomer: $\delta$ 142.0, $136.4,132.60,132.53,129.0,128.8,127.04,126.99,126.8,119.1,110.7$.

\section{(E)-1-(4-(2-(pyridin-2-yl)vinyl)phenyl)ethanone (21)}

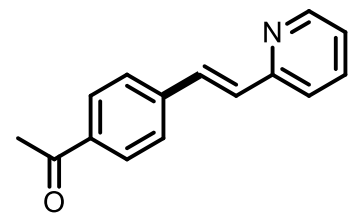

General Procedure E was followed, with one change, for the reaction of 4-bromoacetophenone and 2-vinylpyridine using $10 \mathrm{~mL}$ Hamilton Gastight syringes. The crude product was only separated with saturated $\mathrm{NaCl}$ solution, not with $\mathrm{HCl}$. Column chromatography (20\% $\mathrm{MeCN}$ in toluene) yielded the product as a pale-yellow solid (73.6 min collection time, $52.4 \mathrm{mg}$, 96\% yield). Only the linear E isomer was observed. Characterization data is in agreement with the literature. ${ }^{14}{ }^{1} \mathrm{H}$ $\operatorname{NMR}\left(400 \mathrm{MHz}, \mathrm{CDCl}_{3}\right): \delta 8.63(\mathrm{~d}, \mathrm{~J}=4.1,1 \mathrm{H}), 7.98-7.94(\mathrm{~m}, 2 \mathrm{H}), 7.71-7.63(\mathrm{~m}, 4 \mathrm{H}), 7.42-7.38$ $(\mathrm{m}, 2 \mathrm{H}), 7.27(\mathrm{~d}, \mathrm{~J}=16.1,1 \mathrm{H}), 7.18(\mathrm{ddd}, \mathrm{J}=7.5,4.8,1.0,1 \mathrm{H}), 2.61(\mathrm{~s}, 3 \mathrm{H}) .{ }^{13} \mathrm{C} \mathrm{NMR}(400 \mathrm{MHz}$, $\left.\mathrm{CDCl}_{3}\right): \delta 197.6,155.1,149.9,141.4,136.8,136.6,131.6,130.6,129.0,127.3,122.78,122.76$, 26.7 . 


\subsection{Sonogashira couplings in flow}

\section{1-methoxy-4-(3'-pyridinylethynyl)-benzene (22)}

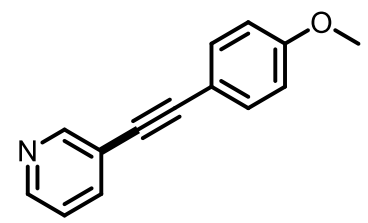

General Procedure F was followed, with one change, for the reaction of 3-iodopyridine and 4ethynylanisole using $10 \mathrm{~mL}$ Hamilton Gastight syringes. The crude product was only separated with saturated $\mathrm{NaCl}$ solution, not with $\mathrm{HCl}$. Column chromatography (0-30\% acetone in hexanes, $5 \%$ increase $/ 50 \mathrm{~mL}$ ) yielded the product as a white solid (40.6 min collection time, $70.8 \mathrm{mg}, 83 \%$ yield). Characterization data is in agreement with the literature. ${ }^{15}{ }^{1} \mathrm{H} \mathrm{NMR}\left(400 \mathrm{MHz}, \mathrm{CDCl}_{3}\right): \delta$ $8.75(\mathrm{~s}, 1 \mathrm{H}), 8.52(\mathrm{~d}, \mathrm{~J}=3.5,1 \mathrm{H}), 7.78(\mathrm{dt}, \mathrm{J}=7.9,1.9,1 \mathrm{H}), 7.51-7.46(\mathrm{~m}, 2 \mathrm{H}), 7.27$ (dd, J = 7.8, 4.8, 1H), 6.92-6.87 (m, 2H), $3.84(\mathrm{~s}, 3 \mathrm{H}) .{ }^{13} \mathrm{C} \mathrm{NMR}\left(400 \mathrm{MHz}, \mathrm{CDCl}_{3}\right): \delta 160.1,152.0,148.1$, $138.3,133.2,123.1,120.9,114.6,114.1,92.8,84.7,55.3$.

\section{1-(2-phenylethynyl)-3-(trifluoromethyl)benzene (23)}

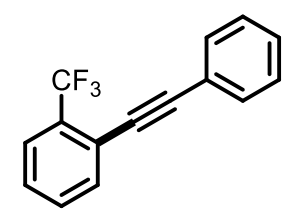

General Procedure F was followed for the reaction of 3-iodobenzotrifluoride and phenylacetylene using 10 mL Hamilton Gastight syringes. Column chromatography (0-4\% acetone in hexanes, 1\% increase $/ 100 \mathrm{~mL}$ ) yielded the product as a white solid (51.5 min collection time, $103 \mathrm{mg}, 97 \%$ yield). Characterization data is in agreement with the literature. ${ }^{16}{ }^{1} \mathrm{H} \mathrm{NMR}\left(400 \mathrm{MHz}, \mathrm{CDCl}_{3}\right): \delta$ $7.81(\mathrm{~s}, 1 \mathrm{H}), 7.70(\mathrm{~d}, \mathrm{~J}=7.7,1 \mathrm{H}), 7.61-7.53(\mathrm{~m}, 3 \mathrm{H}), 7.48(\mathrm{t}, \mathrm{J}=7.8,1 \mathrm{H}), 7.41-7.35\left(\mathrm{~m}, 2 \mathrm{H} .{ }^{13} \mathrm{C}\right.$ NMR (400 MHz, $\left.\mathrm{CDCl}_{3}\right): \delta 134.66,134.65,131.7,128.9,128.8,128.45,128.42,128.38,128.35$, $124.81,124.78,124.74,124.70,124.3,122.6,90.9,87.8$. 


\section{HPLC chromatograms}

(士)-1-acetyl-N-(4-cyanophenyl)pyrrolidine-2-carboxamide<smiles>CC(=O)N1CCCC1C(=O)Nc1ccc(C#N)cc1</smiles>
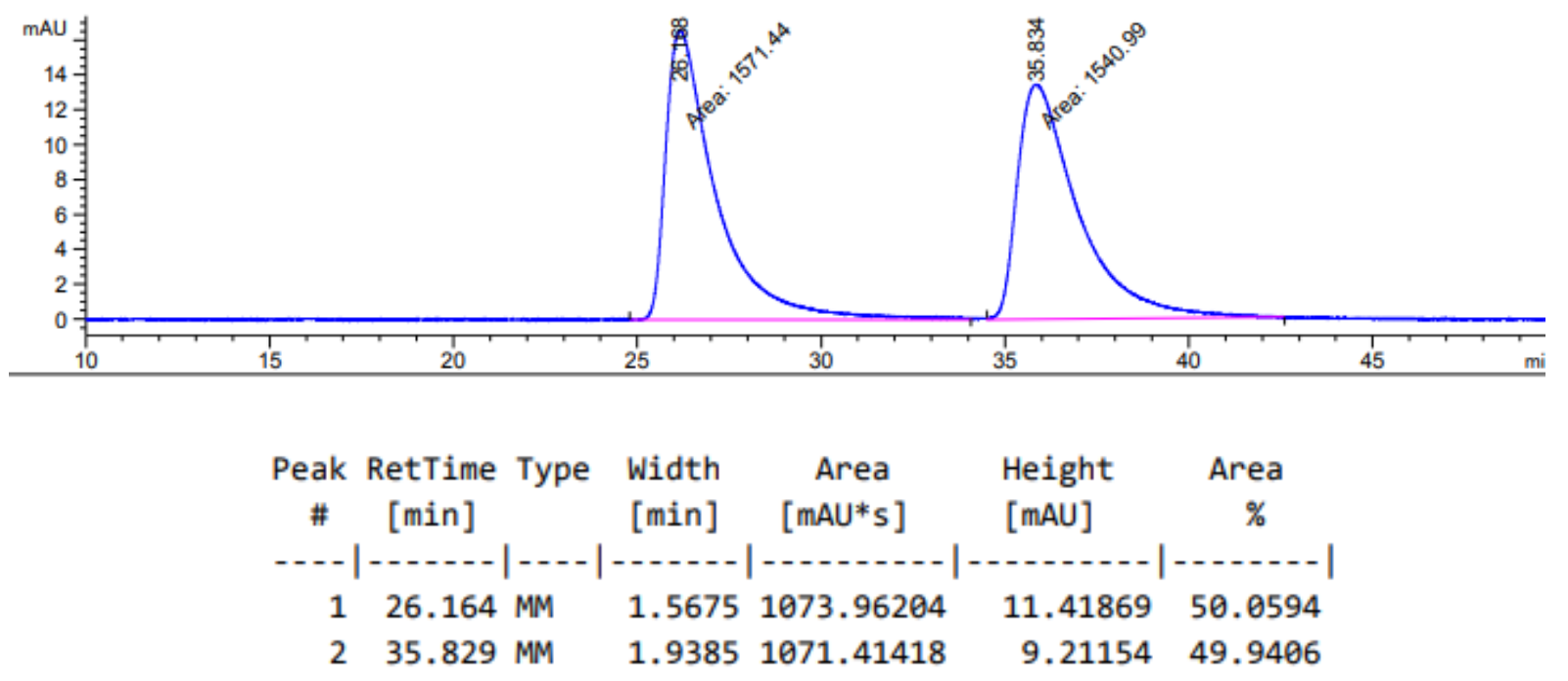

(R)-1-acetyl-N-(4-cyanophenyl)pyrrolidine-2-carboxamide (13)<smiles>CC(=O)N1CCC[C@H]1C(=O)Nc1ccc(C#N)cc1</smiles>

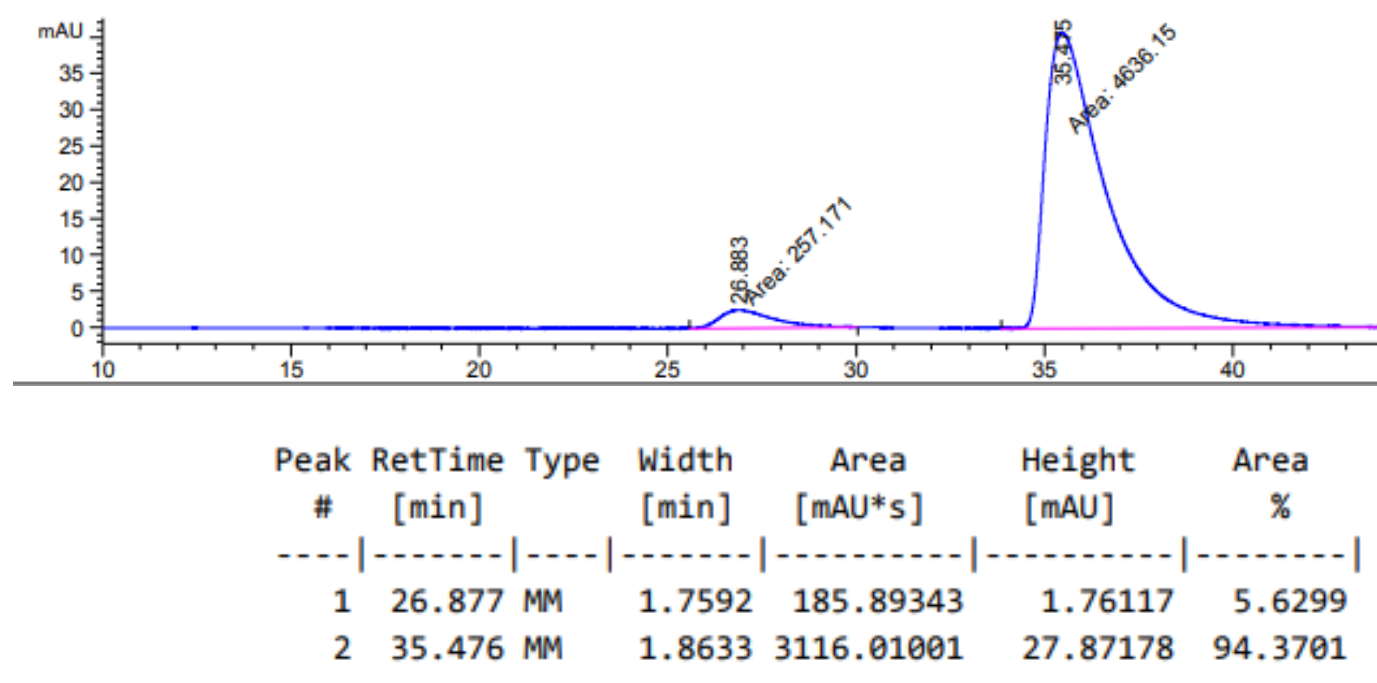




\section{NMR Spectra}

N-(4-cyanophenyl)benzamide (3), X= Cl

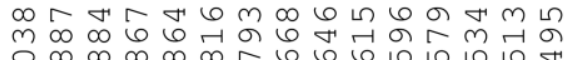
mariraririrararir

m

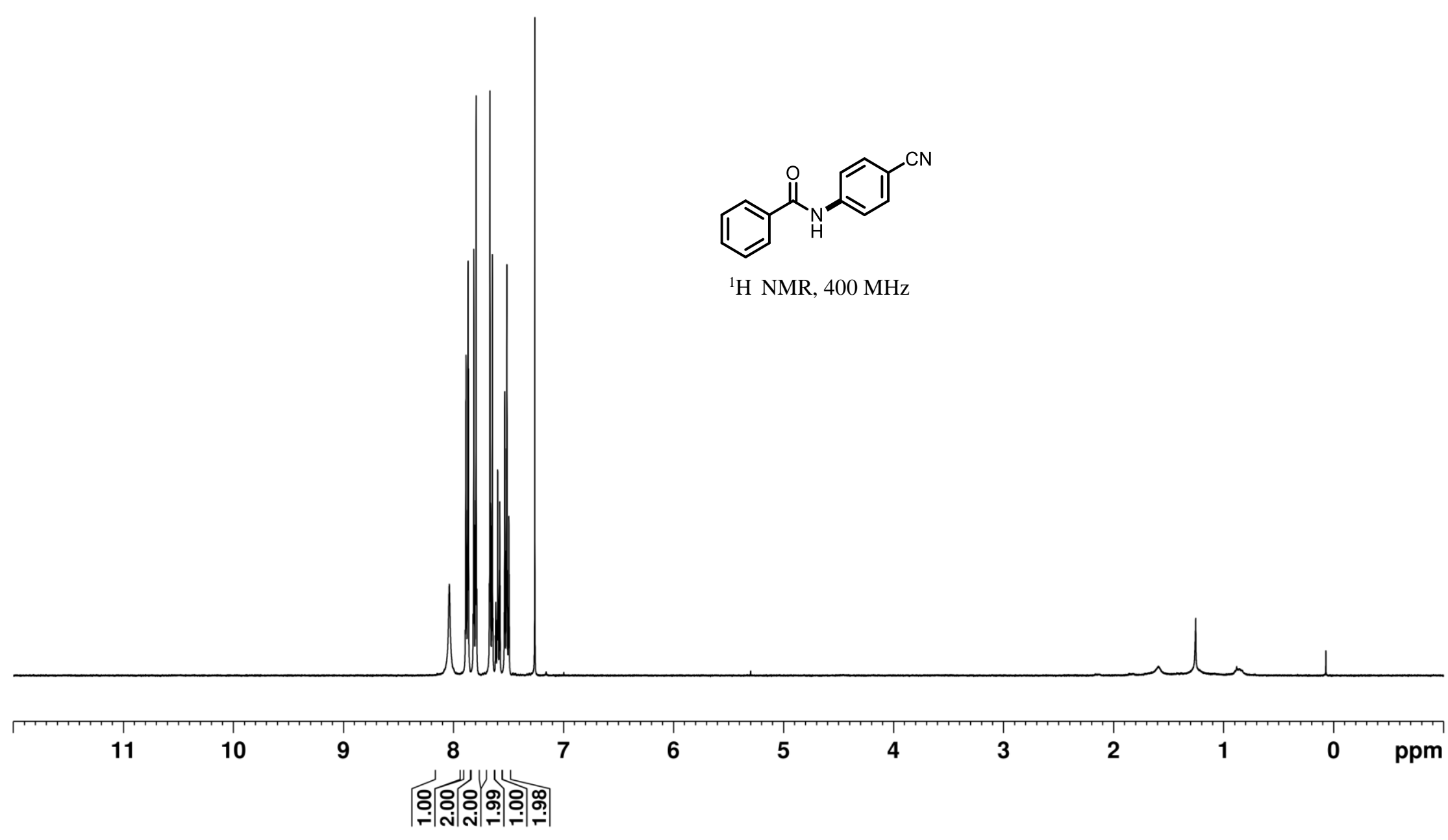




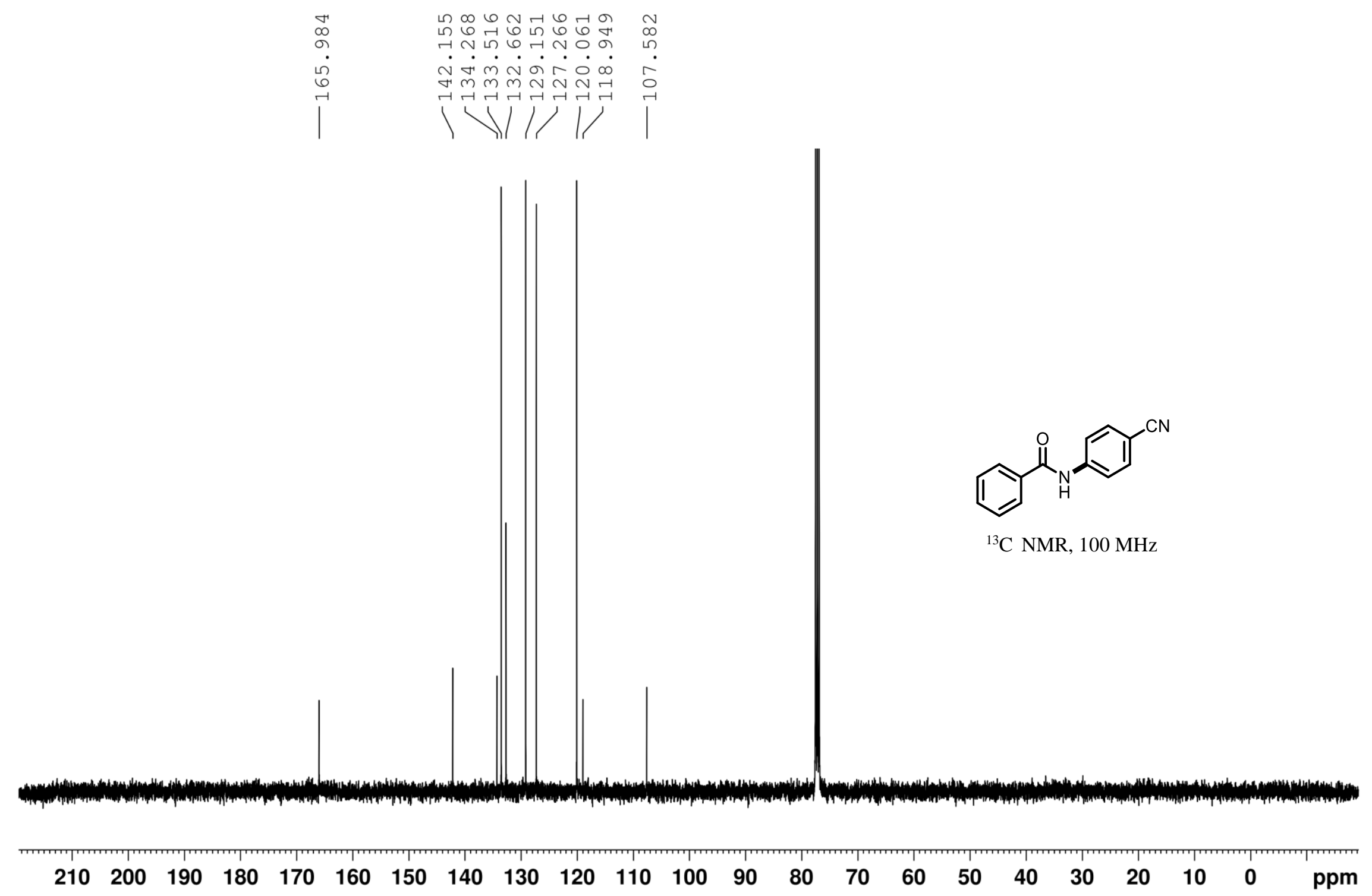


N-(4-cyanophenyl)benzamide (3), $\mathrm{X}=\mathrm{Br}$

의

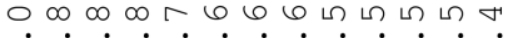

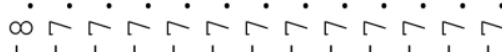

minn

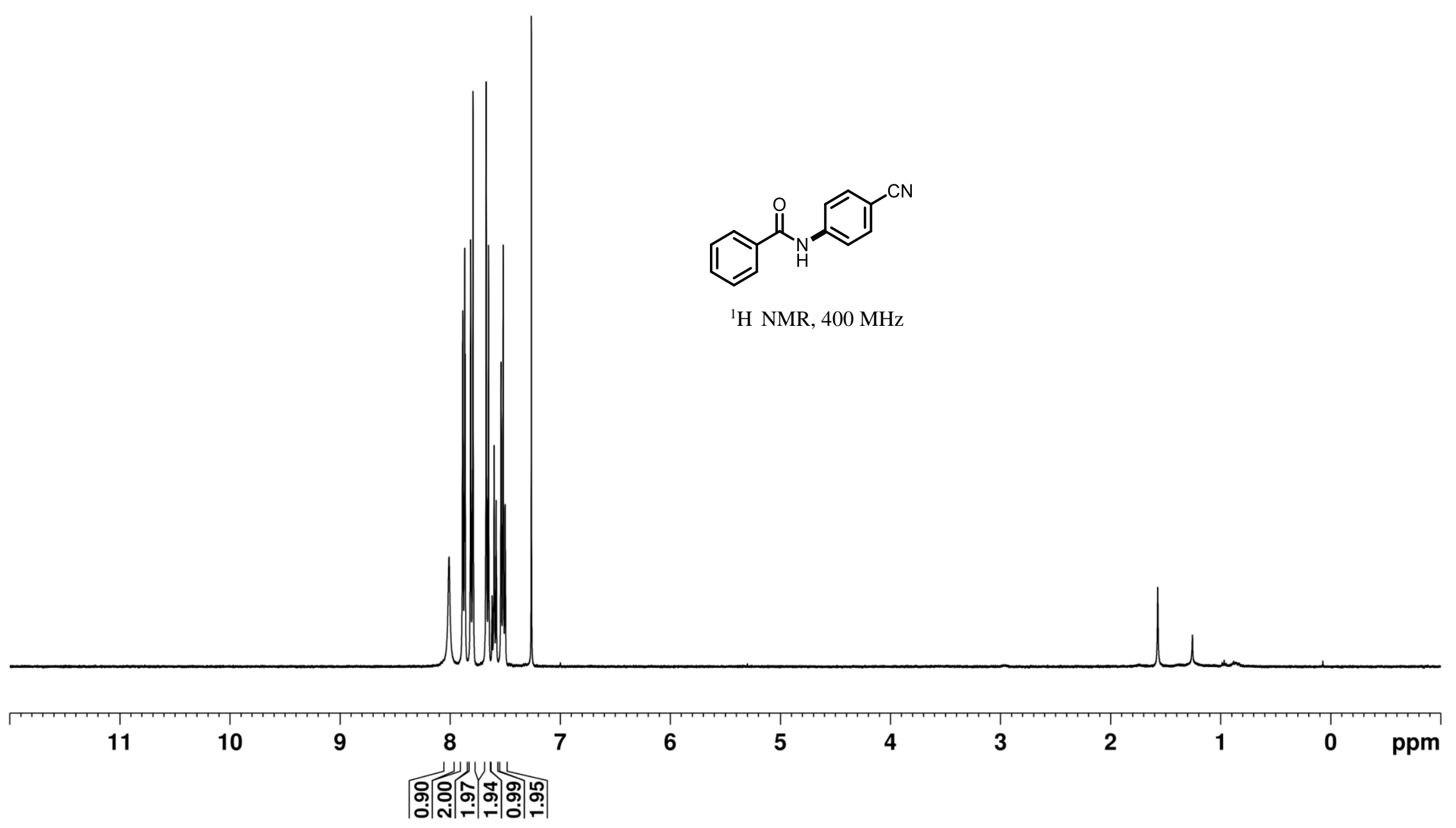




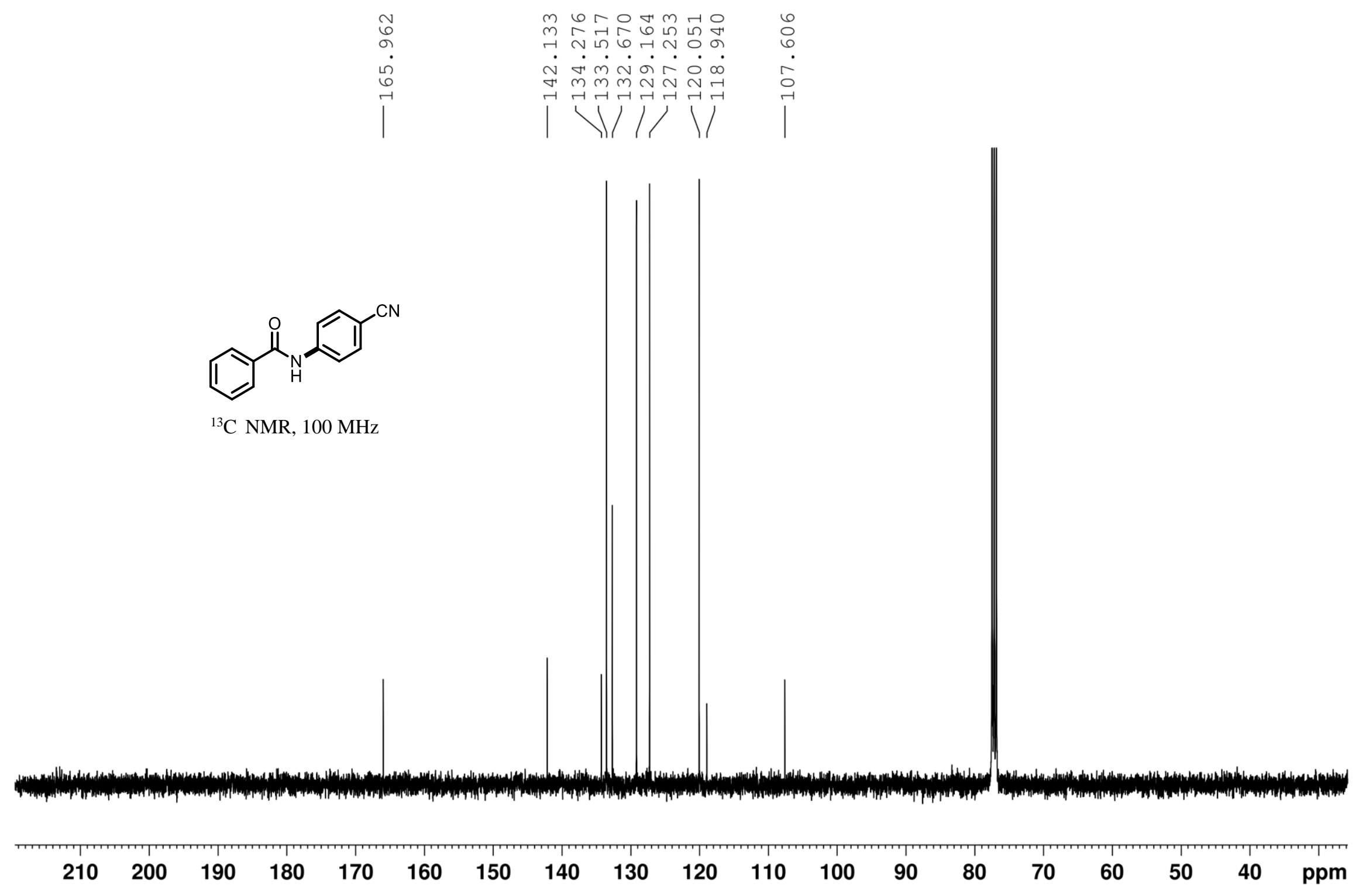


N-(4-cyanophenyl)benzamide (3), X= I
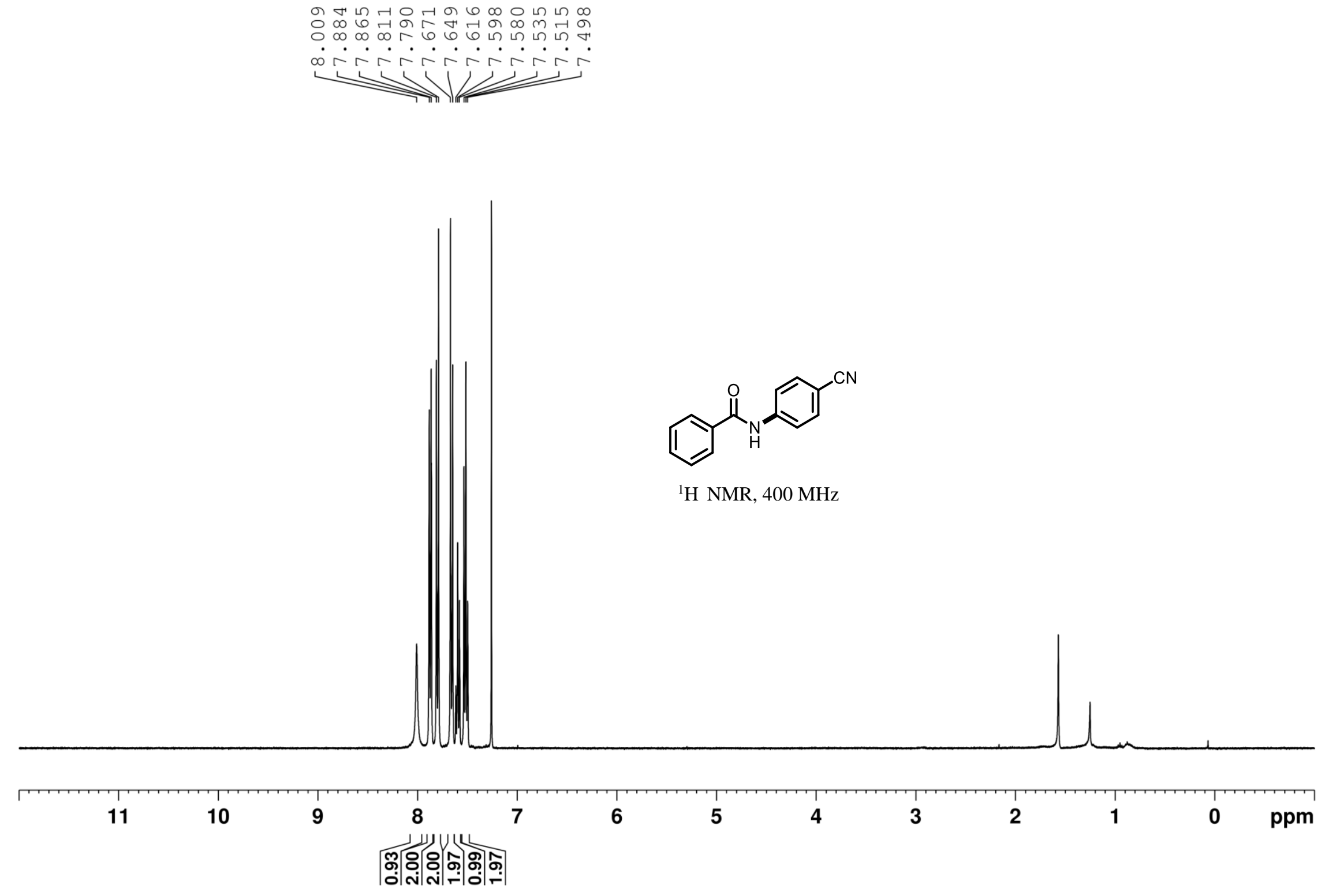


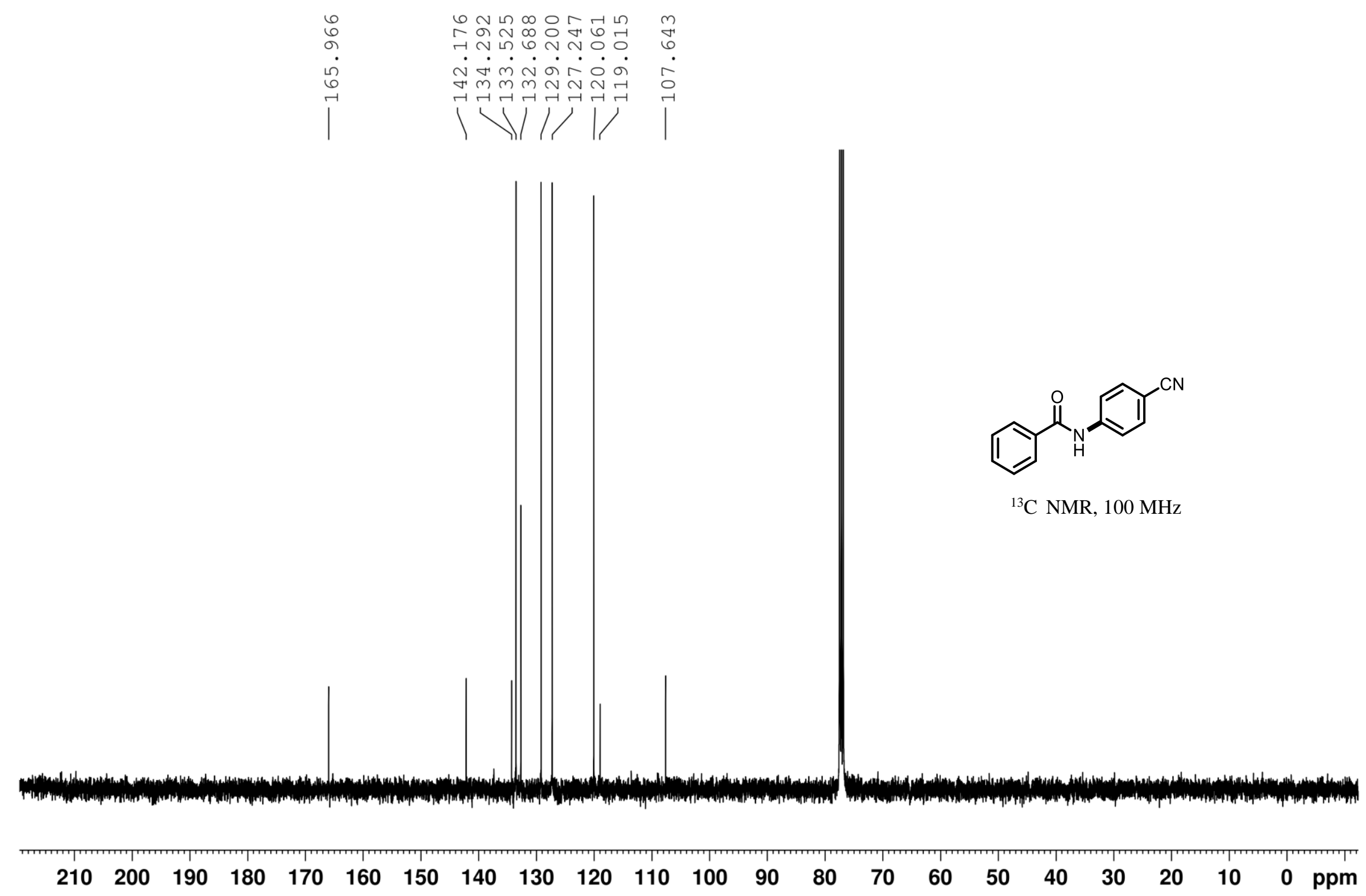




\section{4-(benzylamino)benzonitrile (5)}

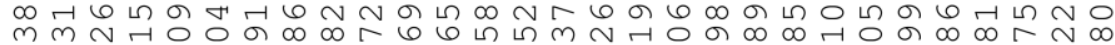

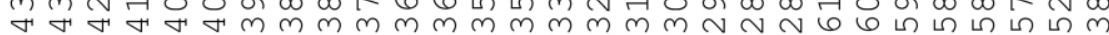

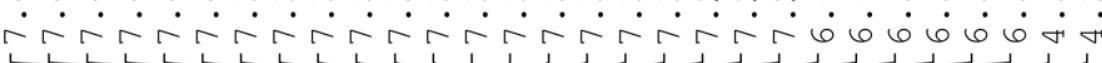
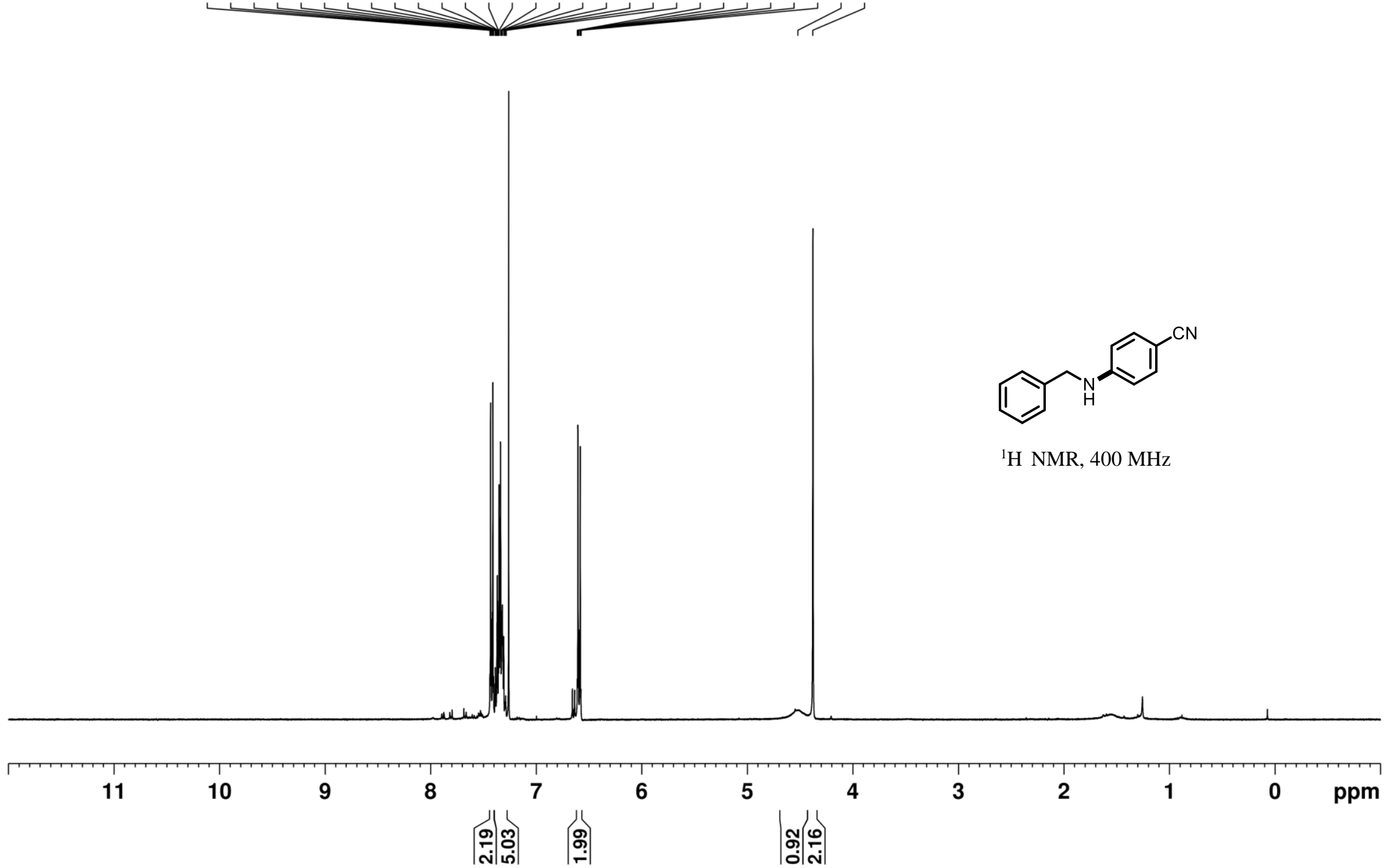


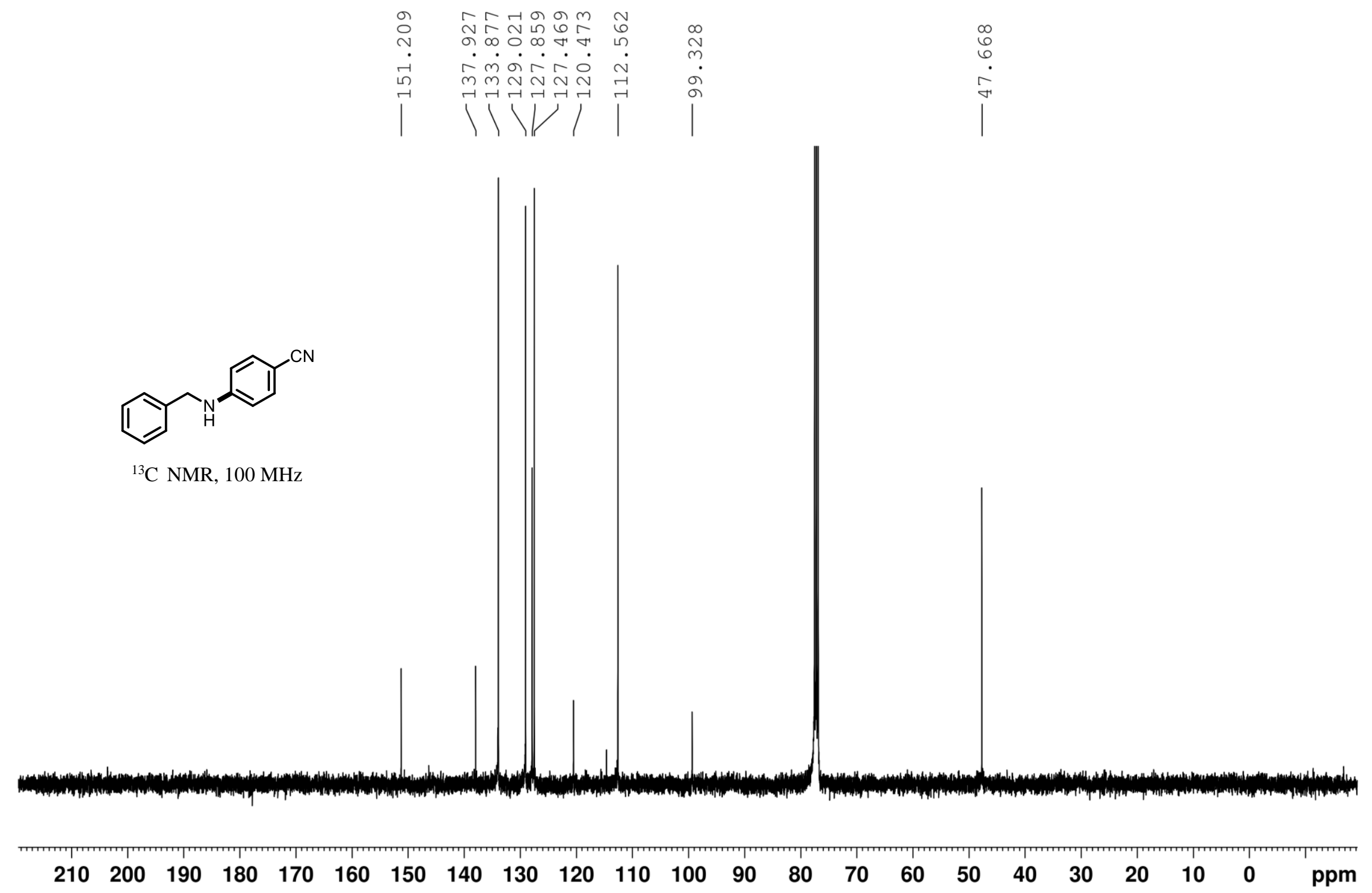



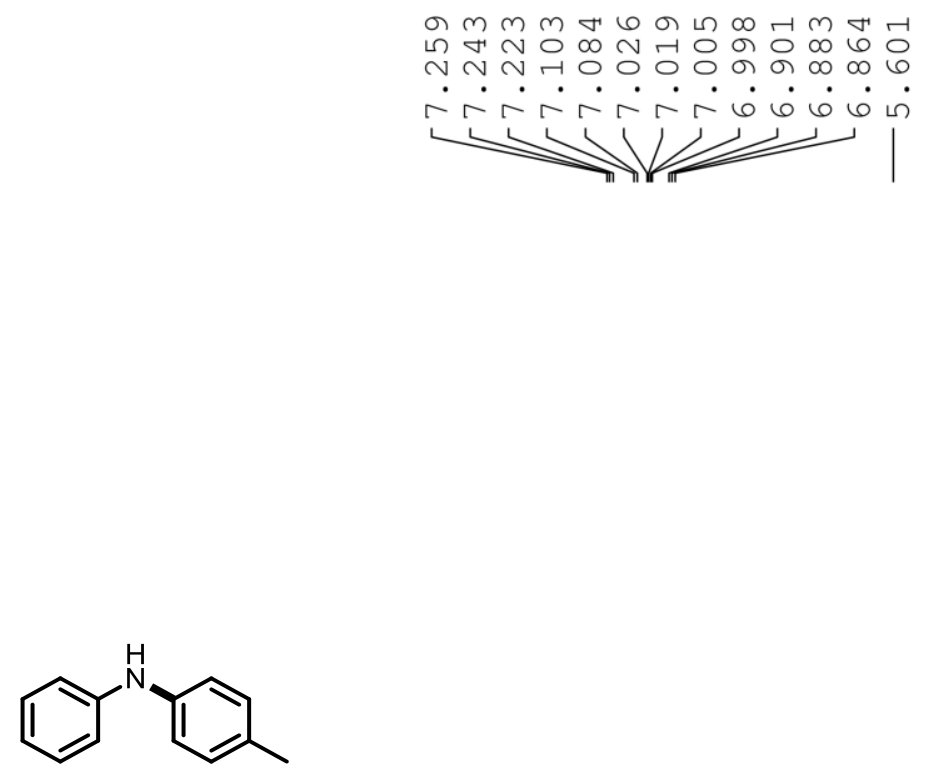

${ }^{1} \mathrm{H}$ NMR, $400 \mathrm{MHz}$

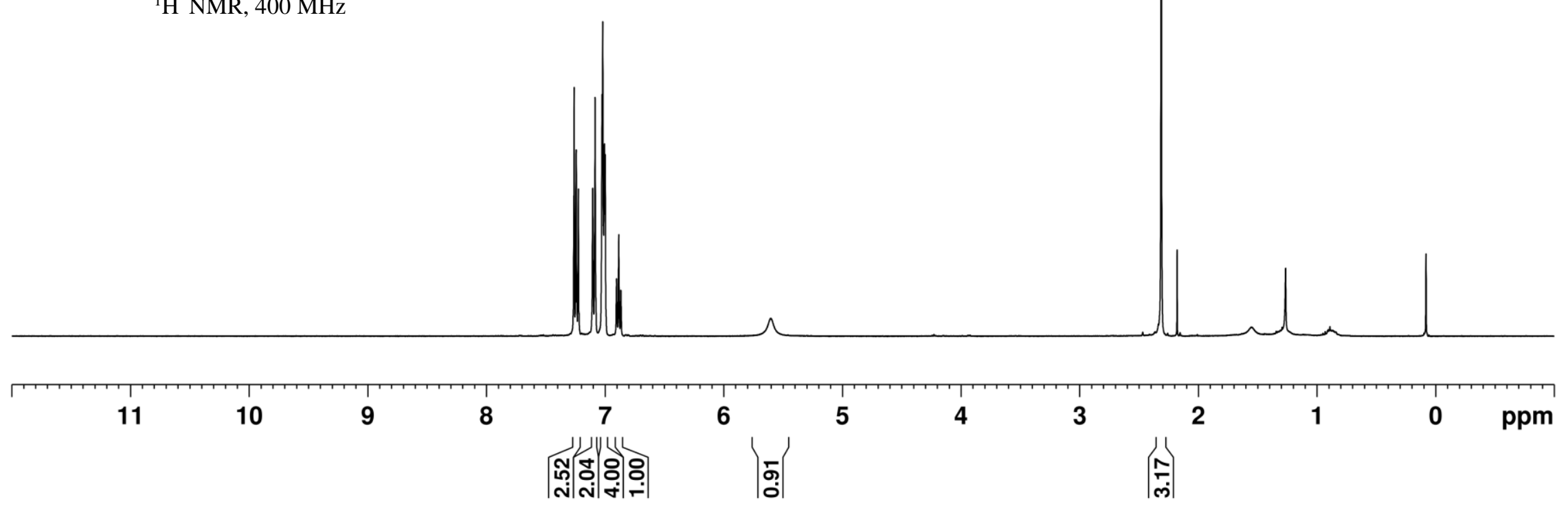




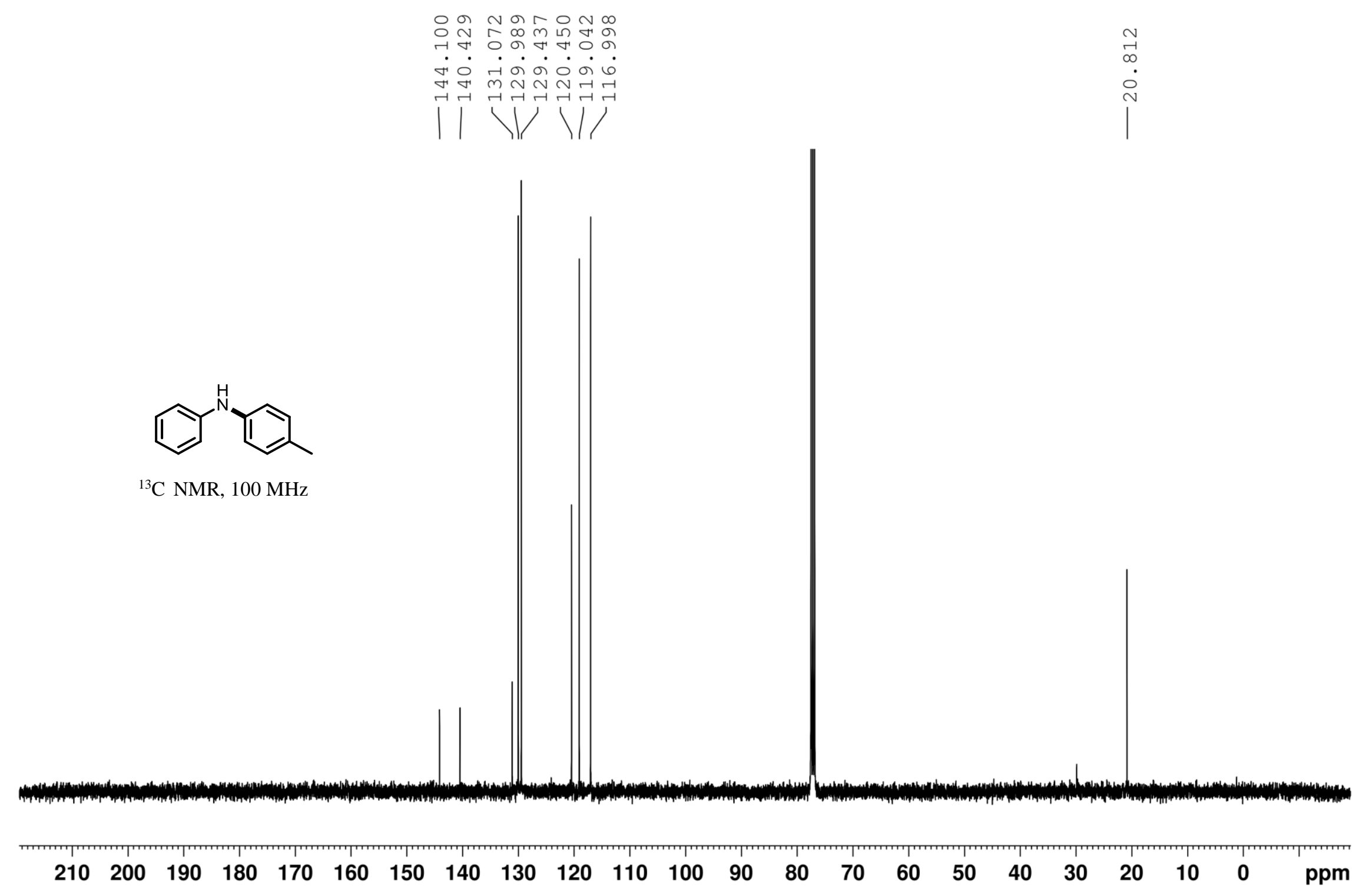




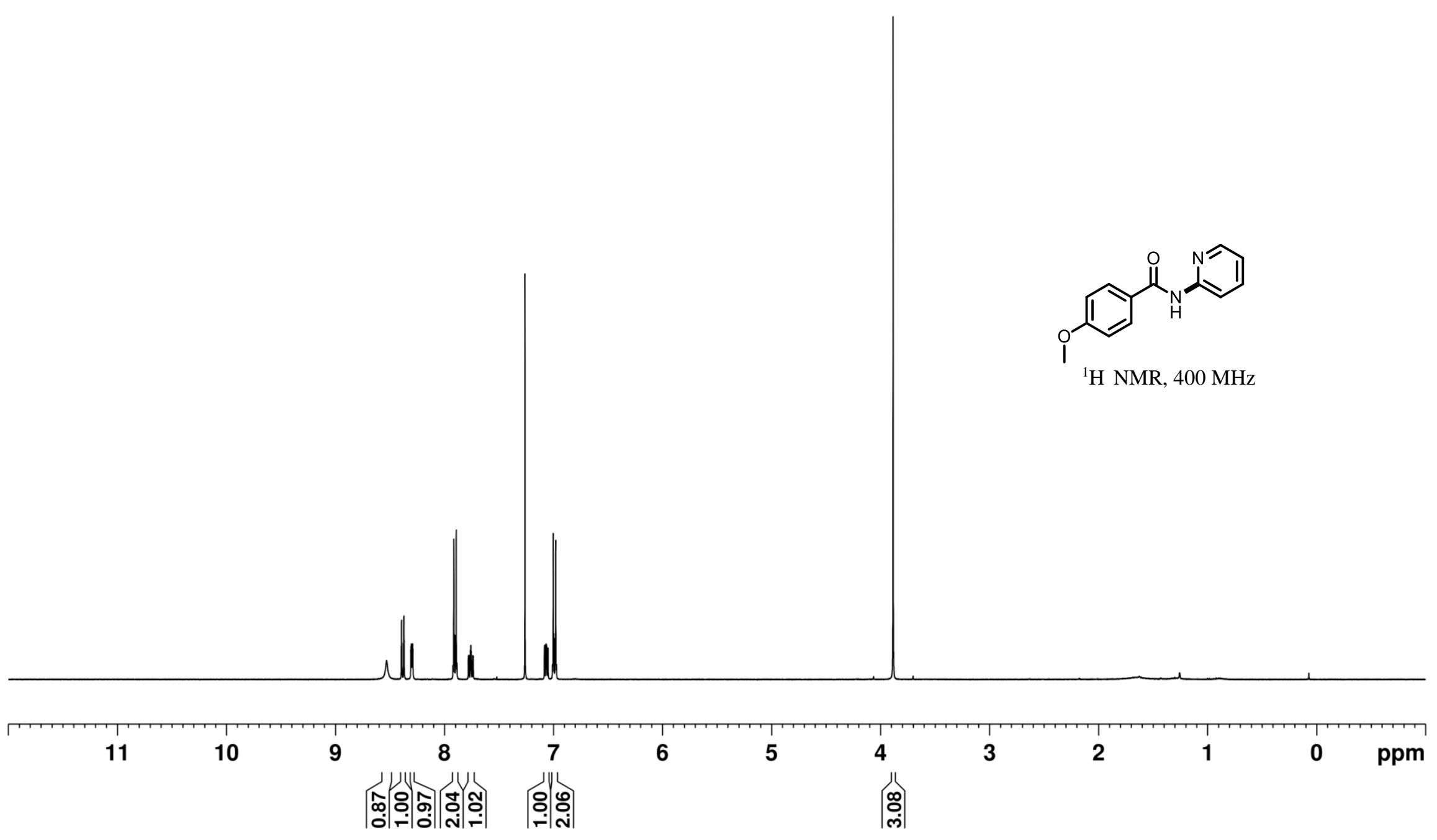




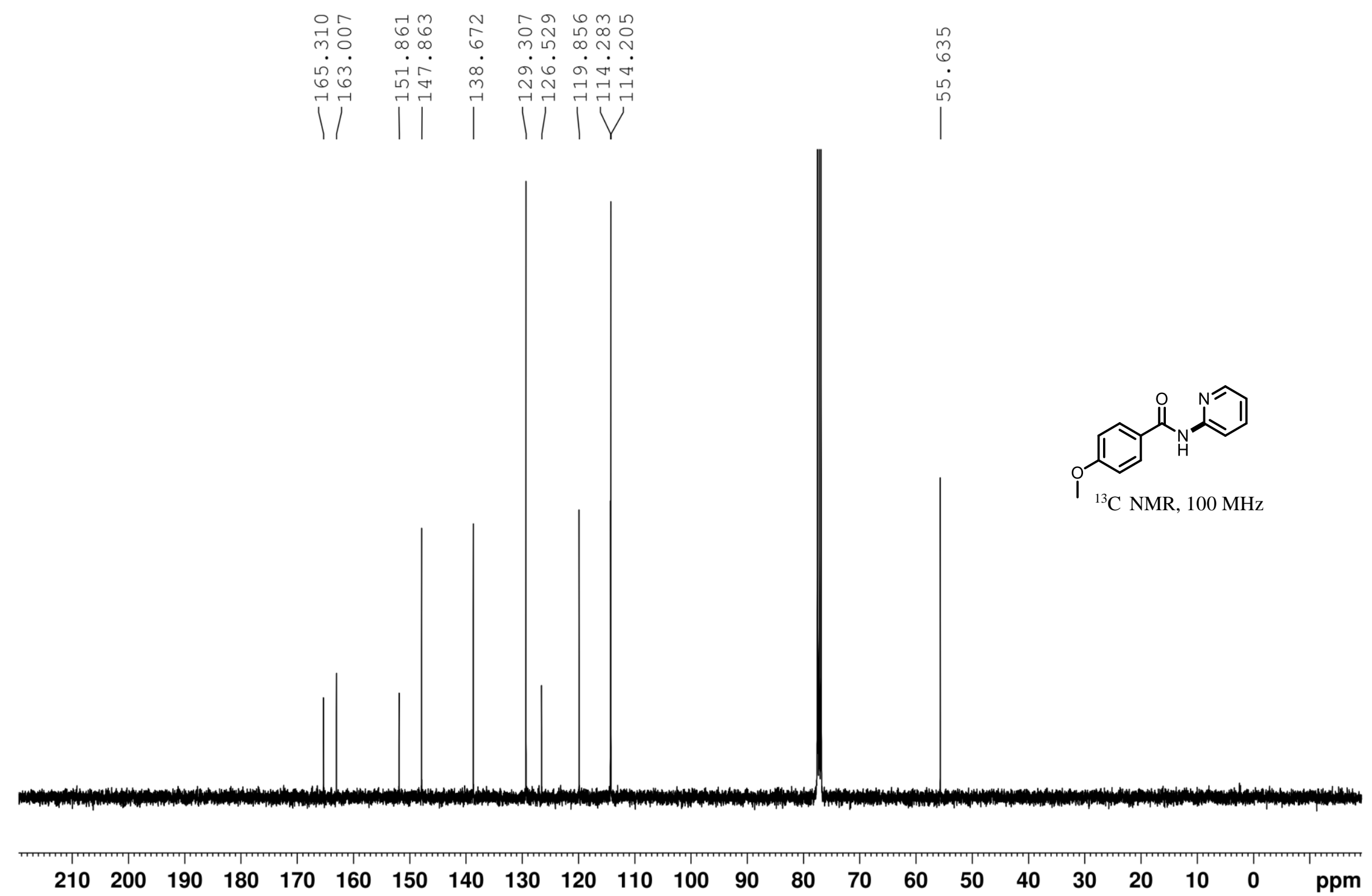


N-(4-nitrophenyl)isonicotinamide (10)
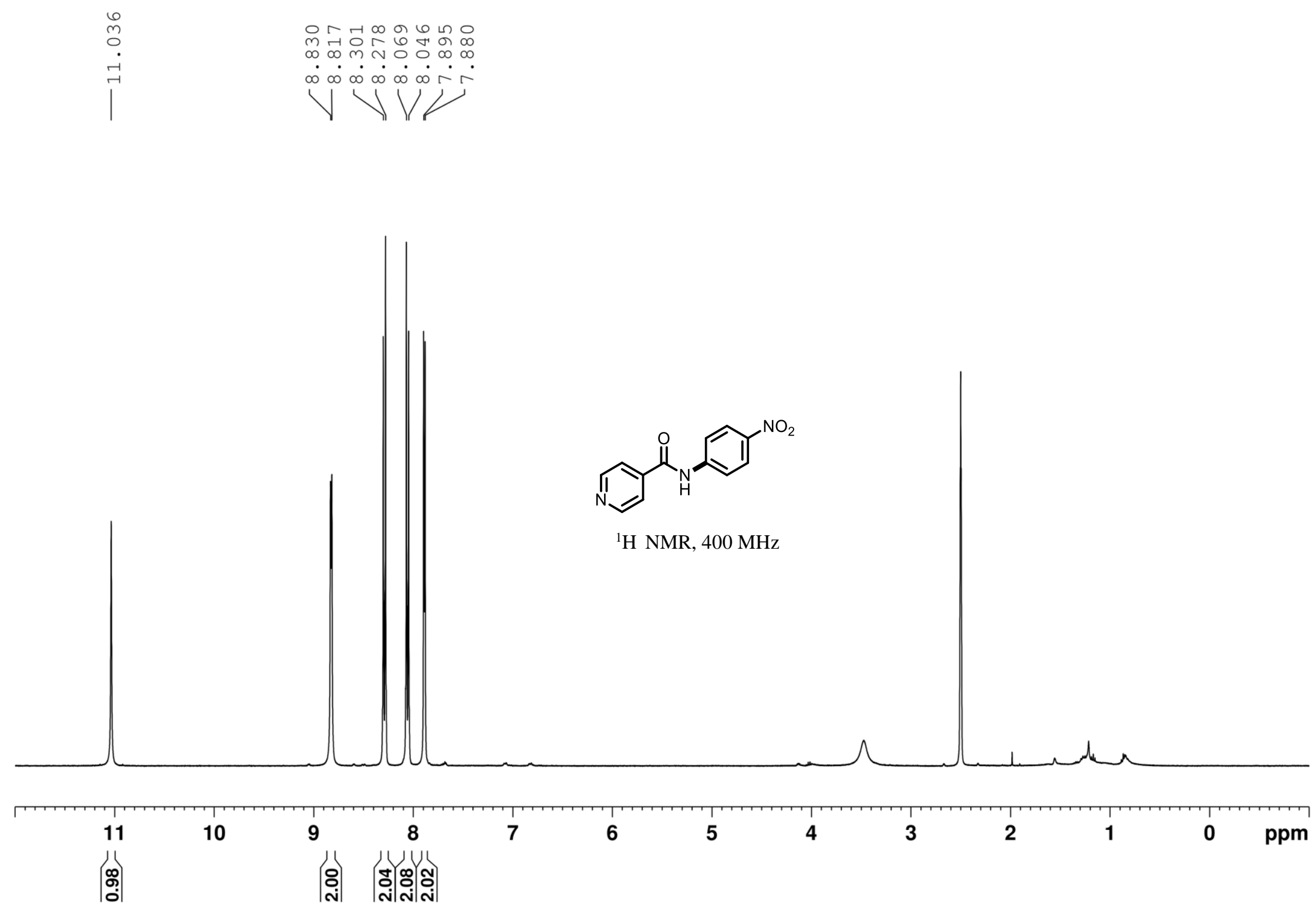


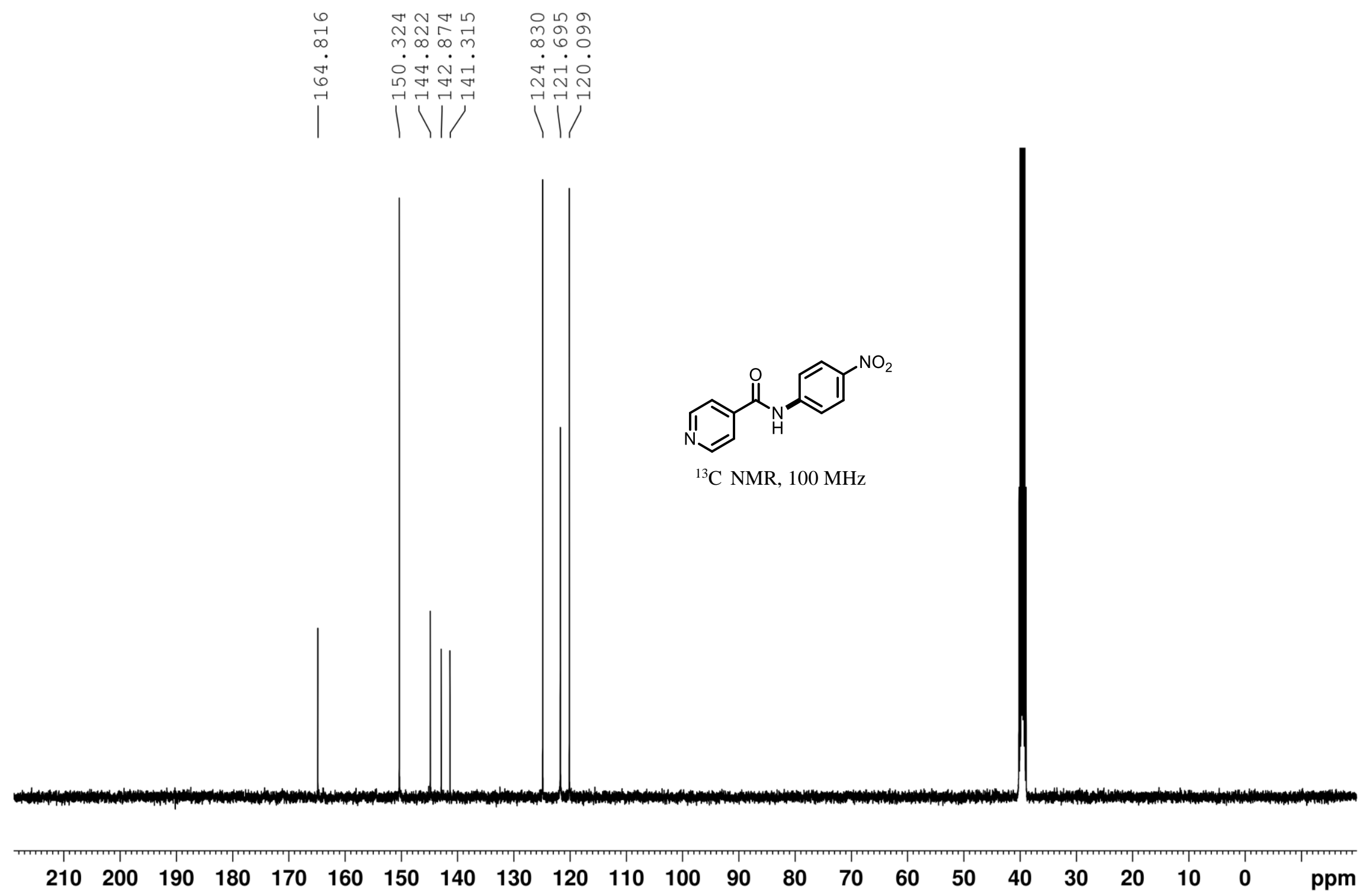




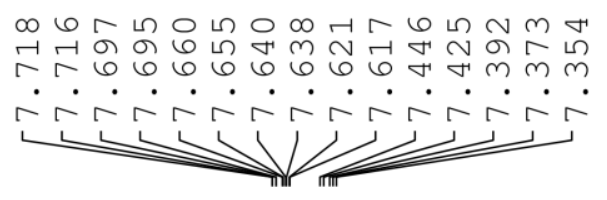

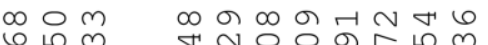

नून

$\dot{m} \dot{x}$

)

G $60 \mathrm{~m} N \stackrel{N}{N}$

$\sim \sim \sim \sim \sim \sim \sim \sim \sim 丿$.

$\rightarrow 1$

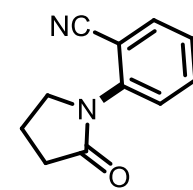

${ }^{1} \mathrm{H}$ NMR, $400 \mathrm{MHz}$

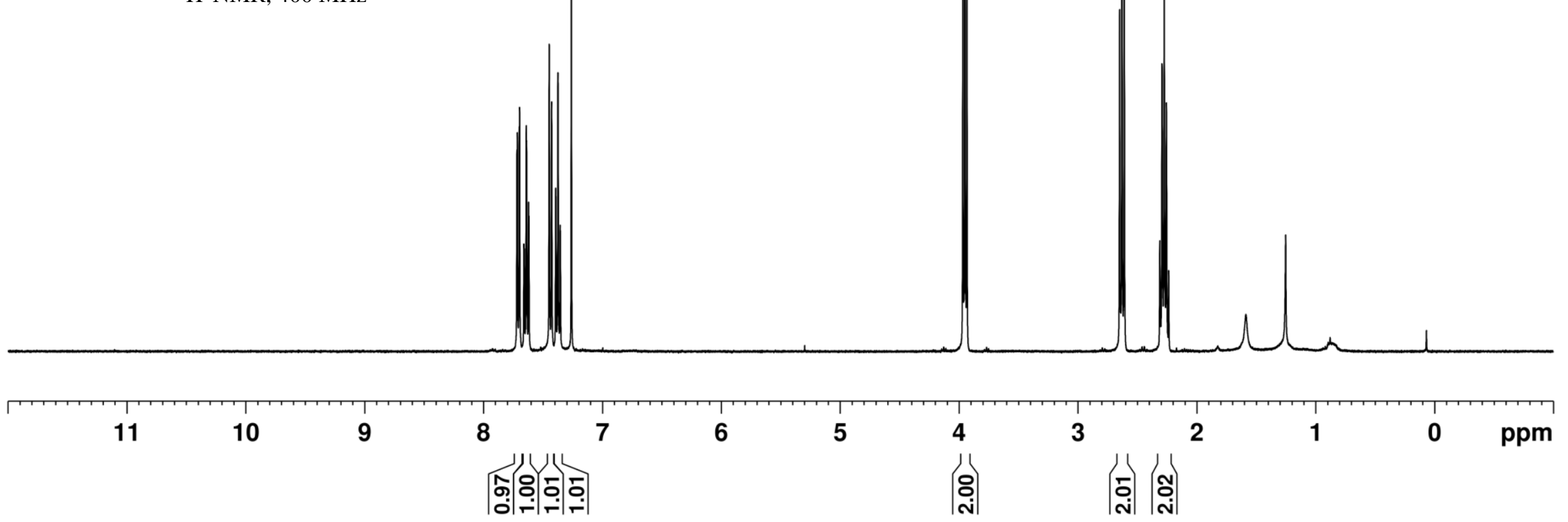




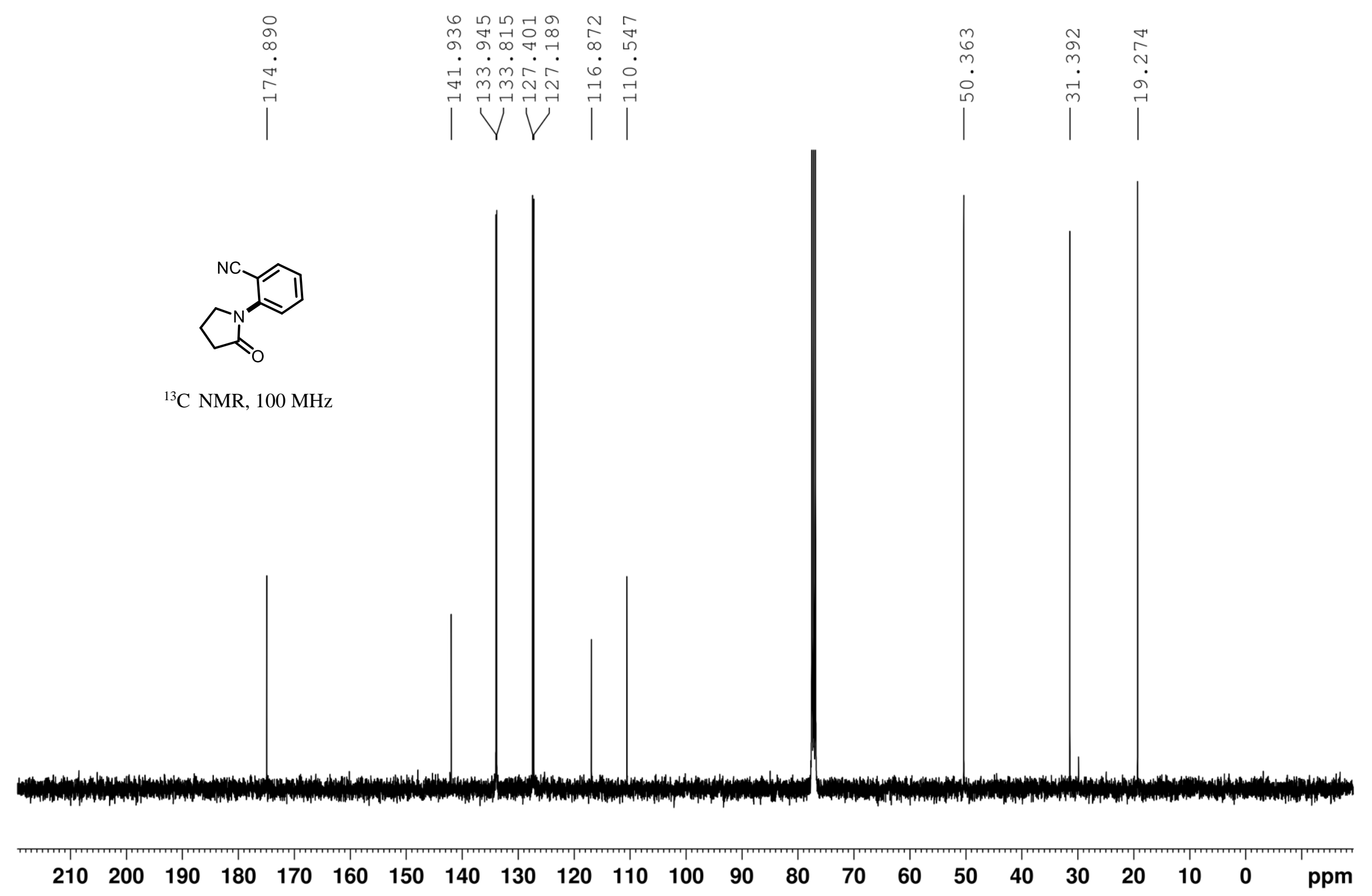


N-(4-acetylphenyl)acetamide (12)
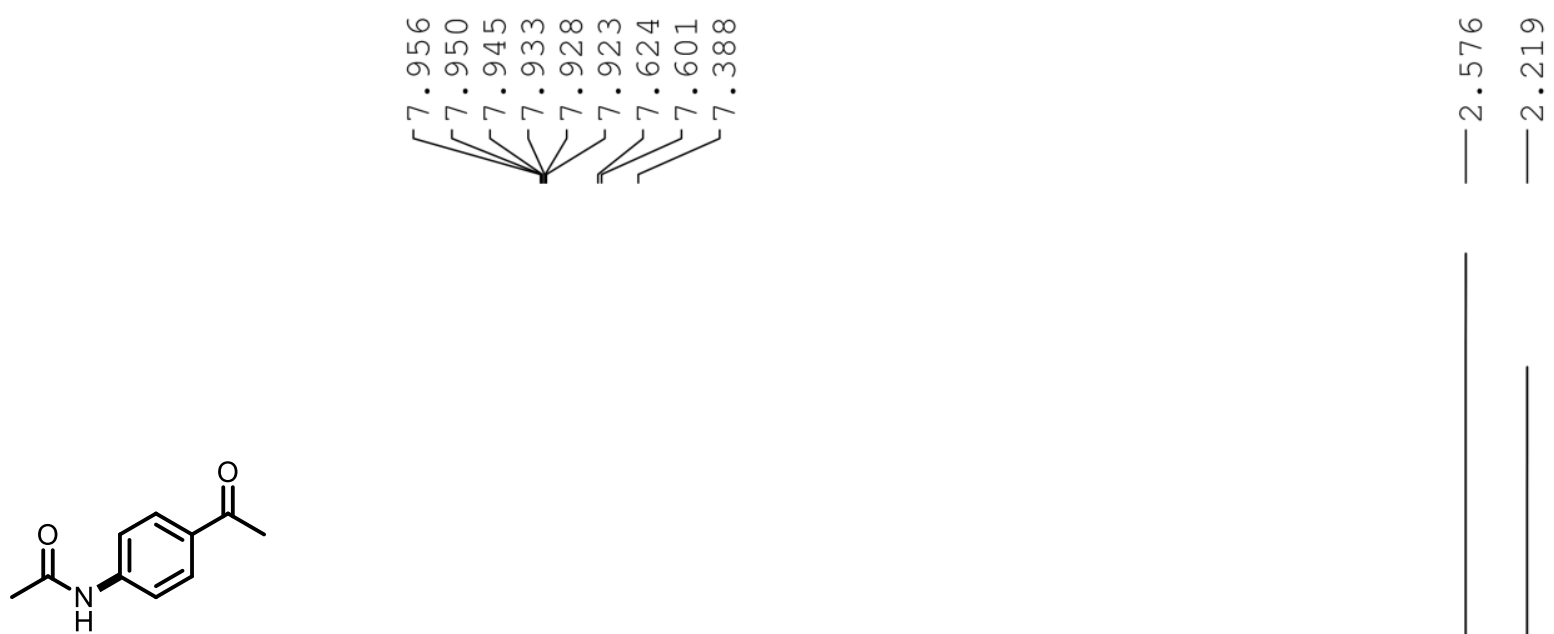

${ }^{1} \mathrm{H}$ NMR, $400 \mathrm{MHz}$

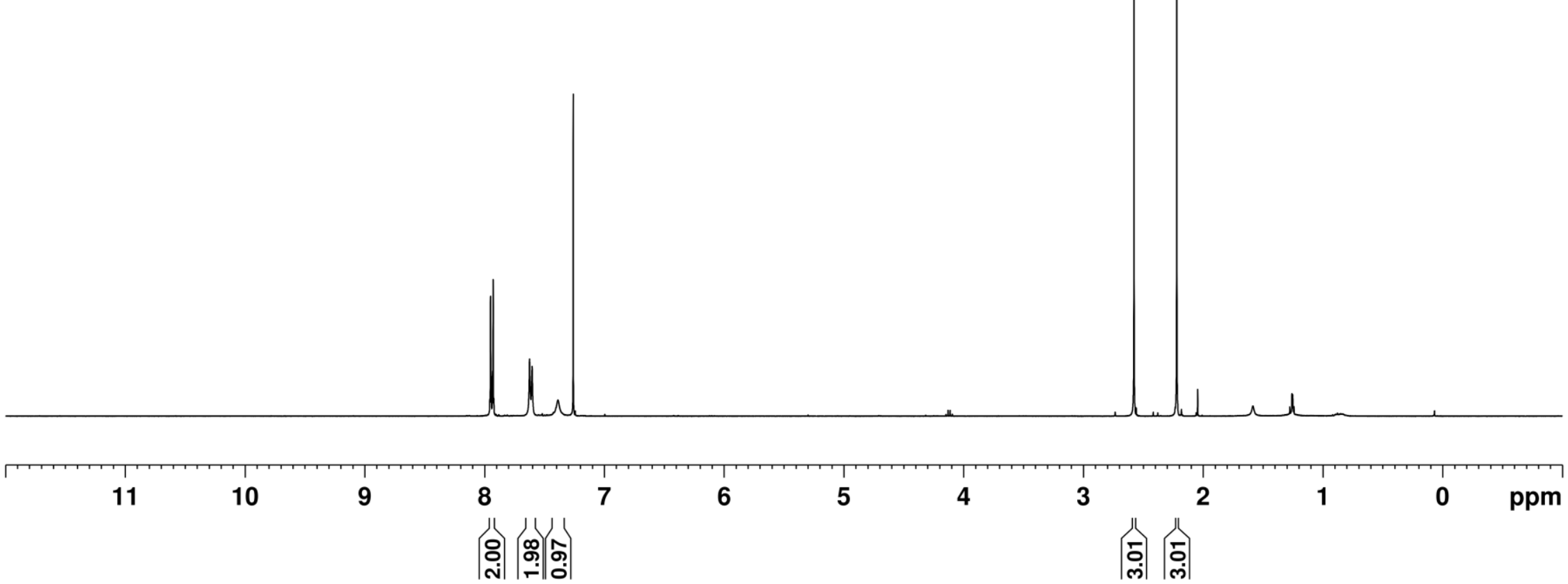




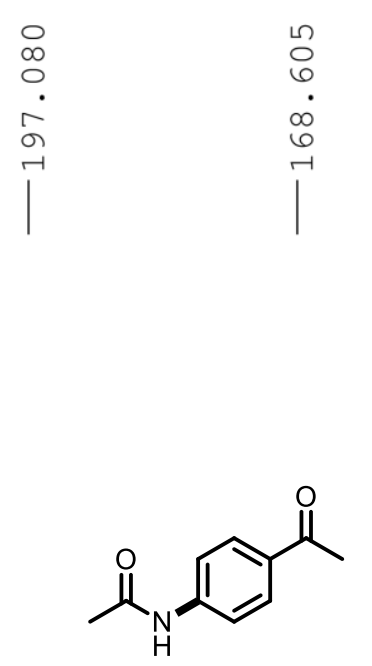

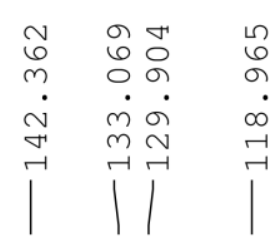

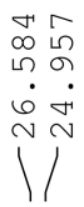

${ }^{13} \mathrm{C}$ NMR, $100 \mathrm{MHz}$
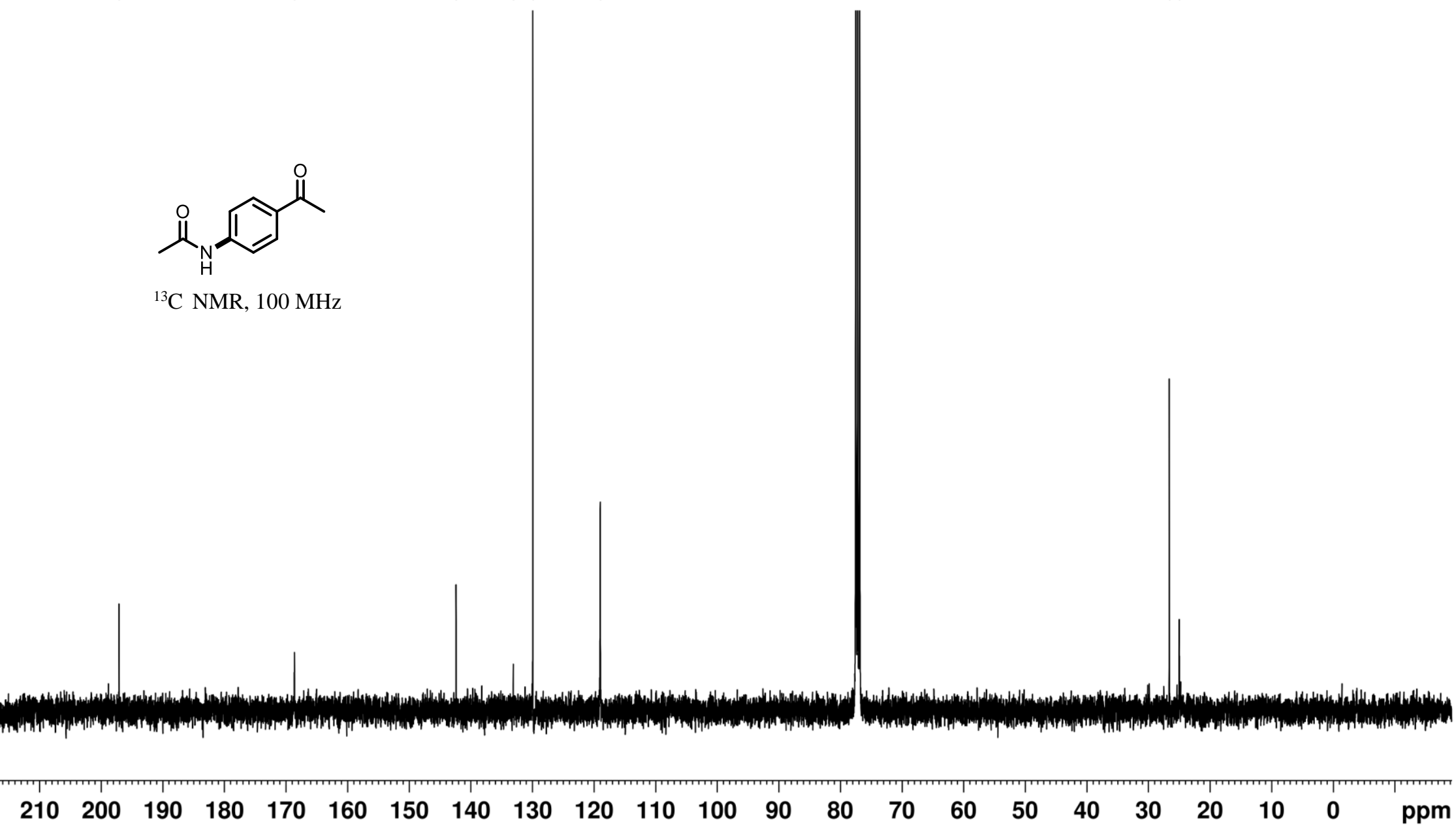
(R)-1-acetyl-N-(4-cyanophenyl)pyrrolidine-2-carboxamide (13)

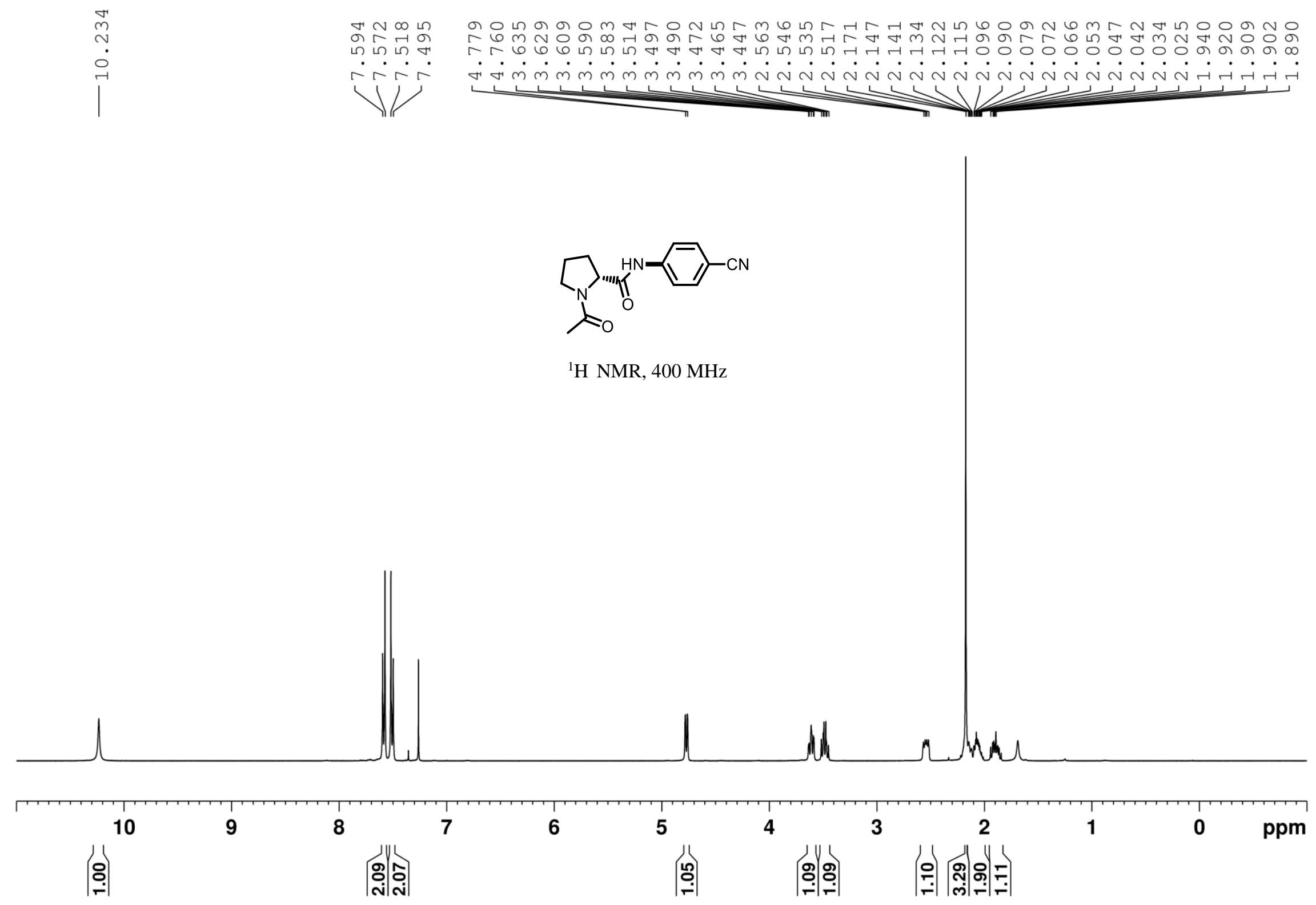




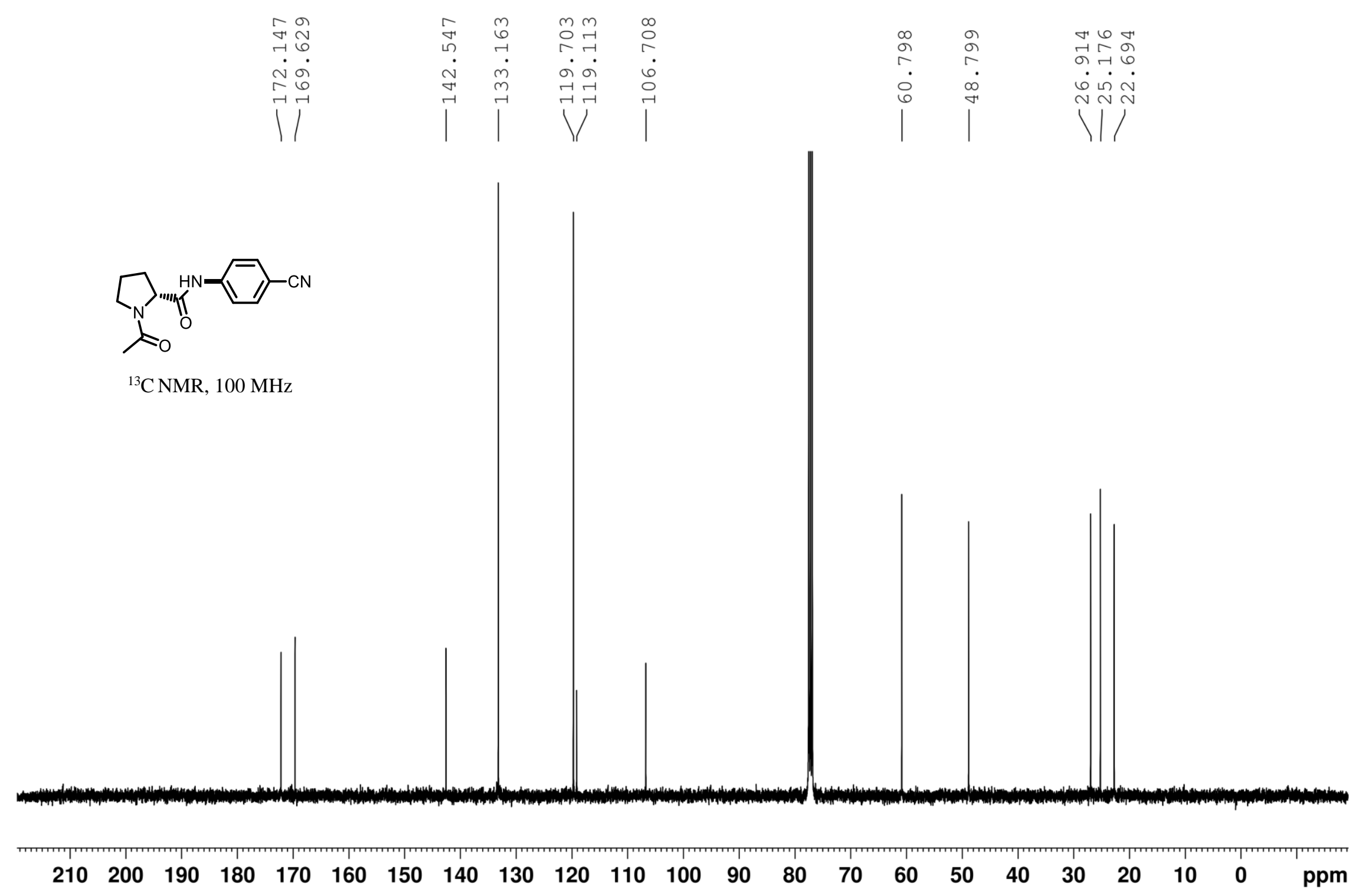




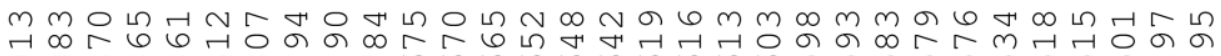

6666666 แ ถ

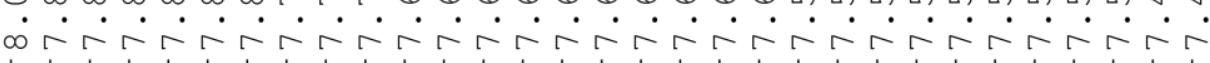

(n)

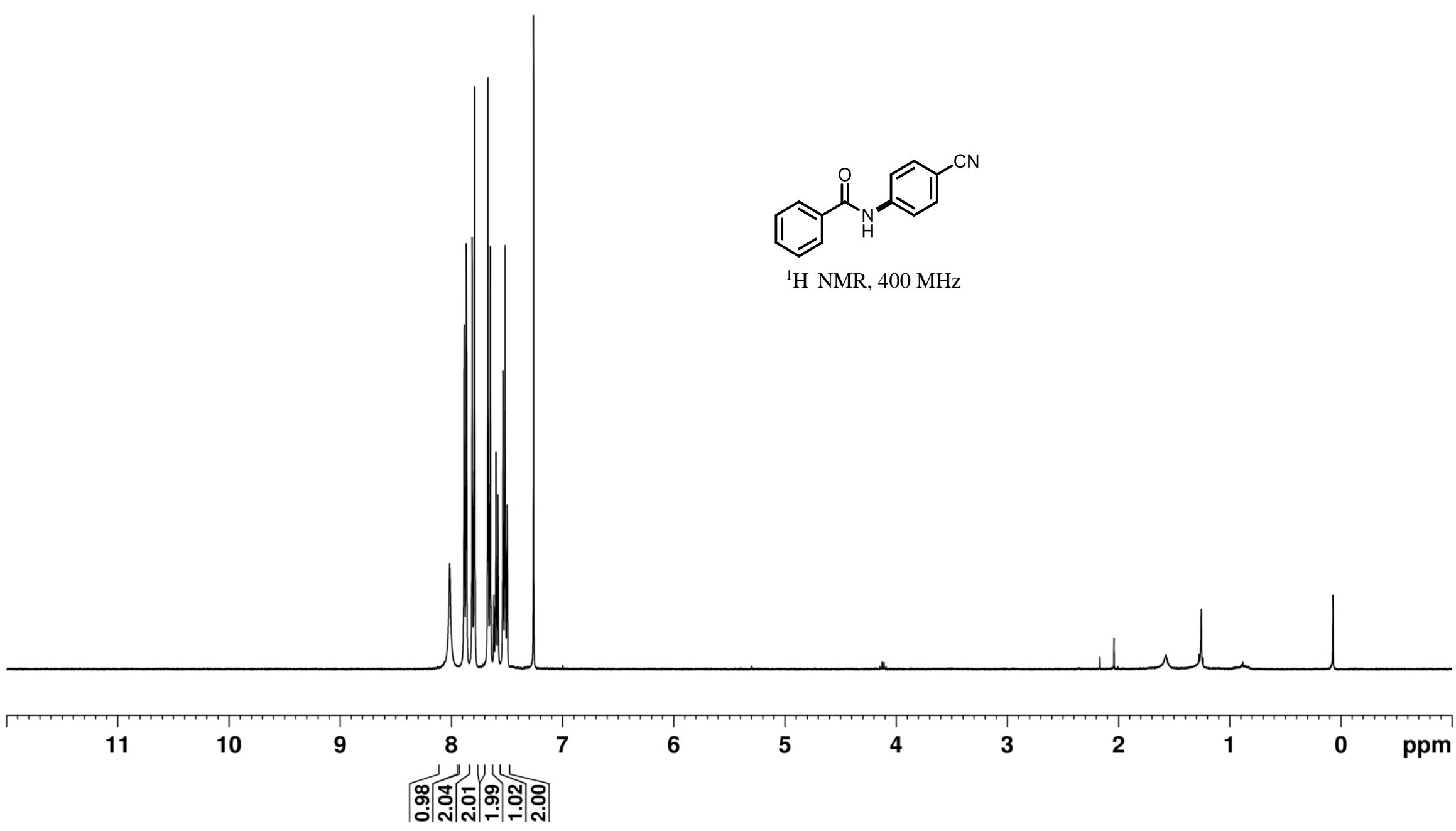




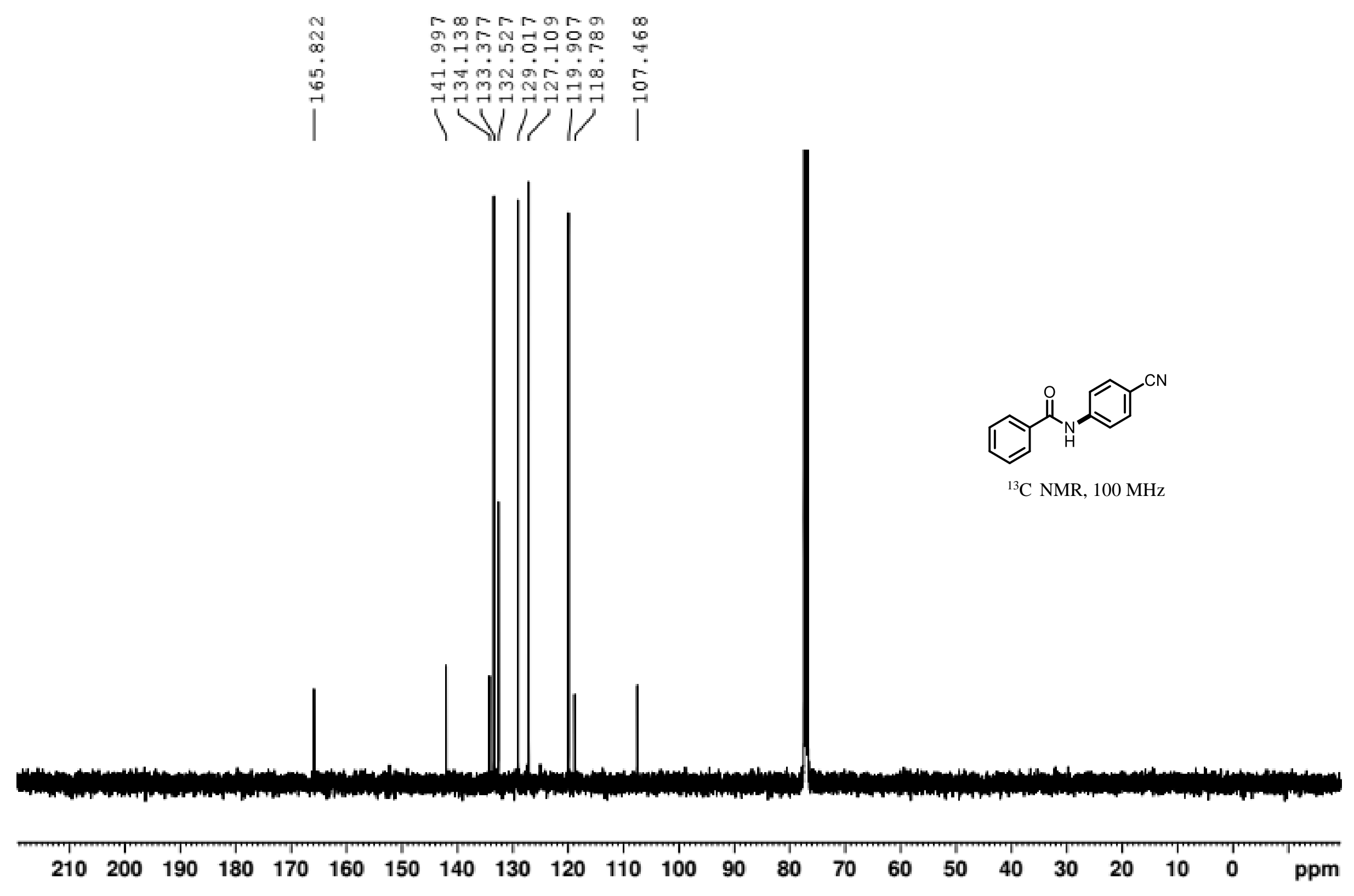




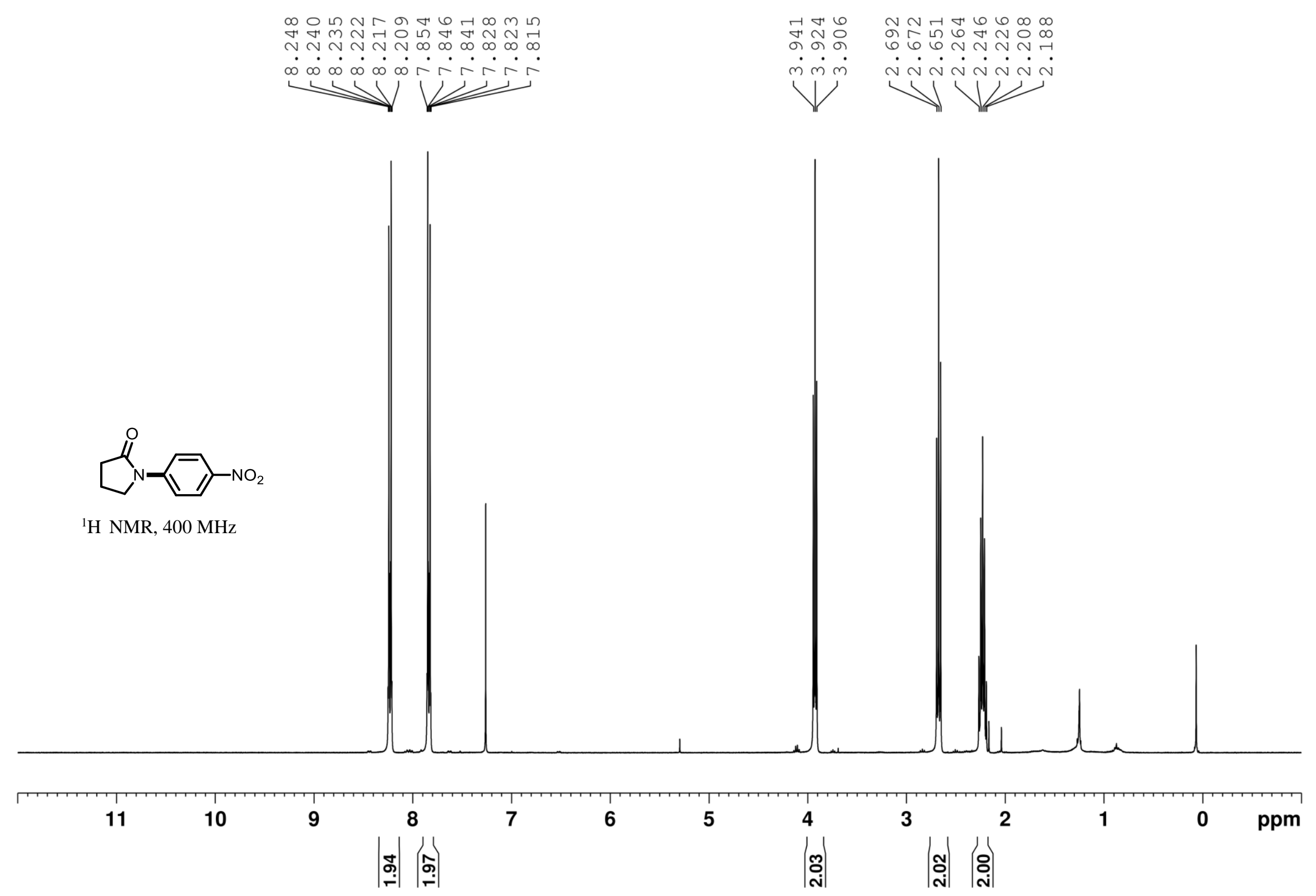




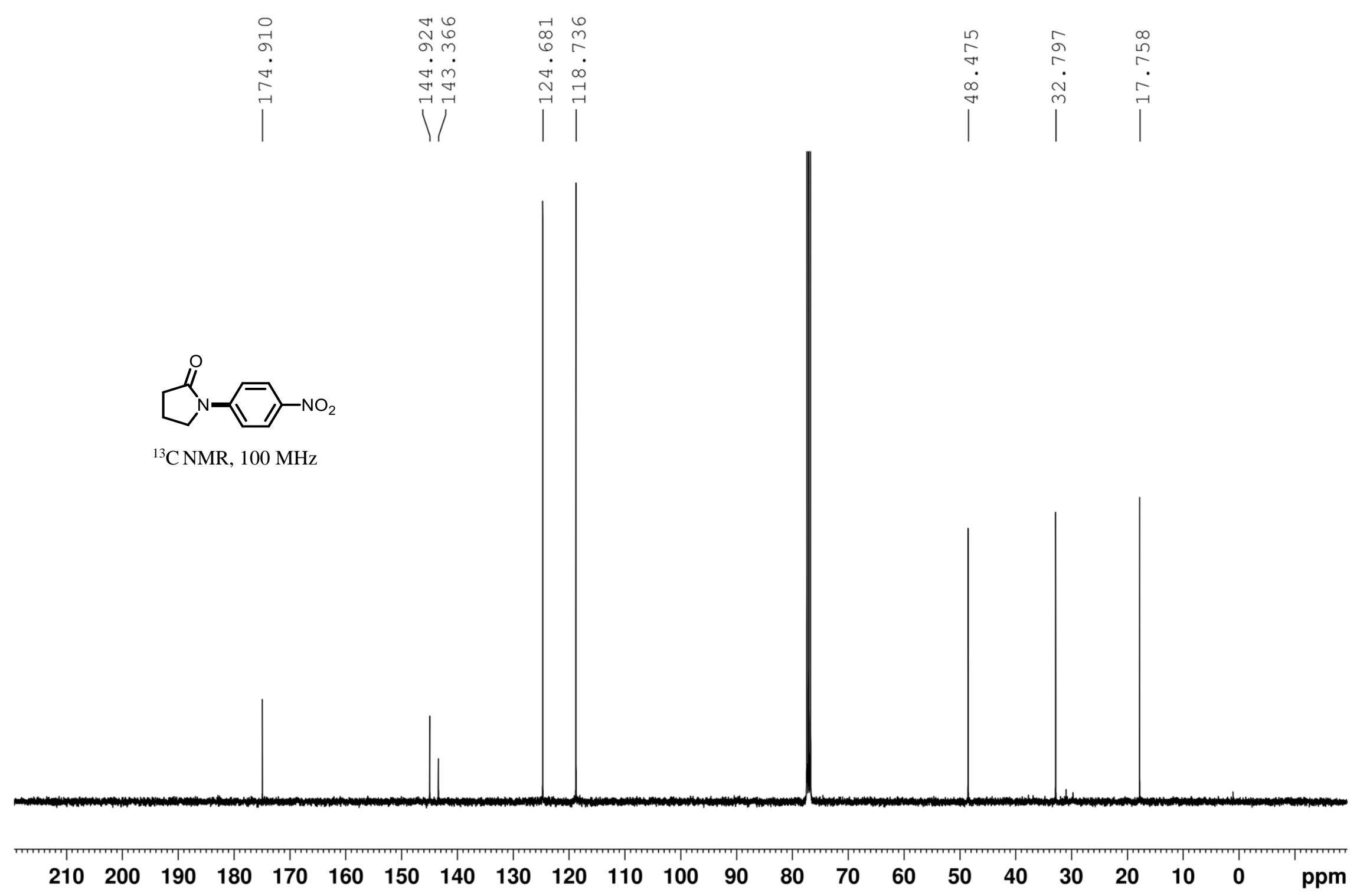




\section{4-(phenylamino)benzonitrile (16)}

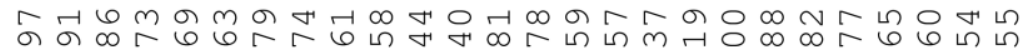
म

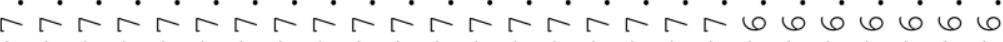

(n)

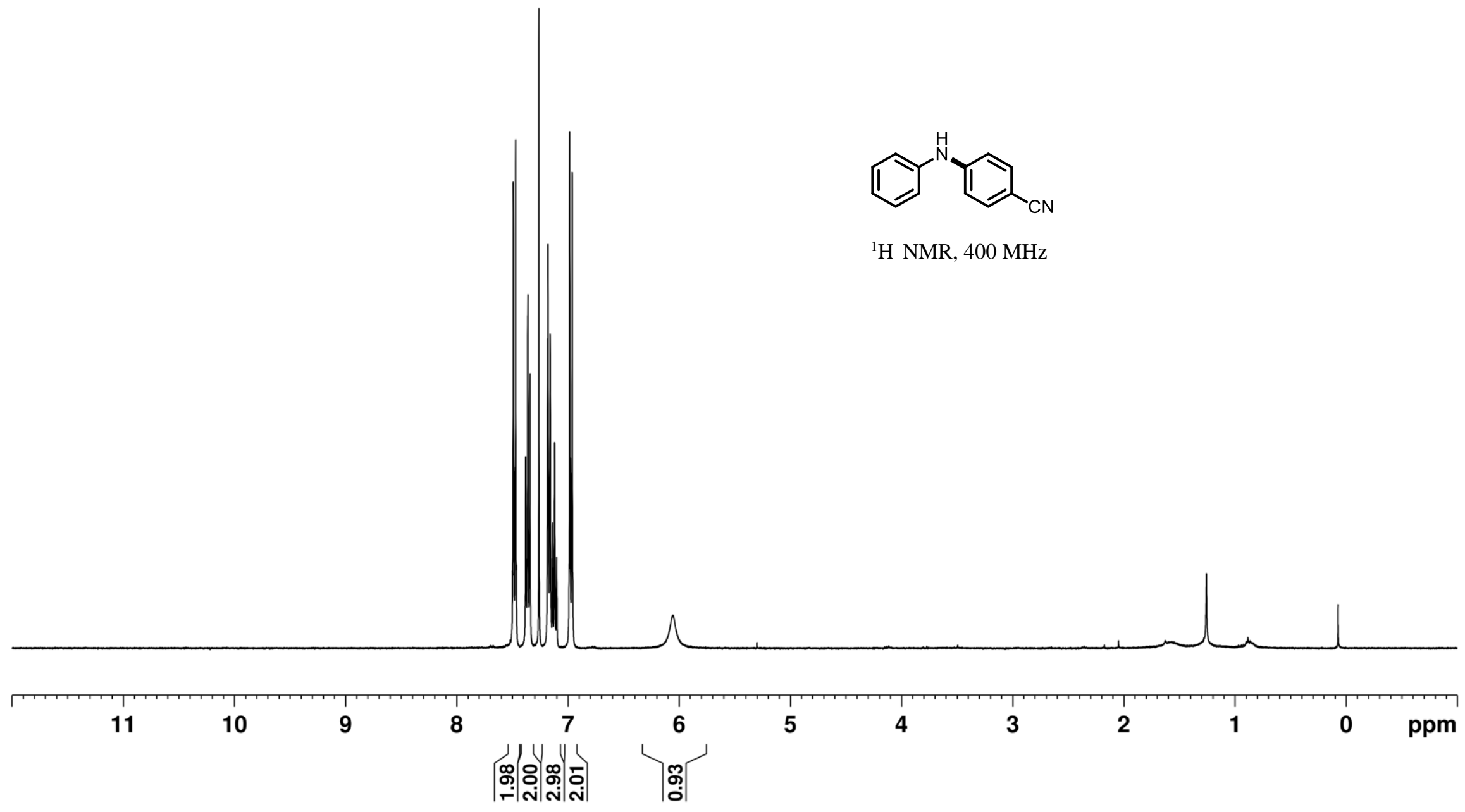




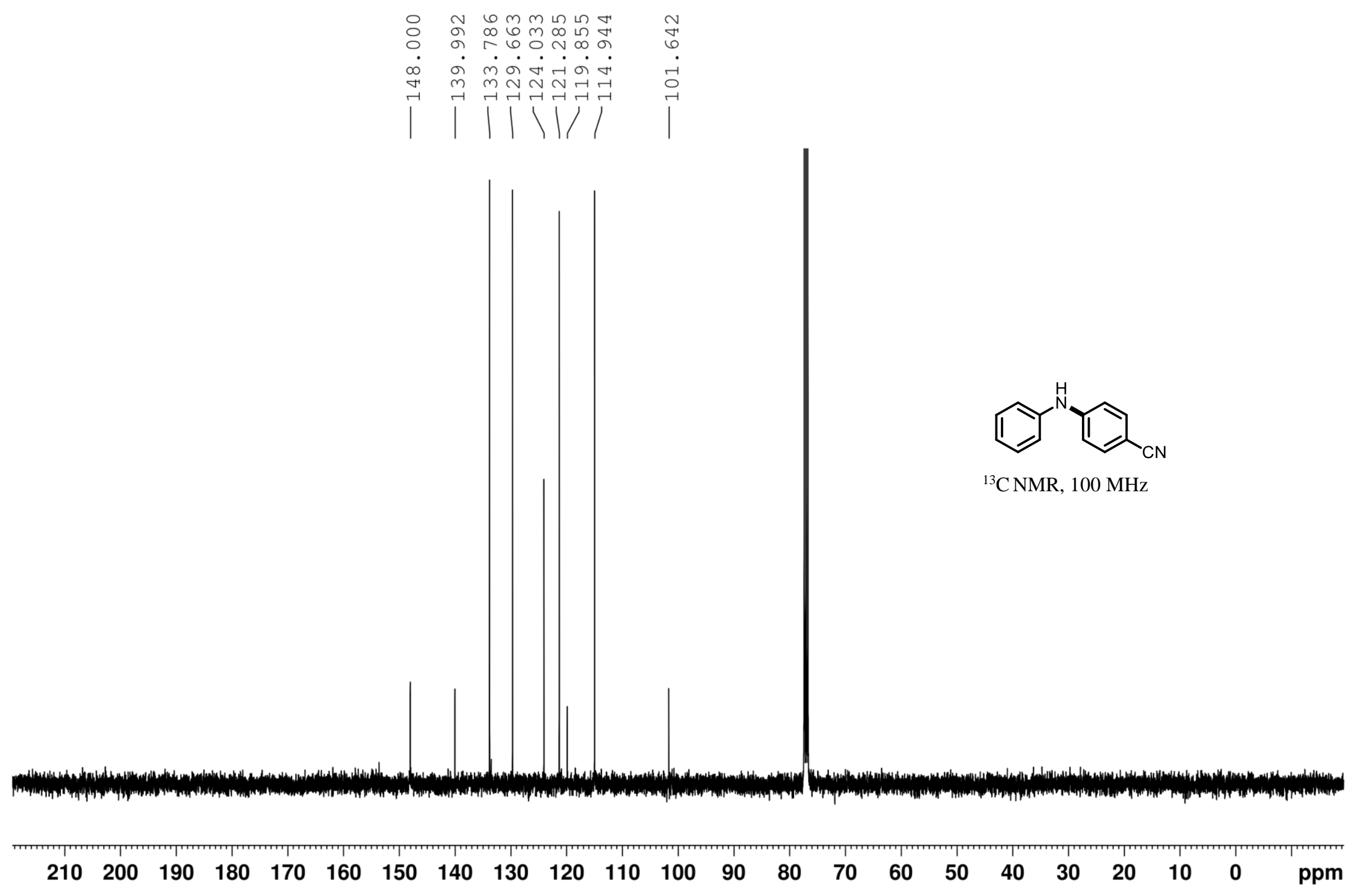




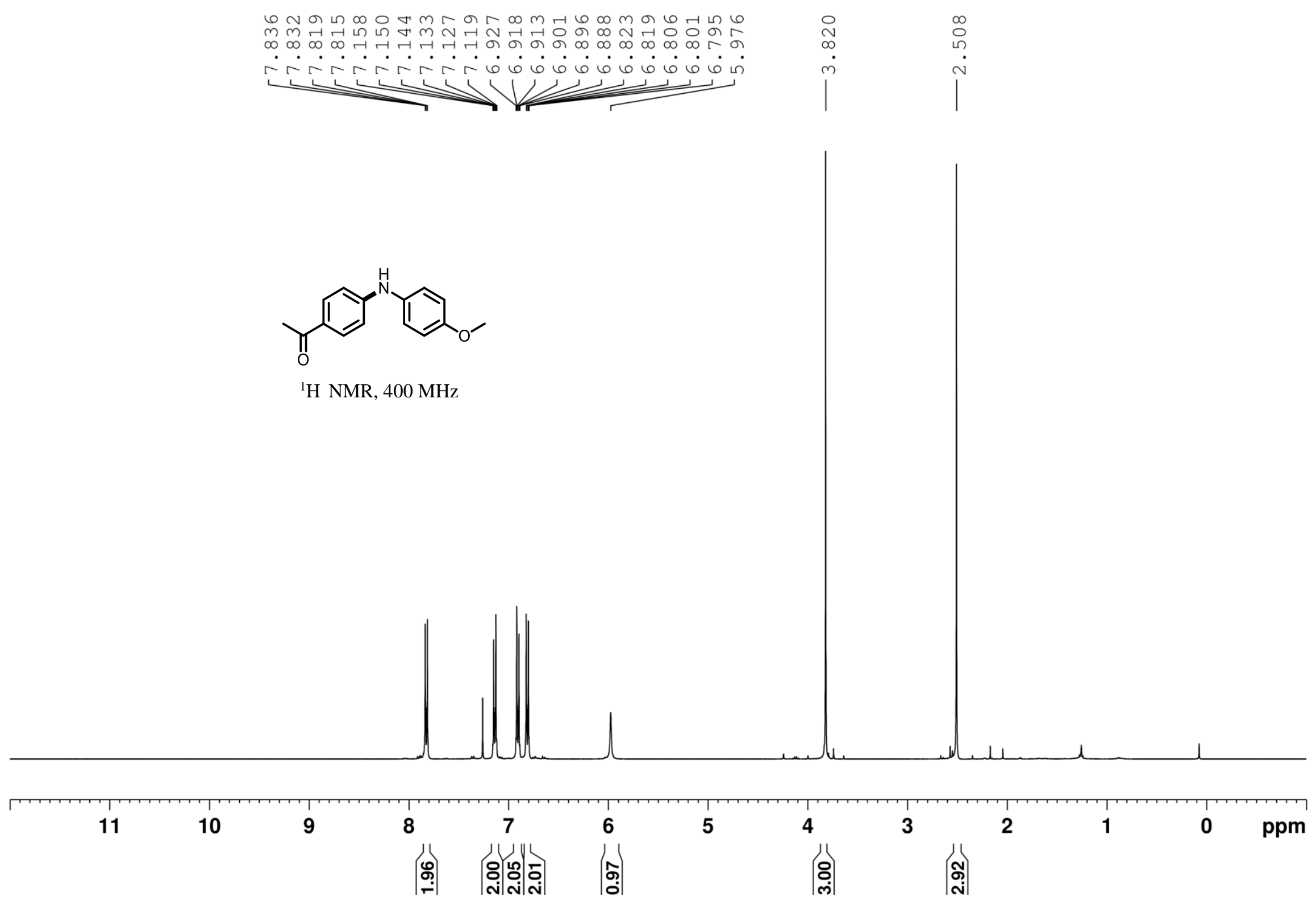



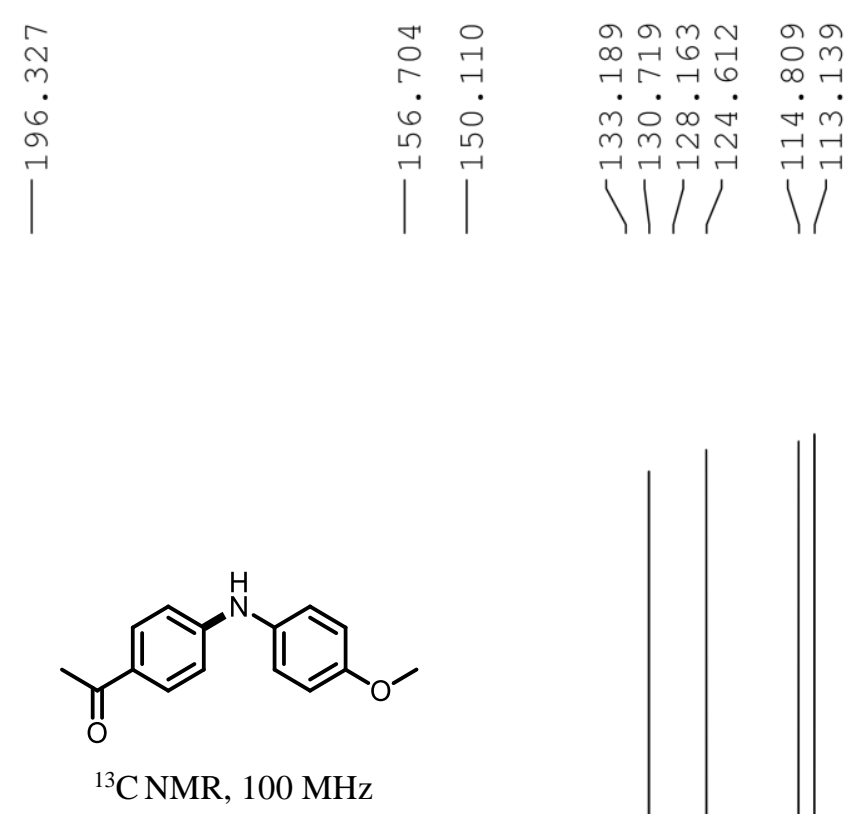

${ }^{13} \mathrm{C}$ NMR, $100 \mathrm{MHz}$
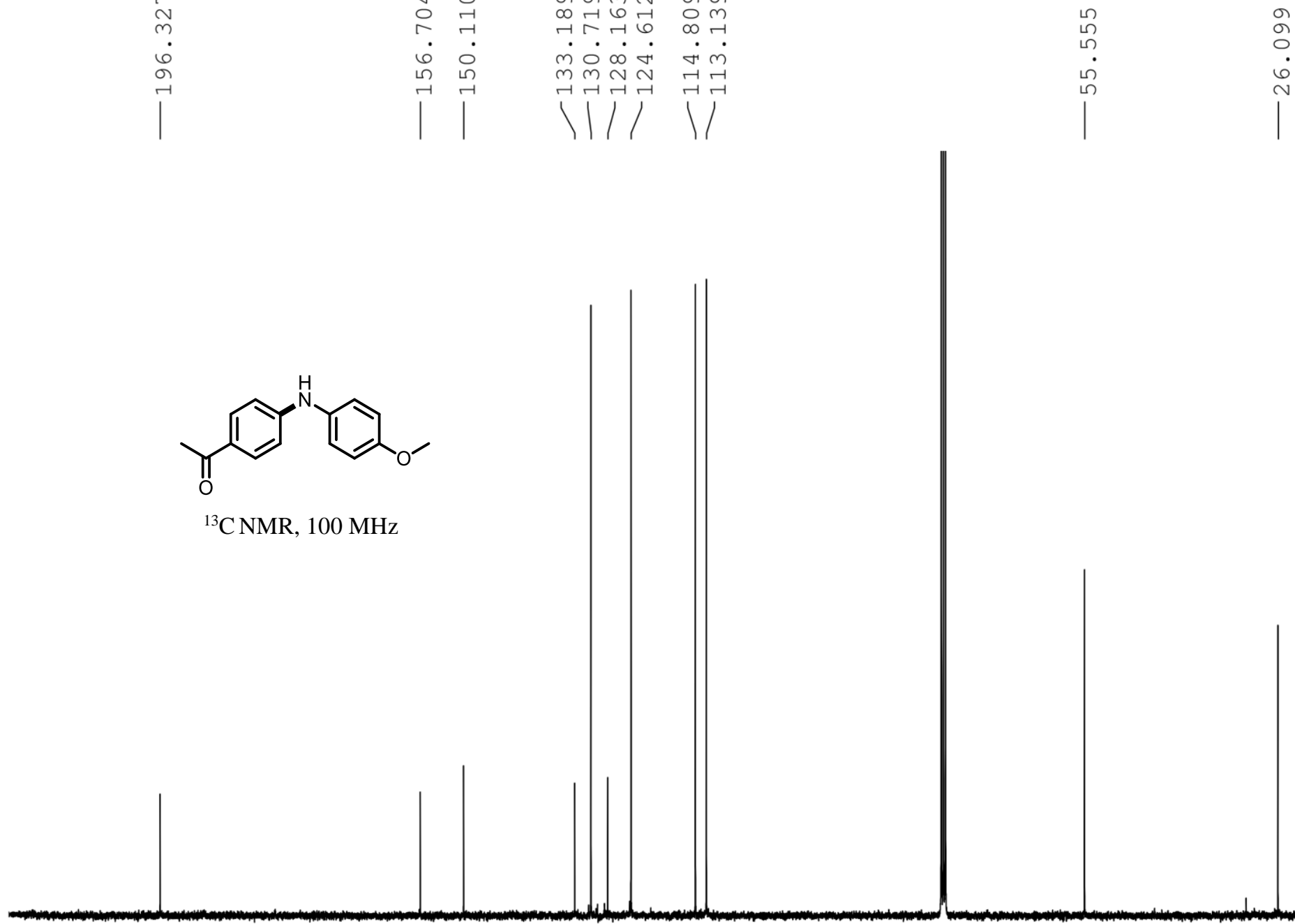

$\begin{array}{llllllllllll}210 & 200 & 190 & 180 & 170 & 160 & 150 & 140 & 130 & 120 & 110 & 100\end{array}$

90

80

70

60

5040

30

2 


\section{1-methoxy-4-styryl-benzene (18)}

幽

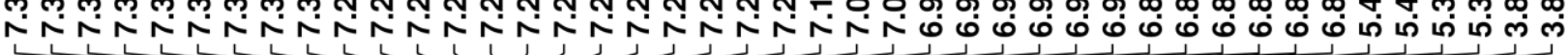

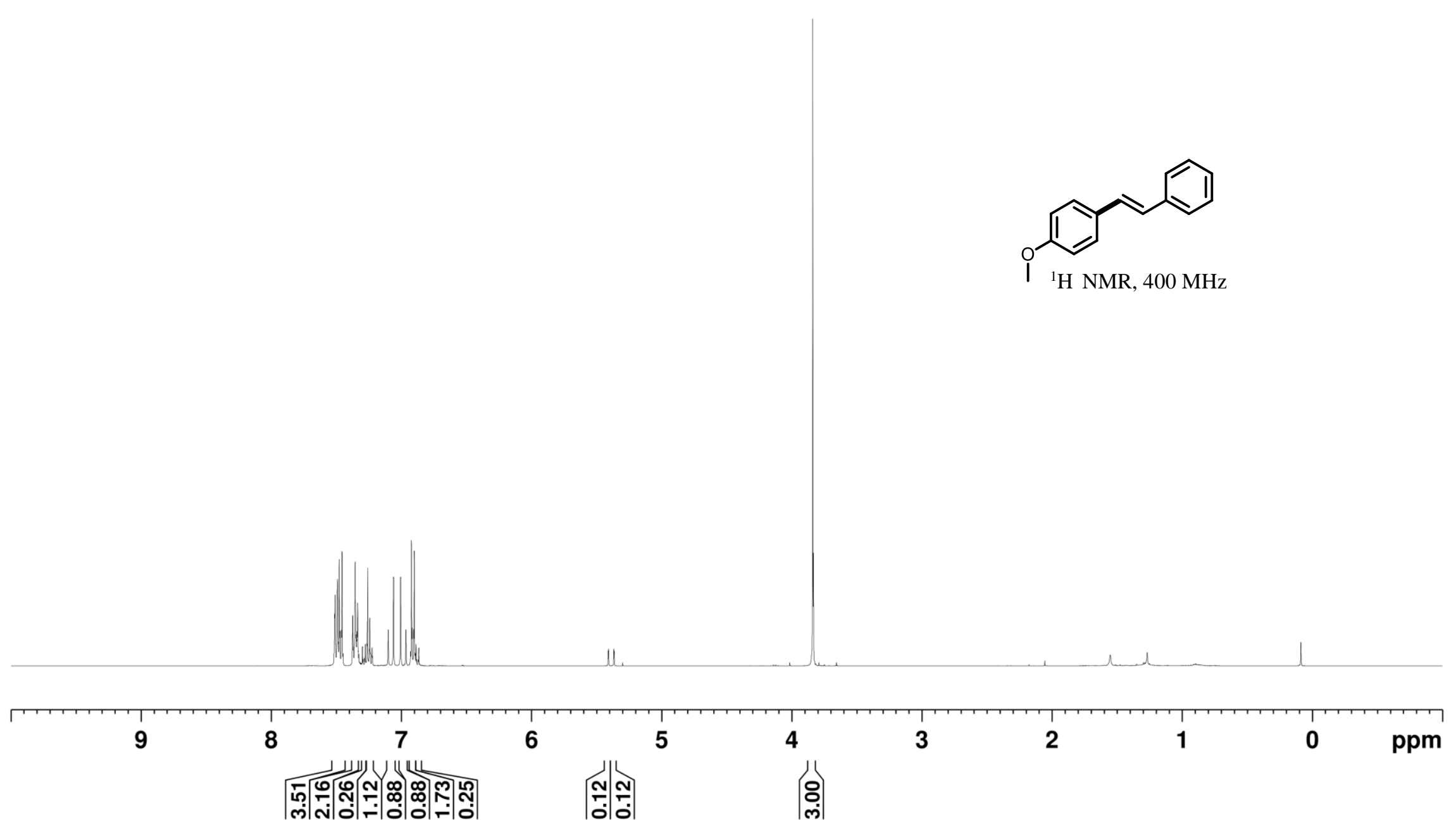




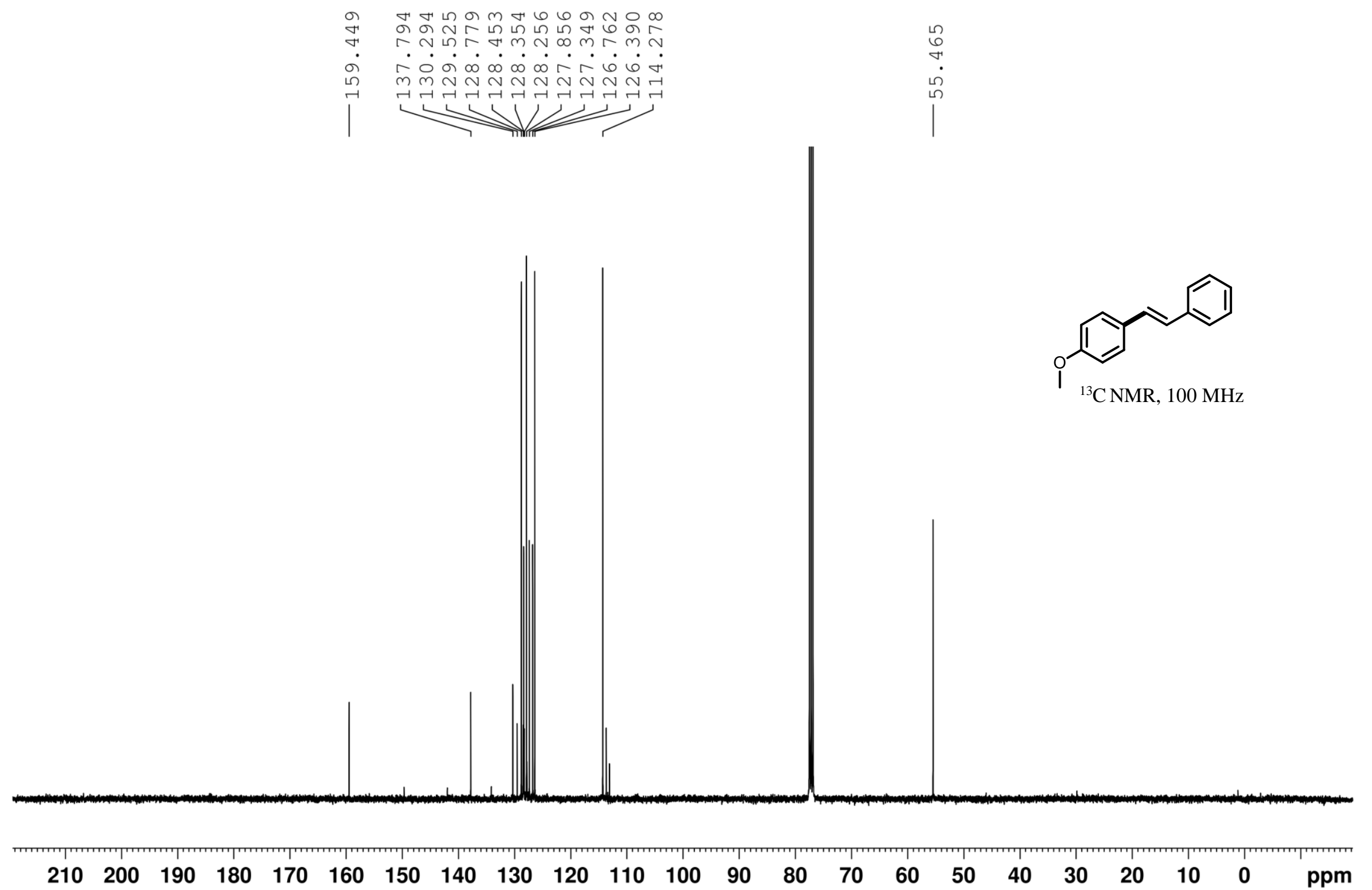




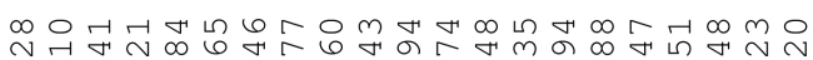

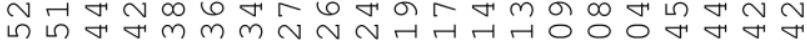
-

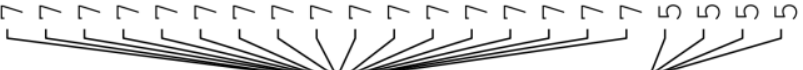

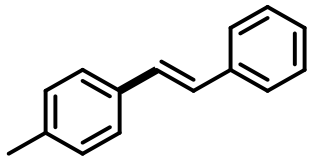

${ }^{1} \mathrm{H}$ NMR, $400 \mathrm{MHz}$

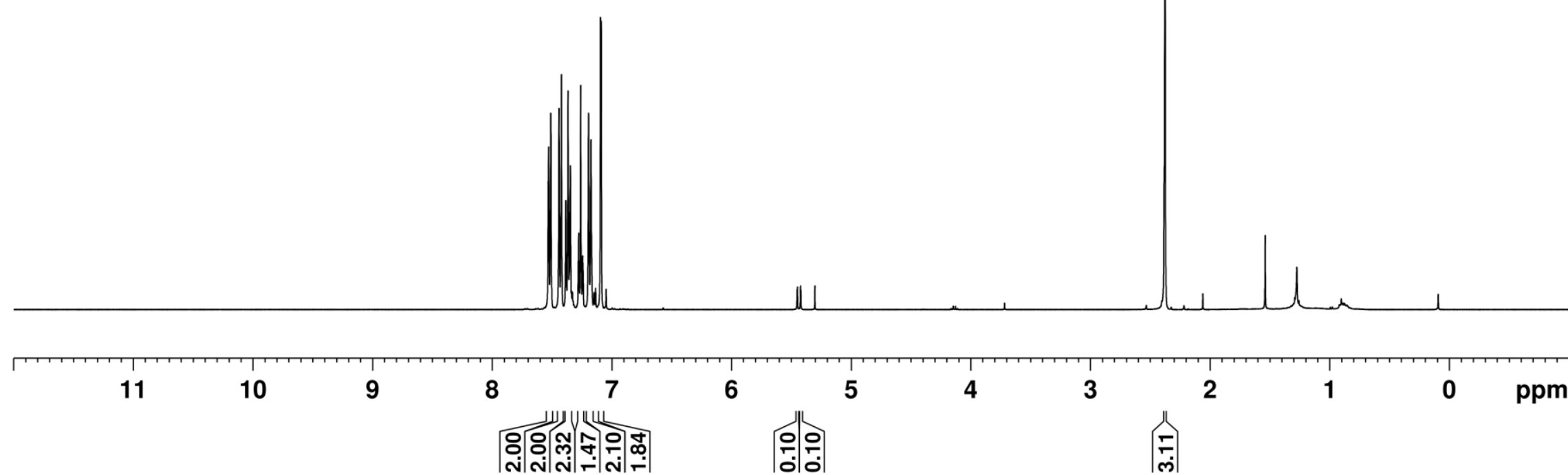




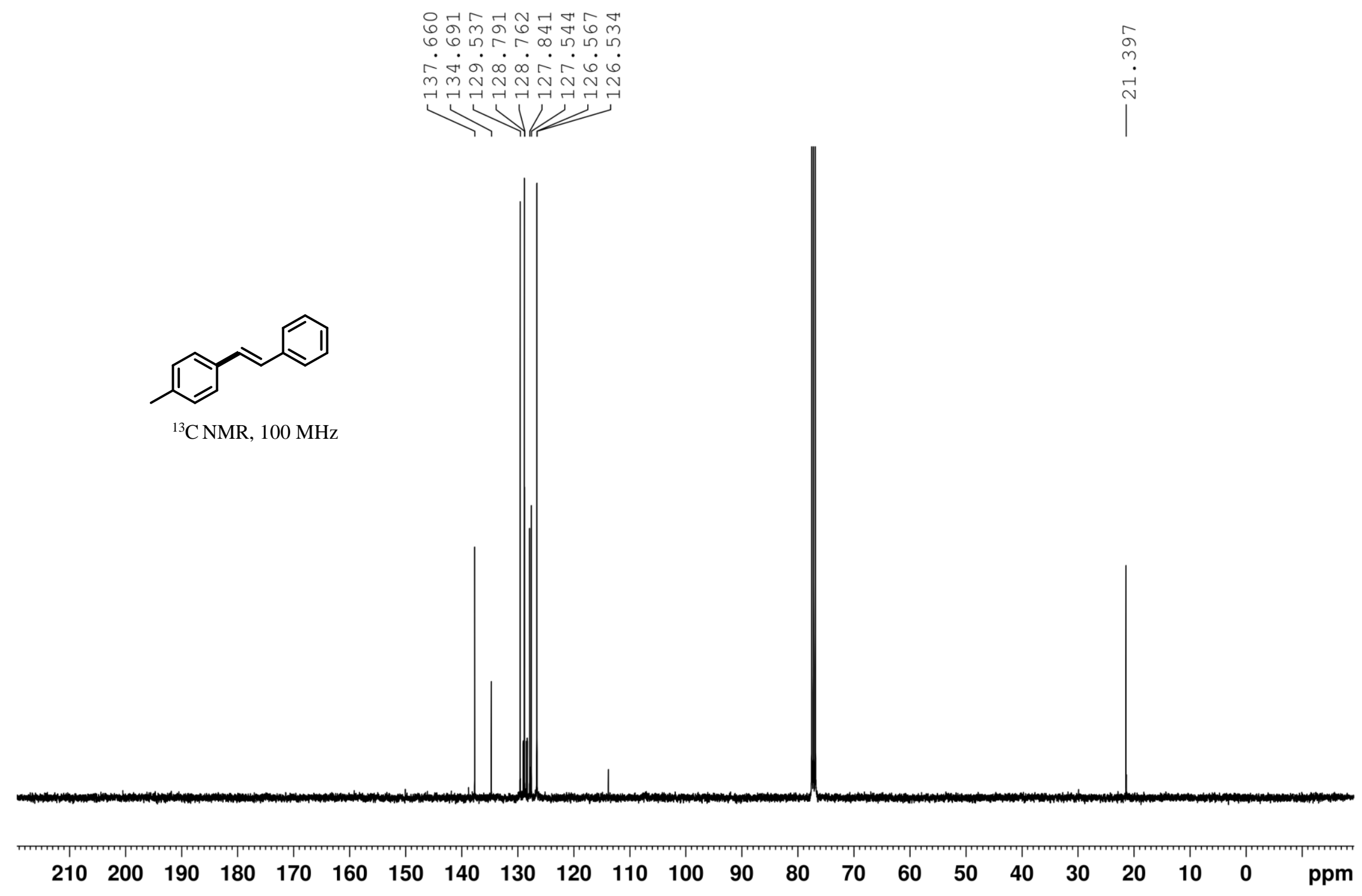


1-cyano-4-styryl-benzene (20)
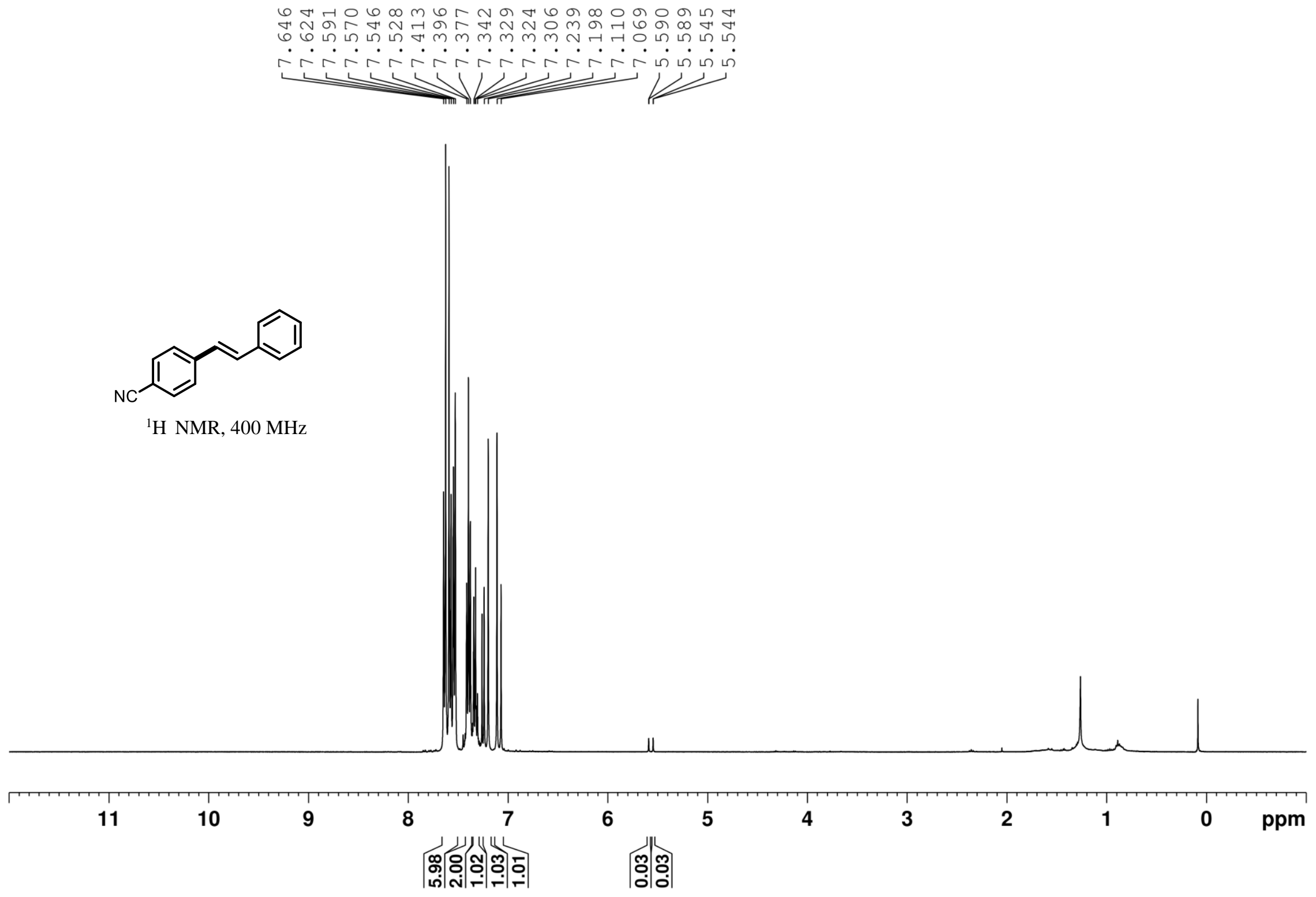


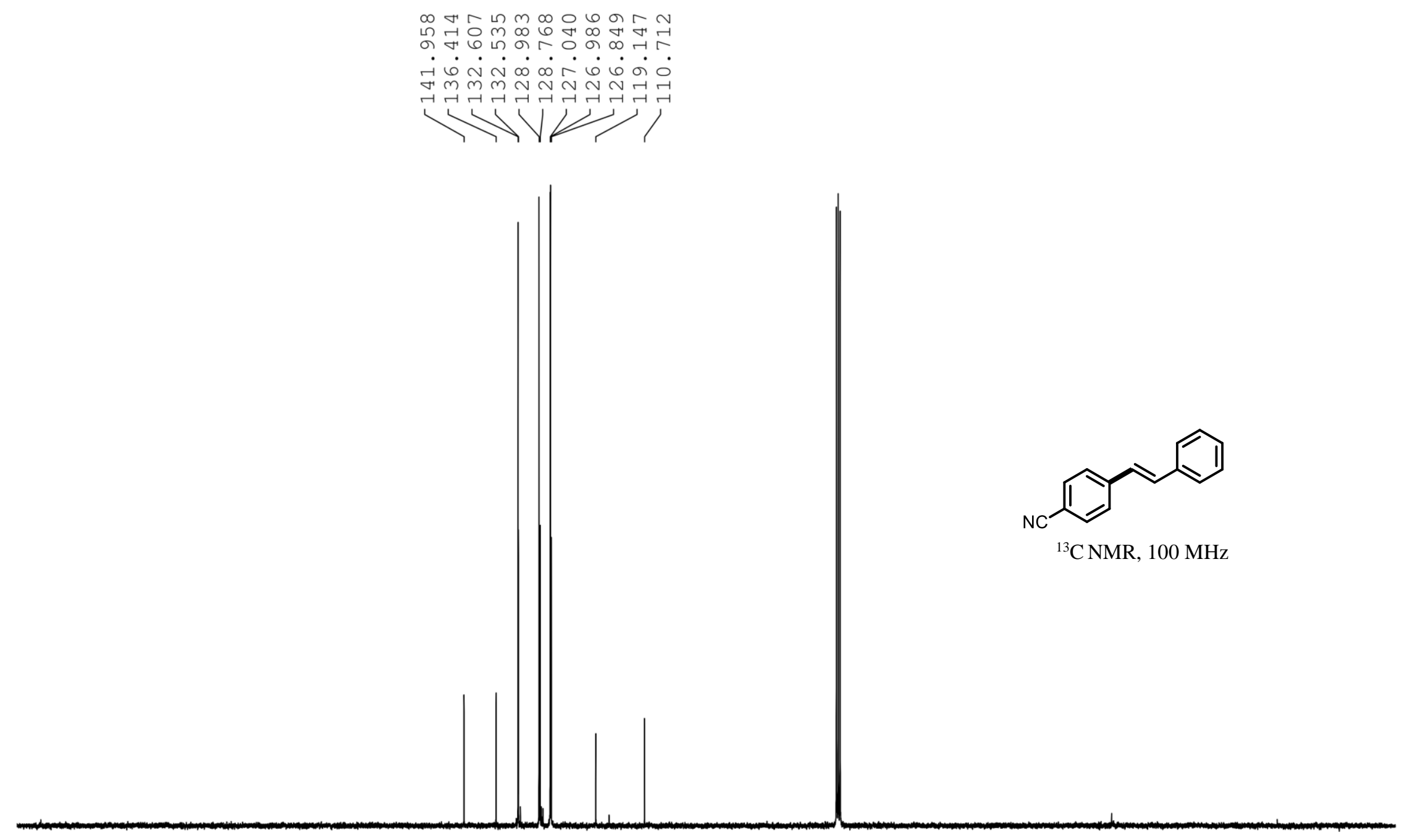

$\begin{array}{lllllllllllllllllllllll}210 & 200 & 190 & 180 & 170 & 160 & 150 & 140 & 130 & 120 & 110 & 100 & 90 & 80 & 70 & 60 & 50 & 40 & 30 & 20 & 10 & 0 & \text { ppm }\end{array}$ 
(E)-1-(4-(2-(pyridin-2-yl)vinyl)phenyl)ethanone (21)
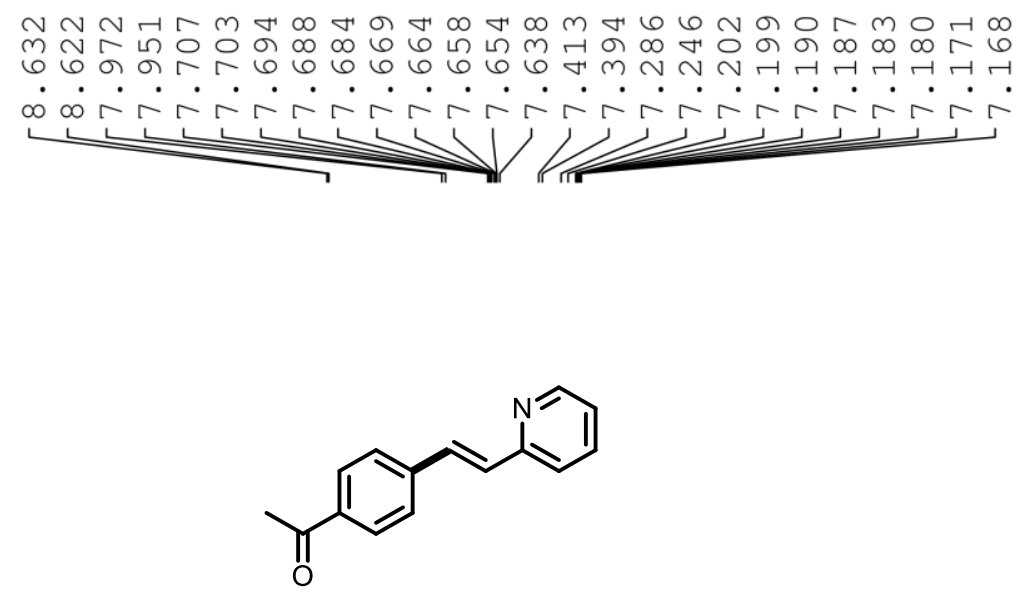

${ }^{1} \mathrm{H}$ NMR, $400 \mathrm{MHz}$
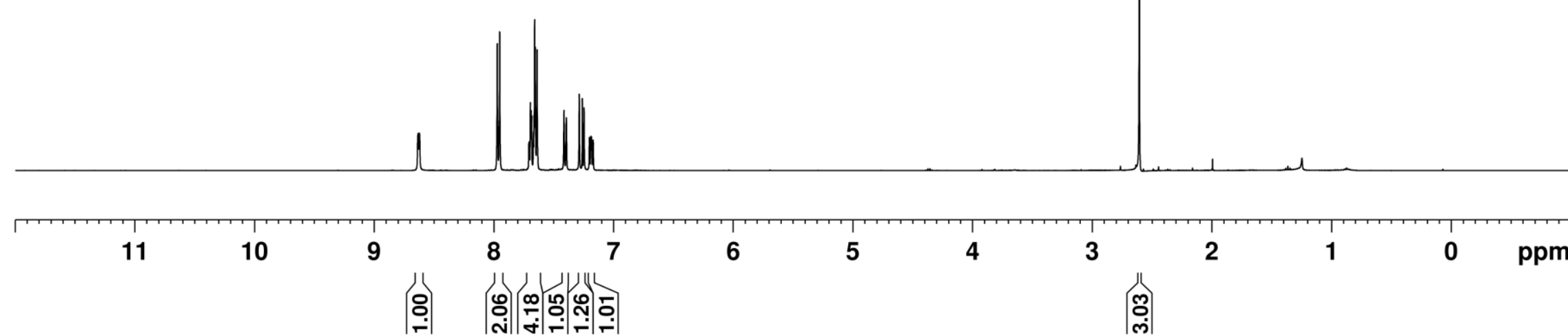


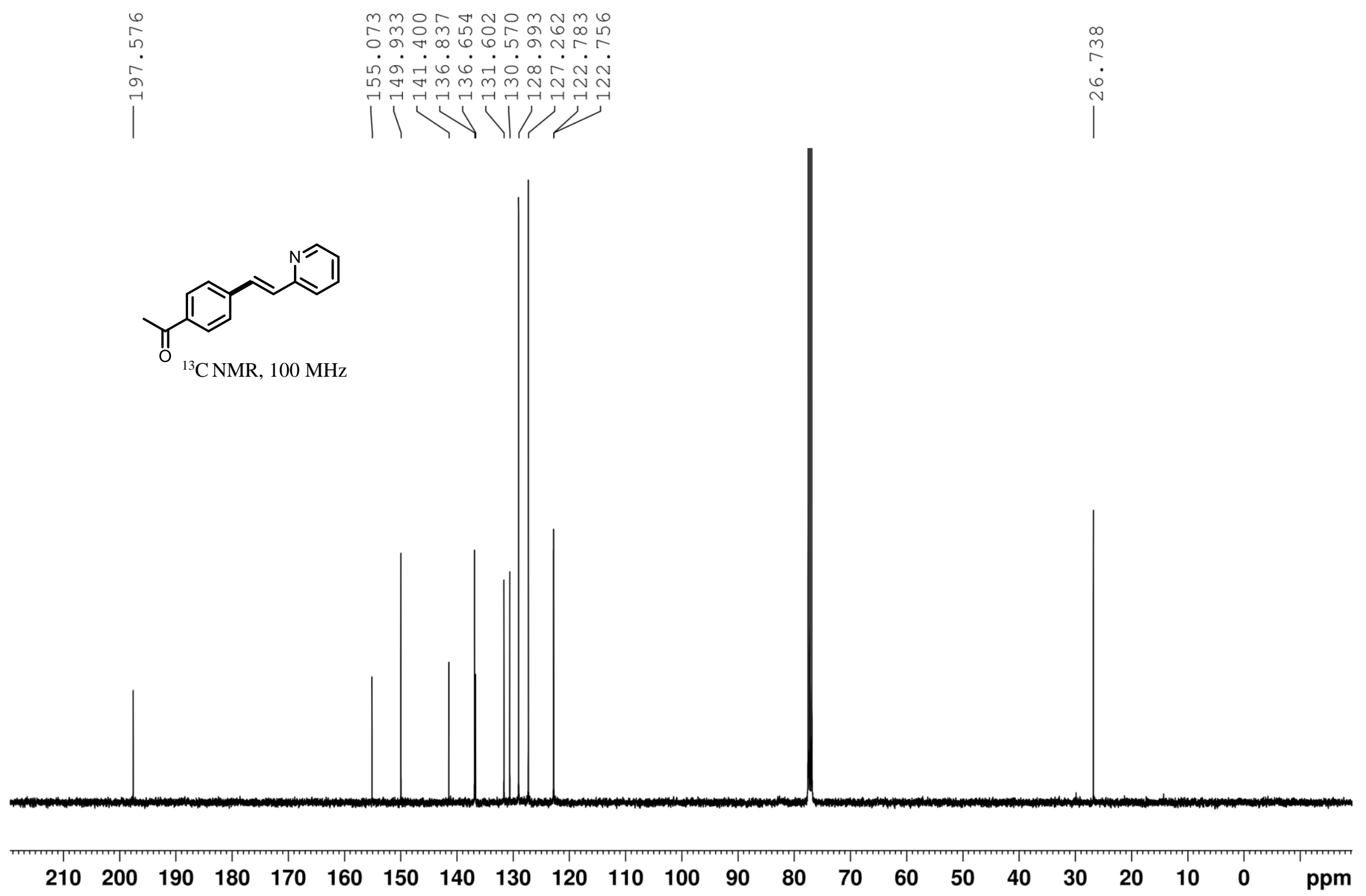


1-methoxy-4-(3'-pyridinylethynyl)-benzene (22)

HNm

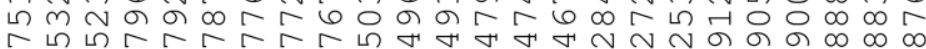
o domararararararab ب

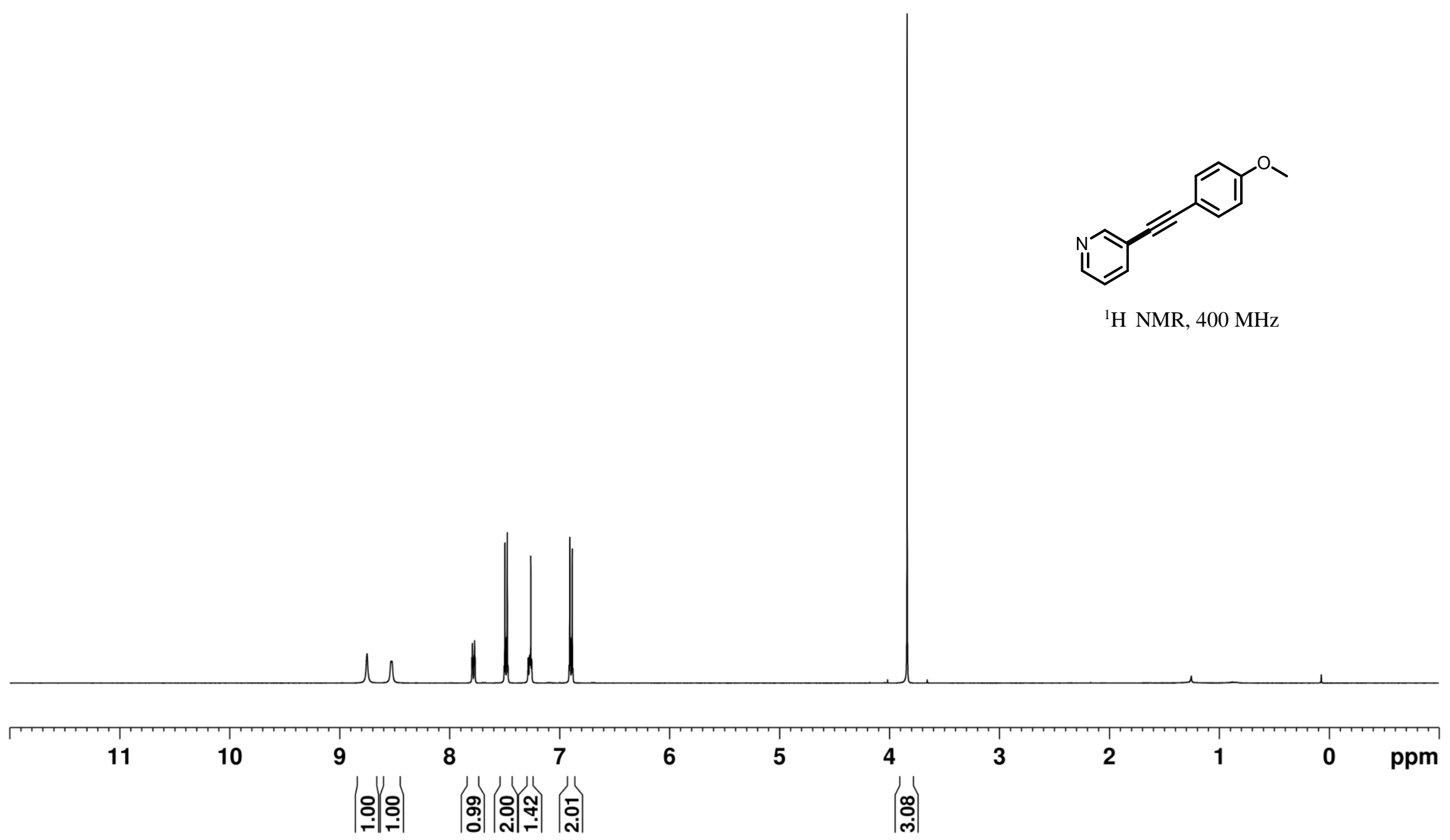



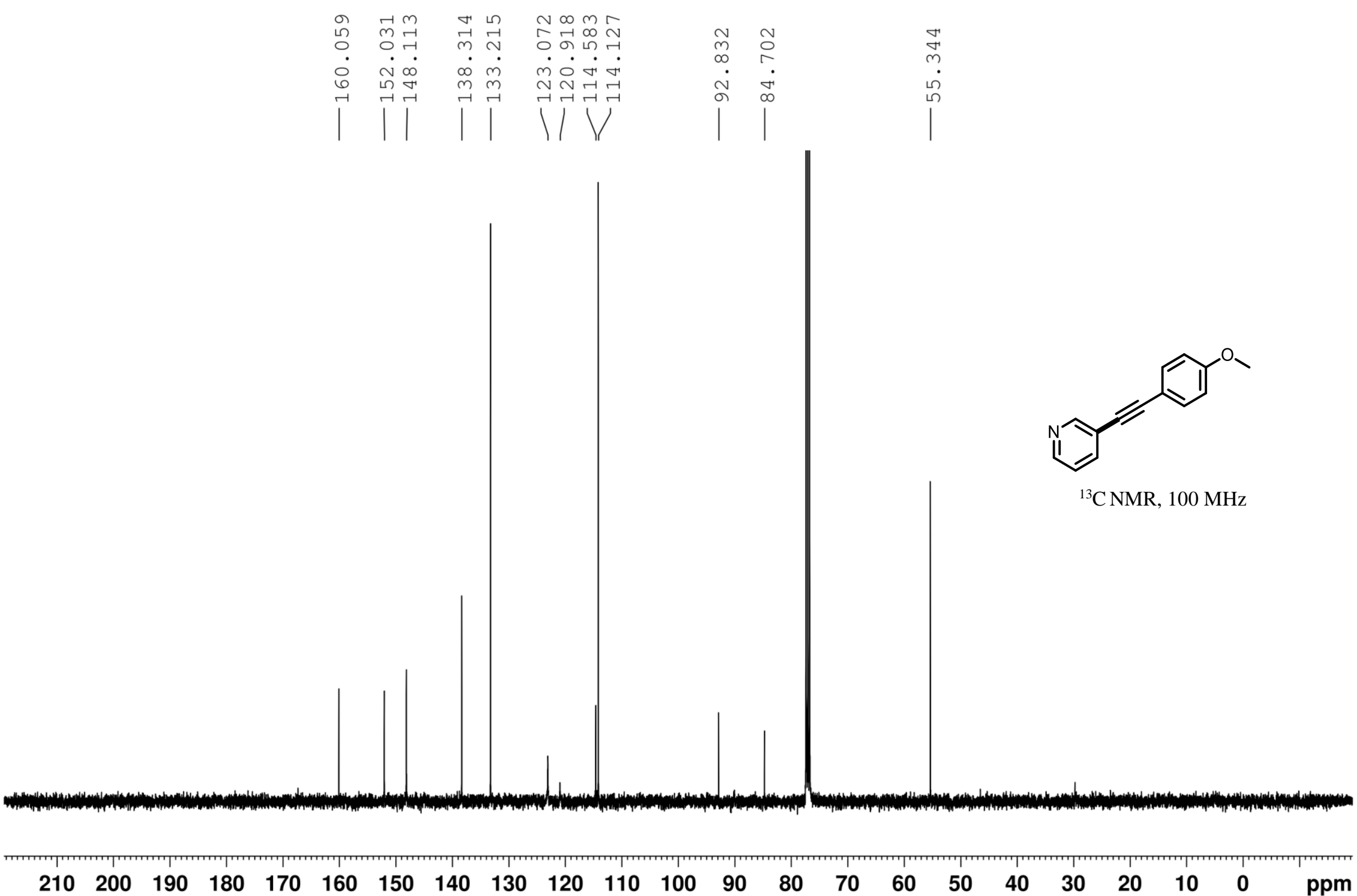


\section{1-(2-phenylethynyl)-3-(trifluoromethyl)benzene (23)}

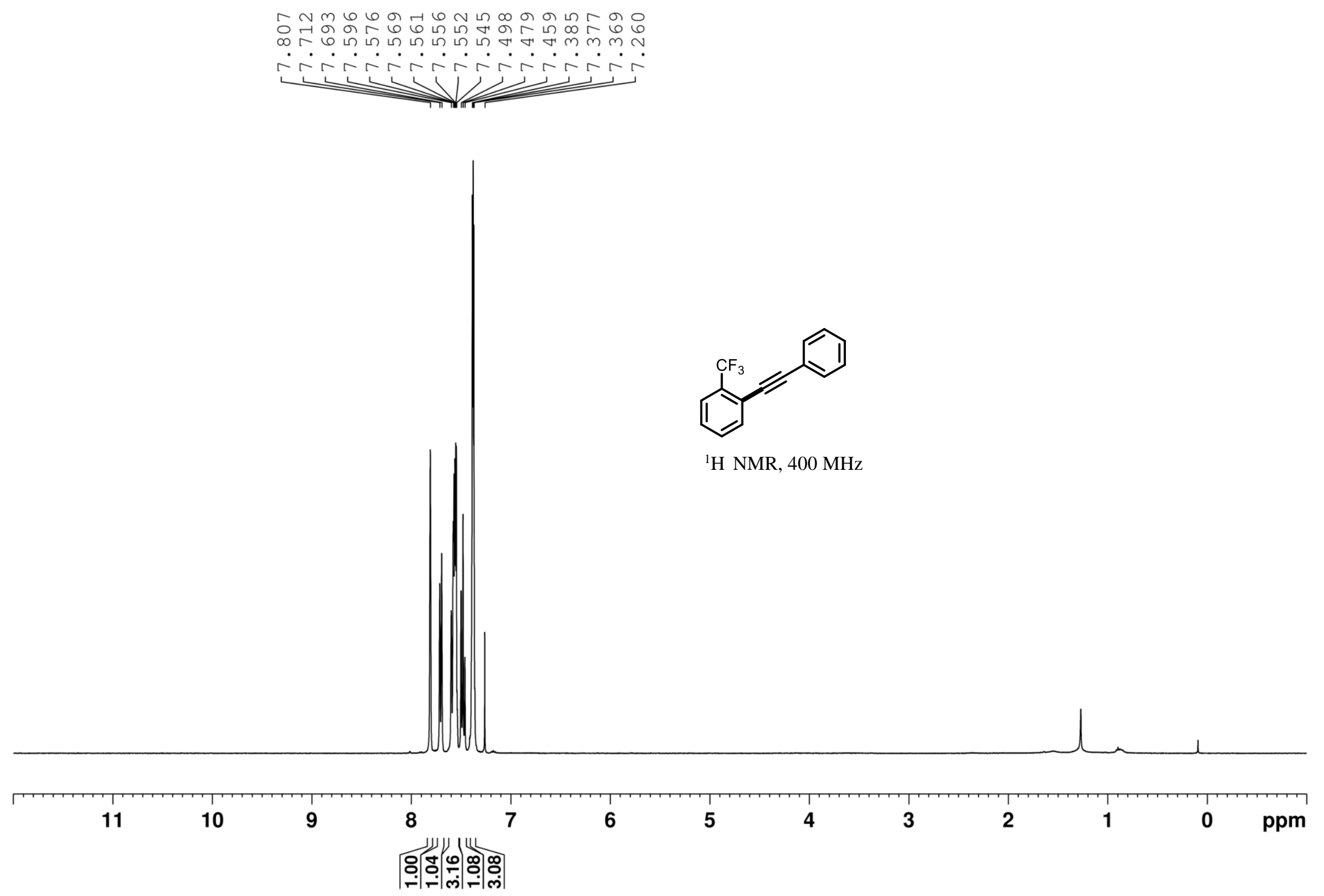



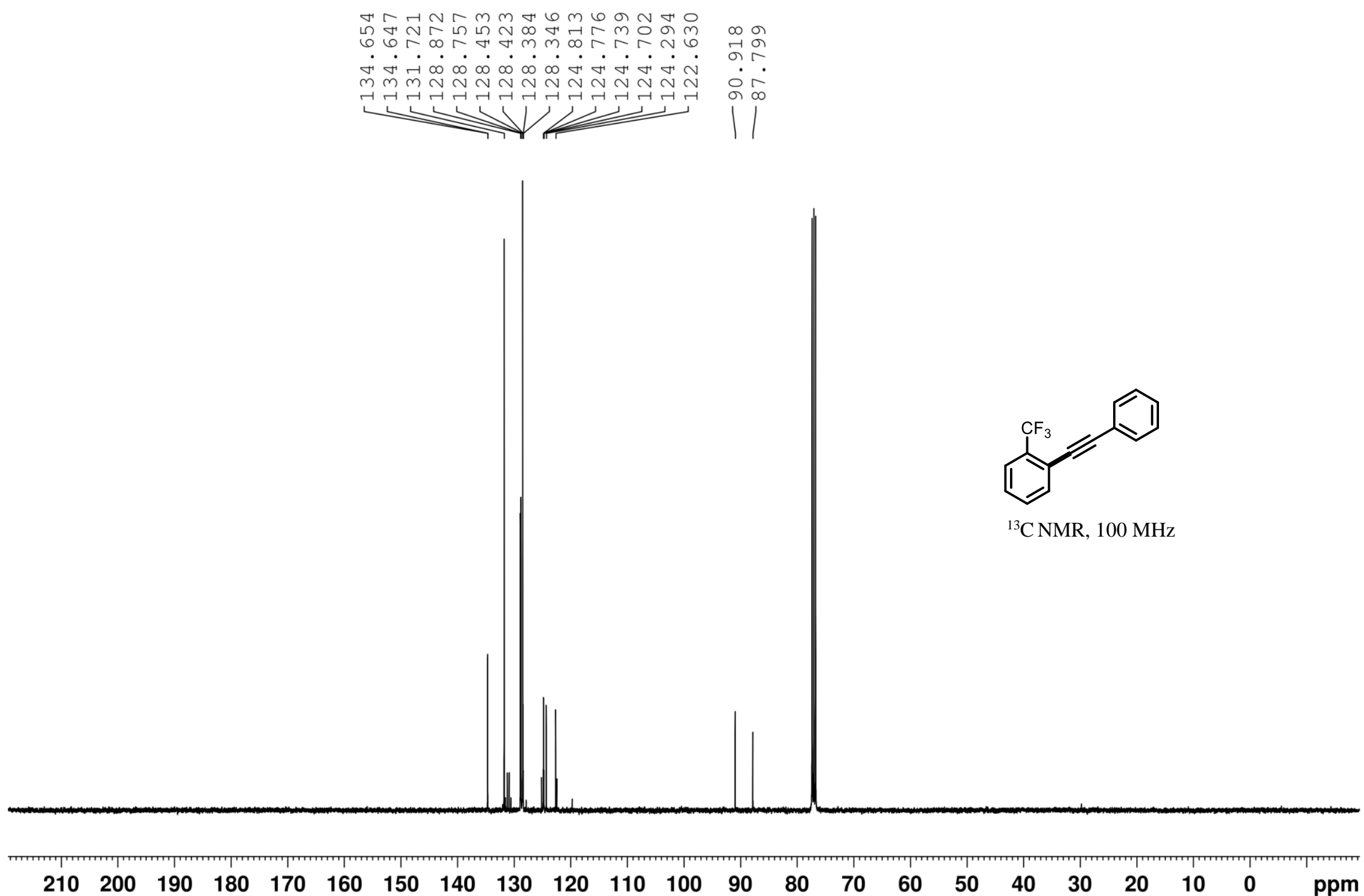


\section{References}

(1) Schneider, T. L.; Halloran, K. T.; Hillner, J. A.; Conry, R. R.; Linton, B. R. Application of H/D Exchange to Hydrogen Bonding in Small Molecules. Chem. - A Eur. J. 2013, 19, 15101-15104.

(2) Zhou, W.; Fan, M.; Yin, J.; Jiang, Y.; Ma, D. CuI/Oxalic Diamide Catalyzed Coupling Reaction of (Hetero)Aryl Chlorides and Amines. J. Am. Chem. Soc. 2015, 137, 1194211945.

(3) Kaboudin, B.; Abedi, Y.; Yokomatsu, T. CuII- $\beta$-Cyclodextrin Complex as a Nanocatalyst for the Homo-and Cross-Coupling of Arylboronic Acids under Ligand-and Base-Free Conditions in Air: Chemoselective Cross-Coupling of Arylboronic Acids in Water. European J. Org. Chem. 2011, 33, 6656-6662.

(4) Chen, Z.; Wen, X.; Qian, Y.; Liang, P.; Liu, B.; Ye, M. Ce(III)-Catalyzed Highly Efficient Synthesis of Pyridyl Benzamides from Aminopyridines and Nitroolefins without External Oxidants. Org. Biomol. Chem. 2018, 16, 1247-1251.

(5) Ji, Y. F.; Yan, H.; Jiang, Q. B. Effective Nitration of Anilides and Acrylamides by TertButyl Nitrite. Eur. J. Org. Chem. 2015, 2015, 2051-2060.

(6) Skillinghaug, B.; Rydfjord, J.; Sävmarker, J.; Larhed, M. Microwave Heated Continuous Flow Palladium(II)-Catalyzed Desulfitative Synthesis of Aryl Ketones. Org. Process Res. Dev. 2016, 20, 2005-2011.

(7) Wang, Z.; Kuninobu, Y.; Kanai, M. Molybdenum-Mediated Desulfurization of Dhiols and Disulfides. Synlett 2014, 25, 1869-1872.

(8) Kundu, D.; Tripathy, M.; Maity, P.; Ranu, B. C. Cobalt-Catalyzed Intermolecular C(Sp$\left.{ }^{2}\right)-$ O Cross-Coupling. Chem. - A Eur. J. 2015, 21 (24), 8727-8732. https://doi.org/10.1002/chem.201500058.

(9) Suárez-Pantiga, S.; Hernández-Ruiz, R.; Virumbrales, C.; Pedrosa, M. R.; Sanz, R. Reductive Molybdenum-Catalyzed Direct Amination of Boronic Acids with Nitro Compounds. Angew, Chem. Int. Ed. 2019, 58, 2129-2133.

(10) Chakraborti, G.; Paladhi, S.; Mandal, T.; Dash, J. "on Water” Promoted Ullmann-Type C-N Bond-Forming Reactions: Application to Carbazole Alkaloids by Selective NArylation of Aminophenols. J. Org. Chem. 2018, 83, 7347-7359. 
(11) Sobhani, S.; Falatooni, Z. M.; Asadi, S.; Honarmand, M. Palladium-Schiff Base Complex Immobilized Covalently on Magnetic Nanoparticles as an Efficient and Recyclable Catalyst for Heck and Suzuki Cross-Coupling Reactions. Catal. Lett. 2016, 146, 255268.

(12) Sun, P.; Zhu, Y.; Yang, H.; Yan, H.; Lu, L.; Zhang, X.; Mao, J. The Ligand and BaseFree Pd-Catalyzed Oxidative Heck Reaction of Arylboronic Acids and Olefins. Org. Biomol. Chem. 2012, 10, 4512-4515.

(13) Gao, S.; Huang, Y.; Cao, M.; Liu, T. F.; Cao, R. The Fabrication of Palladium-Pyridyl Complex Multilayers and Their Application as a Catalyst for the Heck Reaction. J. Mater. Chem. 2011, 21, 16467-16472.

(14) Shen, R.; Chen, T.; Zhao, Y.; Qiu, R.; Zhou, Y.; Yin, S.; Wang, X.; Goto, M.; Han, L. B. Facile Regio- and Stereoselective Hydrometalation of Alkynes with a Combination of Carboxylic Acids and Group 10 Transition Metal Complexes: Selective Hydrogenation of Alkynes with Formic Acid. J. Am. Chem. Soc. 2011, 133, 17037-17044.

(15) Li, P.; Wang, L.; Zhang, L.; Wang, G. W. Magnetic Nanoparticles-Supported Palladium: A Highly Efficient and Reusable Catalyst for the Suzuki, Sonogashira, and Heck Reactions. Adv. Synth. Catal. 2012, 354, 1307-1318.

(16) Sagadevan, A.; Hwang, K. C. Photo-Induced Sonogashira C-C Coupling Reaction Catalyzed by Simple Copper(I) Chloride Salt at Room Temperature. Adv. Synth. Catal. 2012, 354, 3421-3427. 